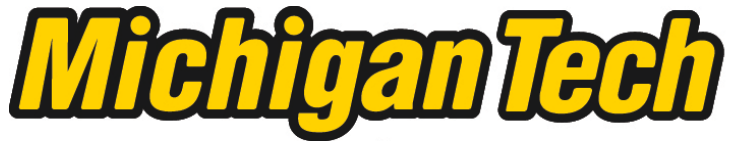 \\ Michigan Technological University Create the Future Digital Commons @ Michigan Tech
}

2014

\section{EVOLUTION OF SELECTED ISOPRENE OXIDATION PRODUCTS IN DARK AQUEOUS AMMONIUM SULFATE}

D.M. Ashraf UI Habib

Michigan Technological University

Follow this and additional works at: https://digitalcommons.mtu.edu/etds

Part of the Other Chemistry Commons

Copyright 2014 D.M. Ashraf UI Habib

\section{Recommended Citation}

Habib, D.M. Ashraf UI, "EVOLUTION OF SELECTED ISOPRENE OXIDATION PRODUCTS IN DARK AQUEOUS AMMONIUM SULFATE", Master's Thesis, Michigan Technological University, 2014.

https://doi.org/10.37099/mtu.dc.etds/868

Follow this and additional works at: https://digitalcommons.mtu.edu/etds

Part of the Other Chemistry Commons 


\title{
EVOLUTION OF SELECTED ISOPRENE OXIDATION PRODUCTS IN DARK AQUEOUS AMMONIUM SULFATE
}

\author{
By \\ D.M. Ashraf Ul Habib
}

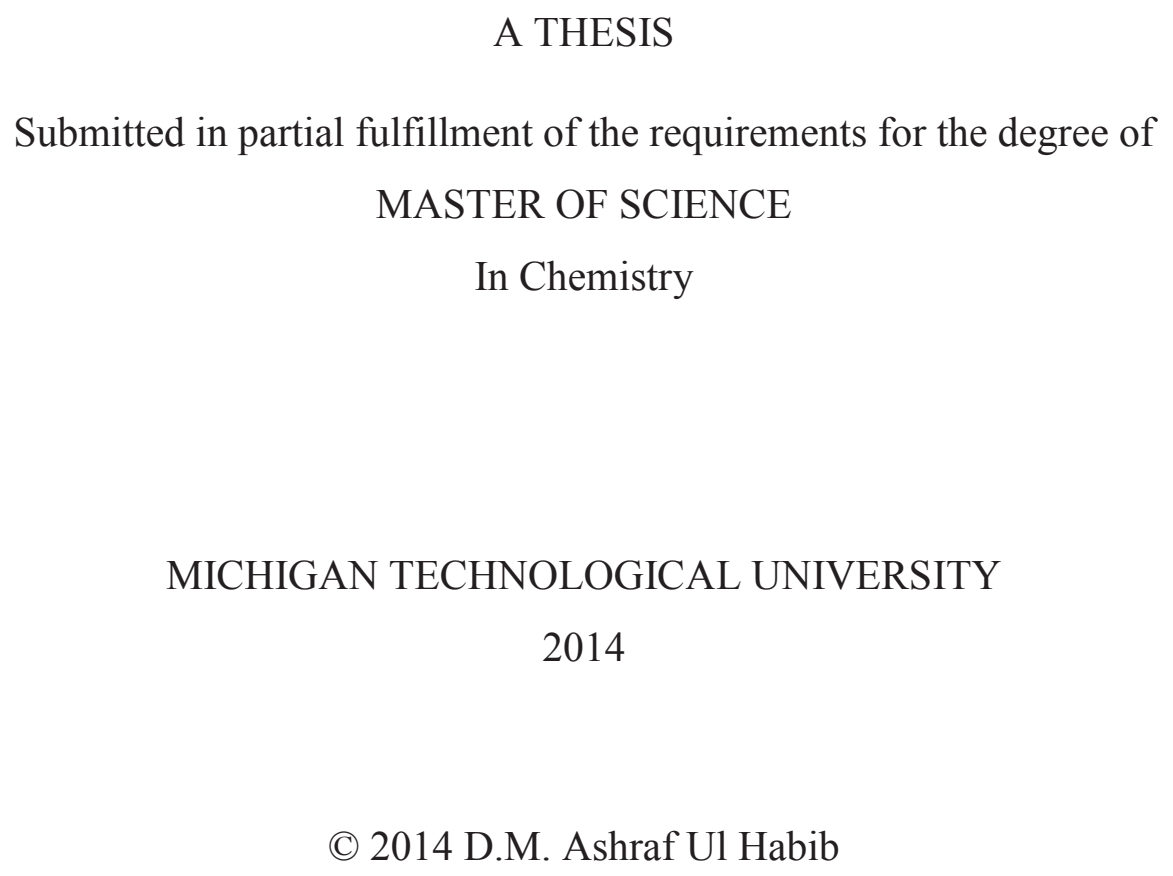


This thesis has been approved in partial fulfillment of the requirements for the degree of MASTER OF SCIENCE in Chemistry

\title{
Department of Chemistry
}

\author{
Thesis Advisor: $\quad$ Dr. Lynn R. Mazzoleni \\ Committee Member: $\quad$ Dr. Will H. Cantrell \\ Committee Member: $\quad$ Dr. Paul V. Doskey \\ Committee Member: $\quad$ Dr. Loredana Valenzano \\ Department Chair: Dr. Cary F. Chabalowski
}




\section{Table of Contents}

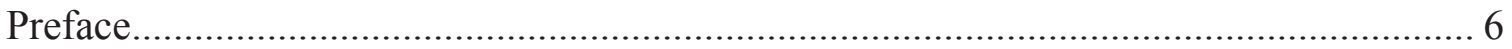

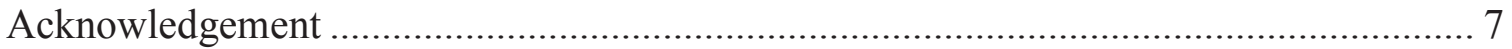

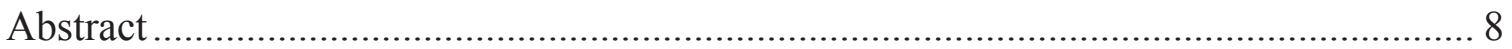

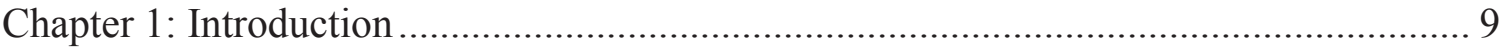

$1.1 \quad$ Atmospheric Aerosol and Processes ................................................................. 9

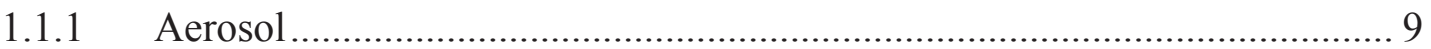

1.1.2 Aqueous Secondary Organic Aerosol (Aq-SOA) ...................................... 12

Chapter 2: Decarboxylation of Pyruvic Acid and Glyoxylic Acid in Ammonium Salt Solutions as Aqueous Aerosol Mimics .................................................................... 15

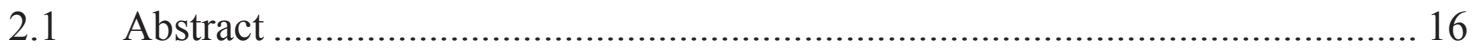

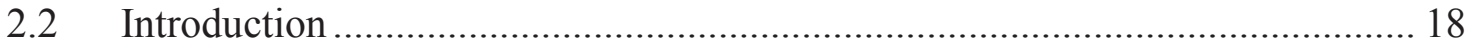

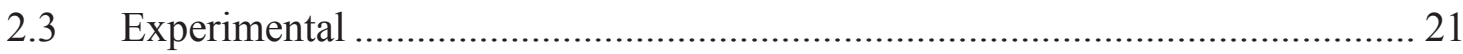

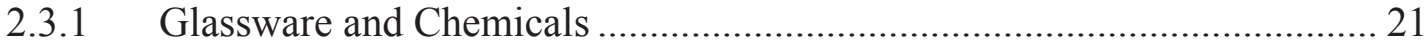

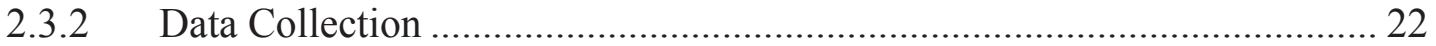

2.3.3 Reaction Setup …………………………………................................ 22

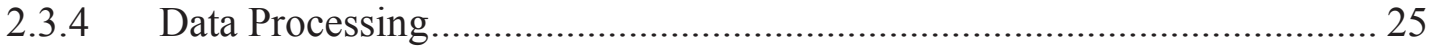

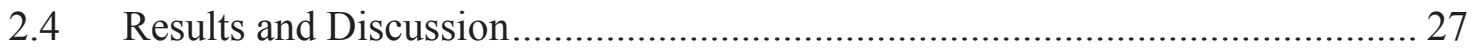

2.4.1 Decarboxylation from glyoxylic and pyruvic acid ................................... 27

2.4.2 Rate of the Decarboxylation and Order of the Reaction .............................. 28

2.4.2.1 Derivation of Rates of Decarboxylation................................................. 28

2.4.2.2 Derivation of the Order of the Reaction............................................... 30

2.4.2.2.1 Determination of Order with Respect to $\mathrm{NH}_{4}{ }^{+}$Ion ............................ 31

2.4.2.2.2 Determination of Order with Respect to Glyoxylic Acid................... 33

2.4.2.2.3 Determination of Order with Respect to Pyruvic Acid....................... 34

2.4.3 Organic Acid Precursors and Concentration................................................ 35

2.4.4 Inorganic Salts and Concentration .............................................................. 38 


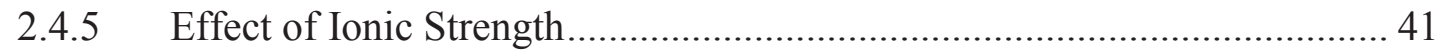

2.4.6 Mechanism of Decarboxylation............................................................... 44

$2.5 \quad$ Atmospheric Relevance............................................................................. 46

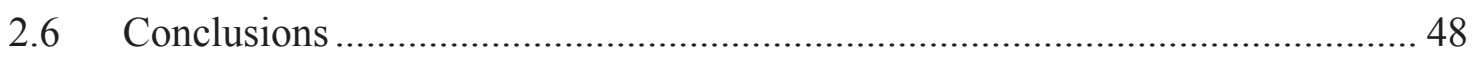

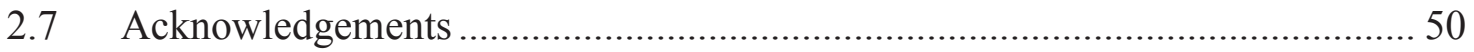

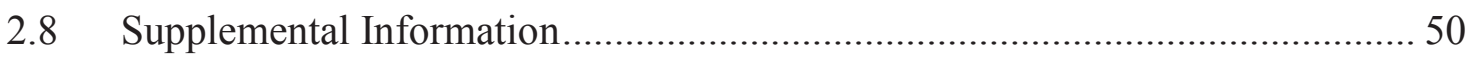

Chapter 3: Ultrahigh Resolution FT-ICR Mass Spectrometry Characterization of Aqueous SOA Formed in Dark Reaction of Methylglyoxal and Ammonium Sulfate .... 51

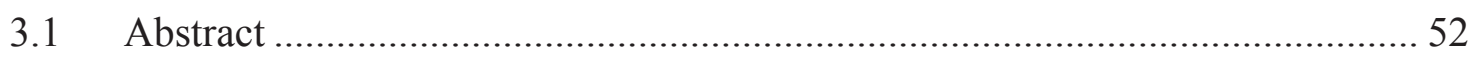

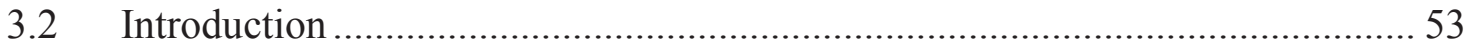

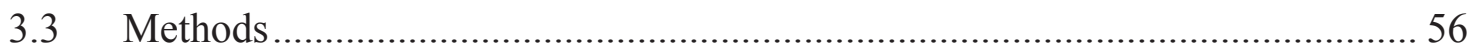

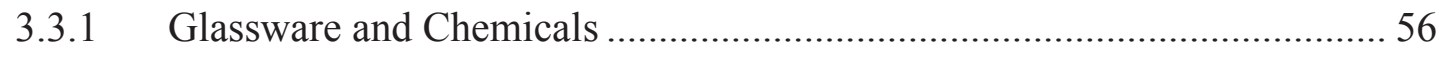

3.3.2 Aqueous SOA Sample Preparation........................................................... 56

3.3.3 Ultrahigh Resolution ESI FT-ICR MS Analysis ………............................... 57

3.3.4 Assignment of Molecular Formulas......................................................... 58

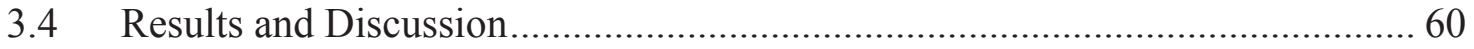

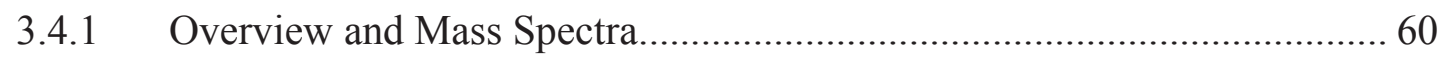

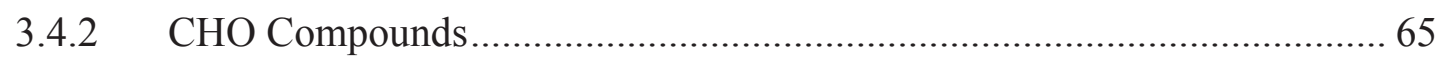

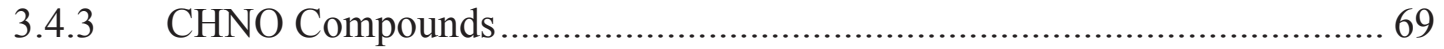

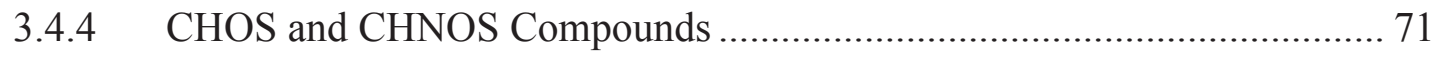

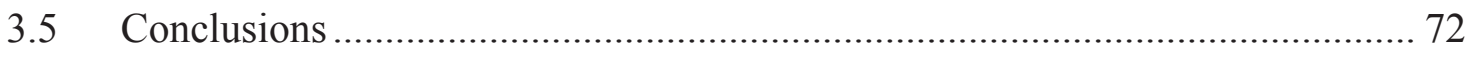

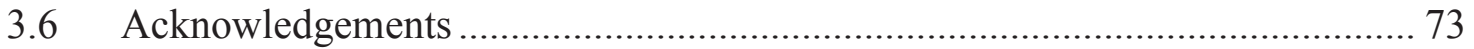

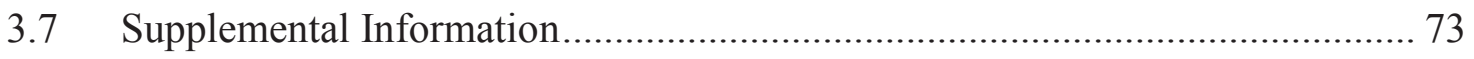

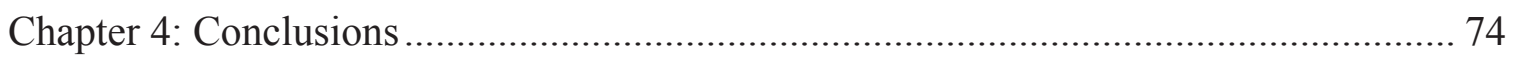

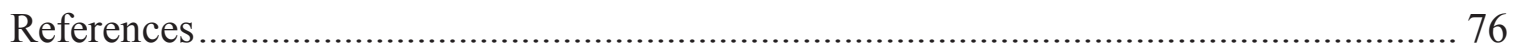


A.1 Supplemental Information: Decarboxylation of Pyruvic Acid and Glyoxylic Acid in Ammonium Salt Solutions as Aqueous Aerosol Mimics ........................... 85

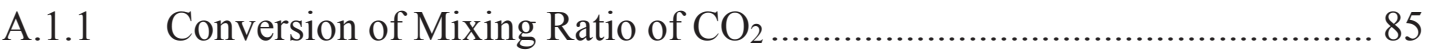

A.1.1.1 Experimental Parameters................................................................... 85

A.1.1.2 Conversion of the Measured $\mathrm{CO}_{2}$ in Moles........................................ 85

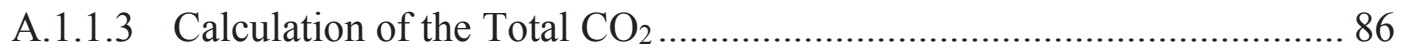

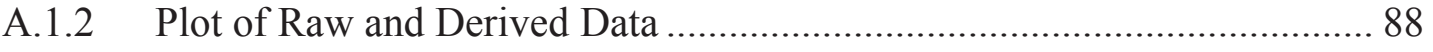

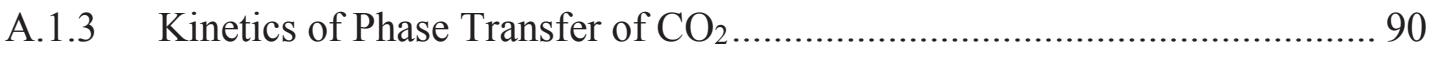

A.1.4 Rate of the Decarboxylation and Order of the Reaction .......................... 92

A.1.4.1 Determination of Order with Respect to Ammonia.......................... 92

A.1.5 Reaction Rates for Pyruvic Acid: OH Radical Reaction vs. Aqueous

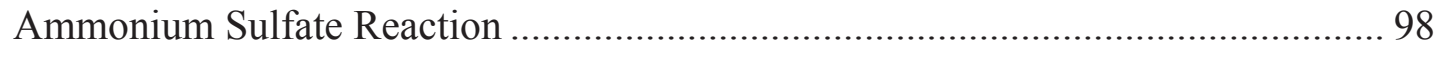

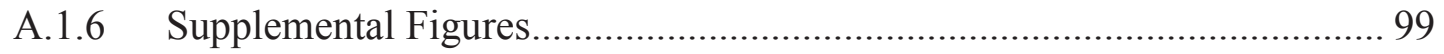

A.2 Supplemental Information: Ultrahigh Resolution FT-ICR Mass Spectrometry Characterization of Aqueous SOA Formed in Dark Reaction of Methylglyoxal and Ammonium Sulfate ........................................................ 106

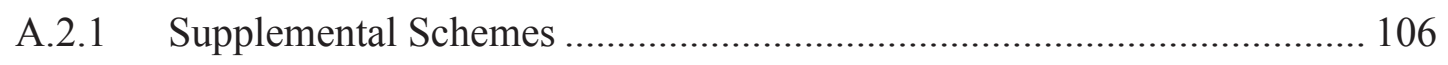

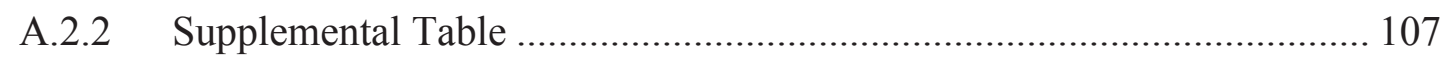

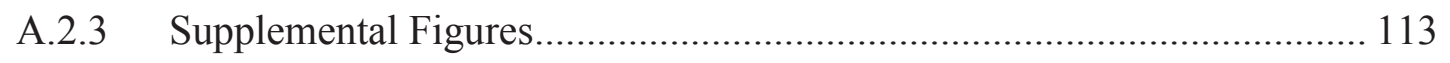




\section{Preface}

Some 43 months ago on a sunny summer day this journey to understand the aqueous phase reactions of few organic compounds began. Since then, it's about the excitement and determination to setup a reaction, the desire to break the fortress of unknown, the hope of best results and the story of reaching to the new level of unknown. It is a script of life; exciting and bitter, smart and dumb, happy and sad, lucky and hapless. It's for them who will take on the journey of unknown and attempt it toward another level.

Chapter 2 represents a manuscript draft to be submitted for publication. The experiments and interpretation were completed by D.M. Ashraf Ul Habib with the supervision of Dr. Lynn R. Mazzoleni. Drs. Heather A. Rypkema and Tony N. Rogers provided helpful advice regarding the reaction kinetics. Drs. Marina Tanasova and Heather A. Rypkema provided helpful advice regarding the proposed reaction mechanisms.

Chapter 3 represents a manuscript draft to be submitted for publication. The experiments and interpretation were completed by D. M. Ashraf Ul Habib with the supervision of Dr. Lynn R. Mazzoleni. 


\section{Acknowledgements}

I am thankful to my mentors, critics, benefactors and people whose wisdom I assimilated, for whom this work was made possible. 


\begin{abstract}
The aqueous phase processing of glyoxylic acid, pyruvic acid, oxalic acid and methylglyoxal was studied simulating dark and radical free atmospheric aqueous aerosol. A novel observation of the cleavage of a carbon-carbon bond in pyruvic acid and glyoxylic acid leading to their decarboxylation was made in the presence of ammonium salts but no decarboxylation was observed from oxalic acid. The empirical rate constants for decarboxylation were determined. The structure of the acid, ionic environment of solution and concentration of species found to affect the decarboxylation process. A tentative set of reaction mechanisms was proposed involving nucleophilic attack by ammonia on the carbonyl carbon leading to fragmentation of the carbon-carbon bond between the carbonyl and carboxyl carbons. Whereas, the formation of high molecular weight organic species was observed in the case of methylglyoxal. The elemental compositions of the species were determined. It was concluded that, additional pathways that are not currently known likely contribute to aqueous phase processing leading to high molecular weight organic species. Under similar conditions in atmospheric aerosol, the aqueous phase processing will markedly impact the physicochemical properties of aerosol.
\end{abstract}




\section{Chapter 1: Introduction}

\subsection{Atmospheric Aerosol and Processes}

\subsubsection{Aerosol}

Particles suspended in air are commonly called aerosol and often the terms aerosol and particles are used interchangeably. The diameters of atmospheric aerosol (haze forming particles, fog droplet, etc.) may be in the range of $1 \mathrm{~nm}$ to $100 \mu \mathrm{m}$. In comparison, the diameter of a typical molecule falls into a sub-nanometer regime. This means aerosol particles are essentially aggregates of molecules dispersed as liquid or solid or combination of both phases surrounded by gases.

Aerosols can be directly emitted into the atmosphere and are called primary aerosol. Sea spray, pollen, dust are common examples of primary aerosol. On the other hand, secondary aerosol is formed in the atmosphere. Gases emitted into the atmosphere from natural and anthropogenic activities can undergo reactive processing (solar irradiation, reaction with $\mathrm{O}_{3}, \mathrm{OH} \cdot$ and other species) resulting in products that often have lower vapor pressures. The lower vapor pressure species can either nucleate new particles or condense upon preexisting particles and in both cases they are secondary aerosol. Sulfuric acid aerosol is an example of secondary aerosol. A schematic of sources and processing of aerosol is given in Figure 1.1.

Regardless of their formation, aerosol has a significant role in determining the planetary albedo, local and regional weather [IPCC, 2013], air quality [Fiore et al., 2012] and nutrient cycling [Mahowald et al., 2011]. Aerosol provides a surface for the condensation of water vapor and consecutively leads to the formation of cloud, fog, mist and rain. The 
magnitude of the impacts of aerosol on these atmospheric processes depends upon its chemical composition, size, morphology and number concentration [IPCC, 2013]. The composition of aerosol is highly variable in space and time. Also, each individual compound is constantly evolving and is scarce in terms of the amount available for analysis [Pöschl, 2005 and references therein]. This dynamic nature and scarcity of the sample poses a formidable analytical challenge toward understanding the composition and its evolution [Pöschl, 2005 and references therein]. This uncertainty of understanding the aerosol formation and composition translated in the uncertainty of our understanding on radiative forcing of our planet [IPCC, 2013]. 


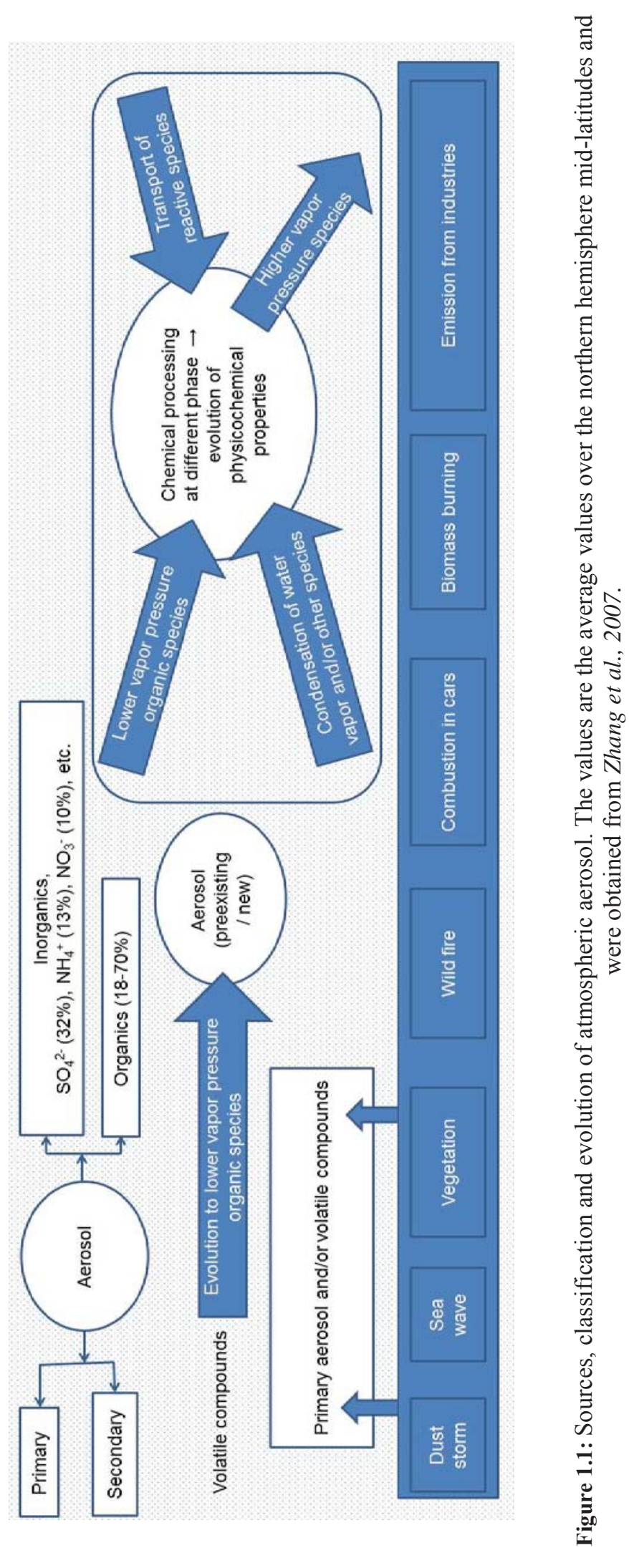




\subsubsection{Aqueous Secondary Organic Aerosol (Aq-SOA)}

The composition of aerosol is broadly classified as inorganic and organic aerosol (Figure 1.1). The organic fraction of aerosol is a collection of hundreds of organic compounds with a wide range of molecular weights and is commonly referred to as organic aerosol (OA). Incorporation of organic compounds into aerosol involves either primary or secondary processes or a combination of both. Secondary organic aerosol (SOA) is formed via the atmospheric processing of volatile organic compounds (VOC). VOCs regardless of their origin can interact with high energy solar radiation or react with $\mathrm{O}_{3}, \mathrm{OH}$, etc. and may form species with lower vapor pressure leading to SOA formation. [Hallquist et al., 2009 and references therein]. Usually, atmospheric SOA are oxidized species and may be found in the atmospheric aqueous phase (e.g., fog, cloud, wet aerosol, rain, etc.). The watersoluble organic species may undergo further processing in aqueous phase leading to modified products which may remain in the particle phase upon droplet evaporation and are called aqueous secondary organic aerosol (Aq-SOA) [Ervens et al., 2011 and references therin].

The global SOA has an estimated flux of $150 \mathrm{Tg} \mathrm{C} \mathrm{yr}^{-1}$ [Hallquist et al., 2009 and references therein] and is believed to be formed from reactions of VOCs originating from biogenic (isoprene and other terpenes) and anthropogenic (aliphatic and aromatic organic compounds) activities. Recently, the global production of Aq-SOA from atmospheric

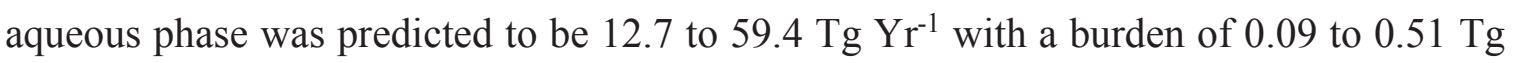
$\mathrm{Yr}^{-1}$ from small molecular weight water-soluble isoprene and other VOCs oxidation products [Lin $G$ et al., 2014]. In the aqueous phase, water-soluble species can undergo further chemical transformation via accretion, oxidation and functionalization reactions 
leading to a modification of the organic species. Water-soluble atmospheric organic matter is a complex array of thousands of compounds and is detected widely in particulate matter [Lin P et al., 2012], rain [Altieri et al., 2009a, 2009b], clouds [Zhao et al., 2013] and fogs [Mazzoleni et al., 2010]. Some of the Aq-SOA are low volatility and water-soluble organic acids (i.e., oxalic acid, pyruvic acid, glyoxylic acid, etc.) and are found to be present widely in the atmospheric gas and particle phase [Bao et al., 2012; Fu et al., 2013; Kawamura and Yasui, 2005; Kawamura et al., 2013; Kundu et al., 2010; Pavuluri et al., 2010; Wang et al., 2006]. However, it is evident from estimations of current models [Lin G et al., 2014] that processing in the atmospheric aqueous phase and the consecutive fate of Aq-SOA is still not well understood and requires further study.

Ammonium, sulfate and nitrate are three major inorganic species in atmospheric aerosol. These species are present in the atmospheric aerosol with water and organic compounds. However, it was only recently realized that inorganic ions such as ammonium participate (i.e., catalyze or react) in organic reactions [Ervens et al., 2011 and references therin]. Although the ammonium salts were shown to produce efficient light absorbing brown carbon species in bulk reactions of dicarbonyl species [Sareen et al., 2010; Shapiro et al., 2009; Yasmeen et al., 2010], the composition of Aq-SOA formed from these reactions were not thoroughly investigated al molecular level. Moreover, to our best knowledge there is no study of dark interactions of ammonium with $\alpha$-oxo acids mimicking atmospheric aerosol phase.

A study of dark aqueous phase processing of $\alpha$-oxo acids in bulk solutions is presented in chapter 2 and a study of dark aqueous reaction of methylglyoxal is presented in chapter 3 . Dark-radical free aqueous reaction systems consisting of ammonium sulfate and $\alpha$-oxo 
acids or methylglyoxal were setup and the transformation of organics were studied. These studies will increase our understanding about the processing of small molecular weight carbonyl compound in bulk aqueous solution and consecutively enhance our knowledge about aging of organic compounds in aqueous phase. 


\section{Chapter 2: Decarboxylation of Pyruvic Acid and Glyoxylic Acid in Ammonium Salt Solutions as Aqueous Aerosol Mimics*}

Approved by Co-author/advisor Dr. Lynn R. Mazzoleni

* This chapter represents a manuscript draft to be submitted for publication. The experiments and interpretation were completed by D.M. Ashraf U1 Habib with the supervision of Dr. Lynn R. Mazzoleni. Drs. Heather A. Rypkema and Tony N. Rogers provided helpful advice regarding the reaction kinetics. Drs. Marina Tanasova and Heather A. Rypkema provided helpful advice regarding the proposed reaction mechanisms. 


\subsection{Abstract}

We studied the interactions of glyoxylic acid, pyruvic acid and oxalic acid with ammonium and corresponding sodium salts in aqueous solutions simulating a dark and radical free atmospheric aqueous aerosol condition. Cleavage of a carbon-carbon bond in pyruvic acid and glyoxylic acid leading to the decarboxylation was observed in the presence of ammonium salts but was not observed from oxalic acid. At the beginning of the reaction, the decarboxylation appeared to proceeding slower compare to the later stage of reaction. The empirical rate constants for decarboxylation in the reaction solutions were estimated using a 'quasi-steady state' model: (i) glyoxylic acid and ammonium sulfate was $3.3( \pm 0.7) \times 10^{-}$ ${ }^{8} \mathrm{M}^{-1} \mathrm{~s}^{-1}$; (ii) glyoxylic acid and ammonium nitrate was $1.4( \pm 0.3) \times 10^{-8} \mathrm{M}^{-1} \mathrm{~s}^{-1}$; (ii) glyoxylic acid and ammonium chloride was $1.9( \pm 0.2) \times 10^{-8} \mathrm{M}^{-1} \mathrm{~s}^{-1}$; and (iii) pyruvic acid and ammonium sulfate was $15.8( \pm 0.4) \times 10^{-8} \mathrm{M}^{-1} \mathrm{~s}^{-1}$. Negligible $\mathrm{CO}_{2}$ was observed in the experiments with the corresponding sodium salts indicating the ammonium ion or ammonia is facilitating the carbon-carbon bond cleavage leading to carboxyl fragmentation of the $\alpha$-oxo carboxylic acids. It was observed that pyruvic acid undergoes decarboxylation at least four times faster than that of glyoxylic acid under similar reaction conditions. This indicates that the structure of the acid plays an important role in the decarboxylation. In the case of pyruvic acid, the reaction is likely faster because of the inhibited hydration of the carbonyl moiety due to the inductive effect of the adjacent methyl group. A tentative set of reaction mechanisms is proposed involving nucleophilic attack by ammonia on the carbonyl carbon leading to fragmentation of the carbon-carbon bond between the carbonyl and carboxyl carbons. Similar carbon-carbon bond cleavage is anticipated for $\alpha$-dicarbonyl 
compounds, which are structurally similar to the $\alpha$-oxo carboxylic acids. In the absence of photolysis and under limited availability of $\mathrm{OH}$ radicals, the decay of pyruvic acid can be dominated by the reaction with ammonium sulfate and can be an order of magnitude higher than the loss via reaction with the $\mathrm{OH}$ radical. Under similar conditions the reactions with ammonium salts are likely be a major sink for $\alpha$-oxo carboxylic acids in the atmospheric aqueous phase. 


\subsection{Introduction}

Organic compounds compose a significant fraction of atmospheric aerosol [Kanakidou et al., 2005; Pöschl, 2005] with a substantial temporal and spatial variability [Baduel et al., 2010; Decesari et al., 2006; Graham et al., 2003; Zhang et al., 2007]. The processing of the organics in the aerosol has a significant impact upon the physicochemical properties of the aerosol and its consecutive effect on our atmosphere [IPCC, 2013]. The organic fraction of the atmospheric aerosol is a complex mixture of numerous individual compounds [Goldstein et al., 2008; Hamilton et al., 2004; Kalberer et al., 2004; Reemtsma et al., 2006] and typically called organic aerosol. Organic aerosol originates from a wide range of natural and anthropogenic sources, where primary organic aerosol is emitted directly and the secondary organic aerosol (SOA) is formed in the atmosphere. Volatile organic compounds (VOCs) can undergo reactions and/or series of reactions (oxidation, functionalization, accretion, etc.) to form products with lower vapor pressure; these products may then partition to the condensed phase to produce SOA [Hallquist et al., 2009; Kroll and Seinfeld, 2008]. In addition, processing of VOCs can produce highly oxygenated organic compounds such that they become appreciably water-soluble [Carlton et al., 2009]. However, the aqueous phase processing of water-soluble organic compounds only recently has been realized to be a contributor of secondary organic aerosol and aqueous-SOA is poorly understood in terms of their formation, composition, effect, and further processing [Ervens et al., 2011].

Small molecular weight water-soluble organic compounds such as $\alpha$-oxo carboxylic acids (pyruvic acid, glyoxylic acid, etc.) are abundant in the atmospheric gas and particle phase 
[Bao et al., 2012; Fu P et al., 2013; Kawamura and Yasui, 2005; Kawamura et al., 2013; Kundu et al., 2010; Pavuluri et al., 2010; Wang et al., 2006]. These compounds are oxidation products of isoprene and other volatile organic compounds [Carlton et al., 2009]. An annual glyoxylic acid production of $8.4-23.0 \mathrm{Tg}$ in the atmospheric aqueous phase was estimated by Lin and coworkers [Lin $G$ et al., 2014]. Also, the annual estimate of production of pyruvic acid is 0.5 to $1.8 \mathrm{Tg} \mathrm{Yr}^{-1}$ in the atmospheric aqueous phase [ $\operatorname{Lin} G$ et al., 2014]. The reason for high annual budget of $\alpha$-oxo acid is because methylglyoxal is readily oxidized to pyruvic acid (92\% in cloud oxidation [Lim et al., 2005]), whereas glyoxylic acid can be formed from glyoxal [Carlton et al., 2009] (the estimated annual production of methylglyoxal and glyoxal are $140 \mathrm{Tg}$ and $40 \mathrm{Tg}$ [Fu T et al., 2008]). Both pyruvic and glyoxylic acid are anticipated to remain in the particle phase upon droplet evaporation contributing to the aqueous secondary organic aerosol (Aq-SOA) mass [Carlton et al., 2006; Ervens et al., 2004]. Also, pyruvic acid has been shown to undergo accretion reactions upon UV-Vis photolysis [Guzmán et al., 2006] and photo-chemical oxidation [Altieri et al., 2006] leading to higher molecular weight compounds. Similar results are anticipated for glyoxylic acid. In addition, the fragmentation (carbon-carbon bond cleavage) of pyruvic acid in the gas and aqueous phases has been studied widely, including: thermal decarboxylation [Saito et al., 1994; Yamamoto and Back, 1985], infrared and near infrared multiphoton photolysis [Larsen and Vaida, 2012; Plath et al., 2009; Takahashi et al., 2008], UV-Vis induced photolysis [Griffith et al., 2013; Guzmán et al., 2006a, 2006b; Leermakers and Vesley, 1963; Reed Harris et al., 2014; Yamamoto and Back, 1985] and oxidation by hydroxyl radical [Boris et al., 2014; Mellouki and Mu, 2003]. However, neither pyruvic acid nor glyoxylic acid was studied in the dark aqueous 
phase in the presence of atmospherically relevant inorganic salts. Recently, the ammonium and carbonate ions were shown to catalyze aldol reactions in aqueous solution [Noziere et al., 2010]. In the presence of the ammonium salts, light absorbing species and Aq-SOA were produced from $\alpha$-dicarbonyl compounds as well [Sareen et al., 2010; Shapiro et al., 2009; Yasmeen et al., 2010]. The aqueous oxidation of pyruvic acid in the presence of ammonium salts was recently shown to be faster than oxidation in pure water [Boris et al., 2014]. Therefore, it is very important that we study the reaction of pyruvic acid and glyoxylic acid in the presence of inorganic ions to understand more about the chemical evolution and dynamics of $\alpha$-oxo carboxylic acids in the aqueous phase.

Organic compounds regardless of their source and physical presence (i.e., gas or condensed phases) are expected to be oxidized to $\mathrm{CO}_{2}$ or be removed from the atmosphere by wet or dry deposition. The conversion of organic compound to $\mathrm{CO}$ or $\mathrm{CO}_{2}$ during atmospheric oxidation is initiated by photolysis, reactions with $\mathrm{OH}$ or $\mathrm{NO}_{3}$ radicals, $\mathrm{O}_{3}$ and $\mathrm{Cl}$ atoms. A cascade of subsequent reactions ultimately leads to the formation of $\mathrm{CO}$ or $\mathrm{CO}_{2}$ [Atkinson, 2007; Atkinson and Arey, 2003]. These reactions can proceed via cleavage of carbon-carbon bonds (fragmentation) or by the addition of polar functional groups to the parent compound without bond cleavage (functionalization) [Atkinson and Arey, 2003]. However to the best of our knowledge, there have not been any prior reports of carboncarbon bond fragmentation initiated from common atmospheric ammonium salts (i.e., ammonium sulfate, ammonium nitrate).

In this work, we report the observations of carbon-carbon bond fragmentation in both pyruvic acid and glyoxylic acid leading to decarboxylation in the presence of ammonium salts 
in dark solutions in the absence of known radical initiators. The kinetics of decarboxylation was studied with continuous monitoring of the evolved $\mathrm{CO}_{2}$ in the gas phase.

\subsection{Experimental}

\subsubsection{Glassware and Chemicals}

All of the glassware was thoroughly washed, dried and baked at $\sim 500{ }^{\circ} \mathrm{C}$ for more than 6 hours. Pyruvic acid (98 \% in water; $\sim 14.1 \mathrm{M}$ ), glyoxylic acid (50\% in water; $\sim 8.98 \mathrm{M}$ ) and oxalic acid (> 97.0\%) were obtained from Sigma-Aldrich (St. Louis, MO) and were used without further purification. Pyruvic acid and glyoxylic acid were stored in a refrigerator $\left(4-8{ }^{0} \mathrm{C}\right)$ until the time of use. All of the salts used in this study were ACS grade unless otherwise stated. Ammonium sulfate ( $\geq 99.0 \%)$ was obtained from Avantor Performance Materials (Center Valley, PA). Sodium sulfate ( $\geq 99.0 \%)$ was obtained from SigmaAldrich (St. Louis, MO). Ammonium nitrate ( $\geq 99.0 \%)$ was obtained from Acros Organics (New Jersey, USA). Sodium nitrate ( $\geq 99.0 \%)$ was obtained from EMD Chemicals (Currently EMD Millipore, Gibbstown, NJ). Ammonium chloride ( $\geq 99.5 \%$ ) was obtained from VWR International (West Chester, PA). Sodium chloride ( $\geq 99.0 \%)$ was obtained from Mallinckrodt Baker (Phillipsburg, NJ). Potassium chloride ( $\geq 99.4 \%)$ was obtained from Fisher Scientific (Fair Lawn, NJ). Ultrapure water was used in all of the experiments and was obtained from an ultrapure water purification system (Thermo Scientific Barnstead D7401 Easypure II UV Type 1, Waltham, MA) at 18.2 M $\Omega . c m$. 


\subsubsection{Data Collection}

The modules for data collection were obtained from Vernier Software and Technology (Beaverton, OR). The $\mathrm{pH}$ of the solution was monitored using Vernier $\mathrm{pH}$ probe $(\mathrm{pH}-$ BTA). The measurements of the mixing ratios of gas phase $\mathrm{CO}_{2}$ were performed using Vernier $\mathrm{CO}_{2}$-BTA probe. The data acquisition was performed using Vernier Lab Pro multichannel interface by Logger Pro software (Version 3.4.6) on a computer.

\subsubsection{Reaction Setup}

The reaction was carried out in a Pyrex 3-neck $500 \mathrm{~mL}$ round bottom flask. The flask was completely wrapped with black polythene and aluminum foil in order to block the UV-Vis light. The $\mathrm{CO}_{2}$ was measured in an adjacent chamber connected by Teflon ${ }^{\circledR}$ tubing with a $\mathrm{CO}_{2}$ sensor (Vernier $\mathrm{CO}_{2}$-BTA) inserted inside. The total volume of the air space for both chambers and tubing was $\sim 1.4 \mathrm{~L}$. The air was circulated between the chambers using a small oil free pump at $0.5 \mathrm{~L} \mathrm{~min}^{-1}$ (Hargraves K113-21-01, Parker Hannifin Corp, Mooresville, NC). Separate chambers were needed to avoid unwanted photolysis of pyruvic acid [Griffith et al., 2013; Leermakers and Vesley, 1963], because the Vernier $\mathrm{CO}_{2}$-BTA probe produces broadband light with wavelength extending into the absorption region of pyruvic acid [Lund Myhre and Nielsen, 2004]. All of the circulation tubing was wrapped with black polythene and aluminum foil to prohibit light intrusions during the experiments. Evolved $\mathrm{CO}_{2}$ gas was retained in the experimental setup using rubber stoppers for the probes and tubing. As soon as the organic acid was introduced to the solution, the setup was sealed using rubber stoppers. This was done so that, no gas can escape nor any gas can intrude into the closed chambers. A schematic of the setup and a photograph of the reaction system 
are given in the supplemental information (Appendix, Figure A.1.6). A complete list of the experimental conditions is provided in Table 2.1. Each experiment is denoted with a number and hereafter the numbers are used to refer to the experiments. Stock solutions of 4.00 M ammonium sulfate, $8.00 \mathrm{M}$ ammonium nitrate, 5.00 M ammonium chloride, 3.00 $\mathrm{M}$ sodium sulfate, $7.00 \mathrm{M}$ sodium nitrate, $5.00 \mathrm{M}$ sodium chloride, $4.00 \mathrm{M}$ potassium chloride and 1.10 $\mathrm{M}$ oxalic acid were prepared and used for consistency throughout the experiments. An adequate amount of the solutions and water were mixed, so that after addition of the acid the desired inorganic ion and acid concentration in $100.0 \mathrm{~mL}$ reaction solution was reached. The solution was continuously stirred using a Teflon ${ }^{\circledR}$ coated magnetic stir bar ( $\sim 2.9 \mathrm{~cm}$ long and $\sim 0.8 \mathrm{~cm}$ thick) at $350 \mathrm{rpm}$. The background $\mathrm{CO}_{2}$ level was monitored prior to the addition of organic acid and only after the background $\mathrm{CO}_{2}$ became stable, the acid was added. Afterward, the evolution of the gas phase $\mathrm{CO}_{2}$ concentration was monitored along with the $\mathrm{pH}$ of the solution for 10 hours or until the $\mathrm{CO}_{2}$ detector became saturated. The $\mathrm{pH}$ of the solution and $\mathrm{CO}_{2}$ concentration were measured and recorded by Logger Pro software every six seconds. 


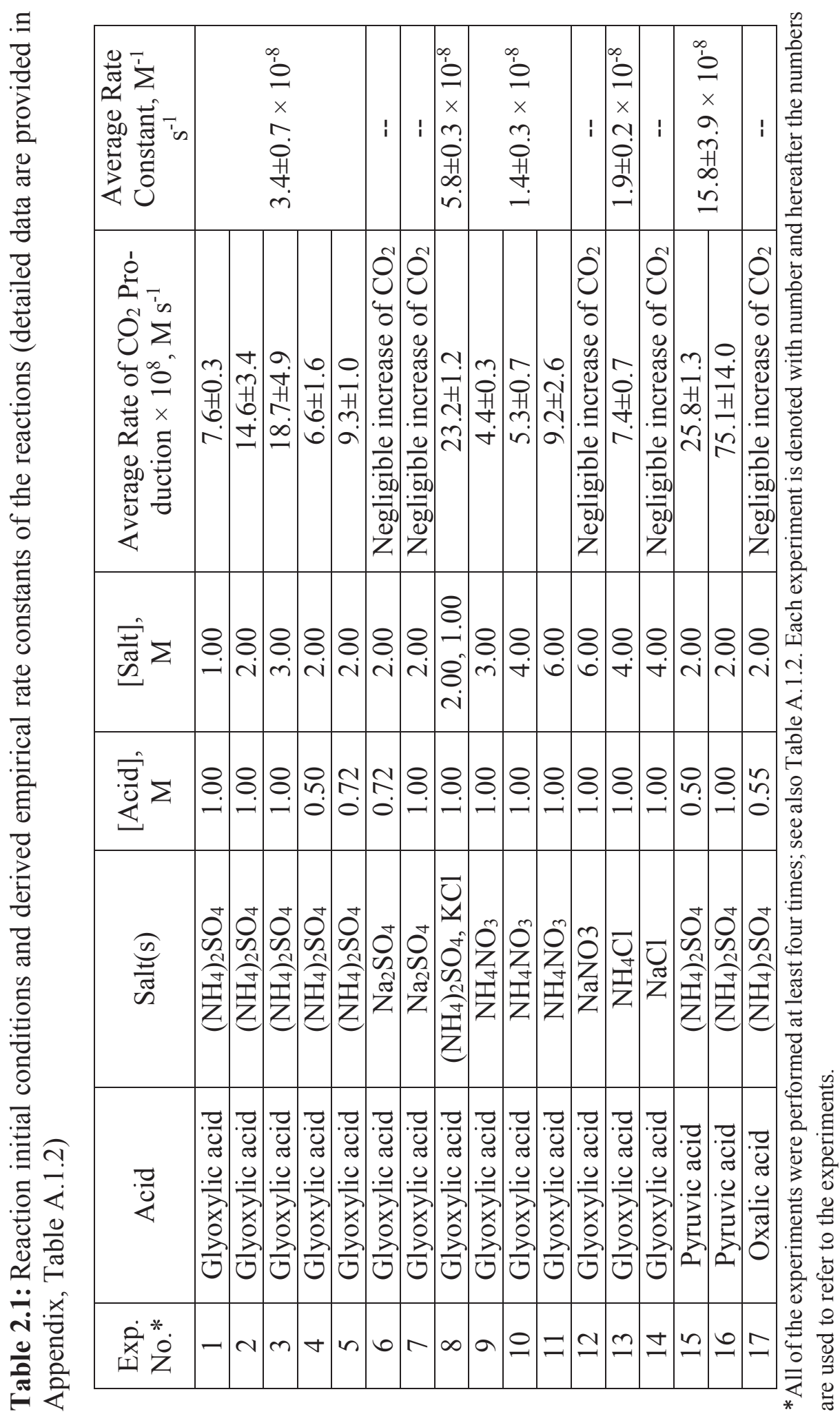




\subsubsection{Data Processing}

A batch of 17 sets of experiments with varied precursor organic acids, salts and their concentrations were conducted (Table 2.1, Table A.1.2). Each of the experiments was repeated at least 4 times to evaluate the reproducibility of the results. The gas phase concentration of $\mathrm{CO}_{2}$ and the solution $\mathrm{pH}$ for each of the individual experiments were monitored for up to 10 hours or until the $\mathrm{CO}_{2}$ detector was saturated. The replicates were necessary because the temperature of the experiments was not controlled and could have fluctuated.

The measured gas phase $\mathrm{CO}_{2}$ mixing ratios were used to study the kinetics of the decarboxylation process. The $\mathrm{CO}_{2}$ diffusion from the solution to gas phase was assumed to be a faster process than the production of $\mathrm{CO}_{2}$ and virtually does not have any effect on the rate of decarboxylation. The kinetics of phase transfer is discussed in supplemental information (Appendix A.1.3). The gas phase mixing ratio of $\mathrm{CO}_{2}$ was converted to aqueous phase concentrations imagining all produced $\mathrm{CO}_{2}$ were to remain in the solution. Conversion of the measured gas phase mixing ratio to an aqueous phase $\mathrm{CO}_{2}$ concentration was performed for kinetic calculations and to relate the $\mathrm{CO}_{2}$ concentration to those of the other aqueous species. The calculations are available in the Appendix (A.1.1). The rates of the reaction, empirical reaction order with respect to each of the reactants and rate constant were calculated (Section 2.4.2.1). The values of $\mathrm{CO}_{2}$ from each replicated experiments were used to calculate the rate and empirical rate constants and is tabulated in Table 2.1 and Table A.1.2. The data presented here were not corrected to remove the variability associated with the laboratory temperature, which fluctuated $\left(70-80{ }^{0} \mathrm{~F}\right.$, according to the room thermostat) during the experiments. 


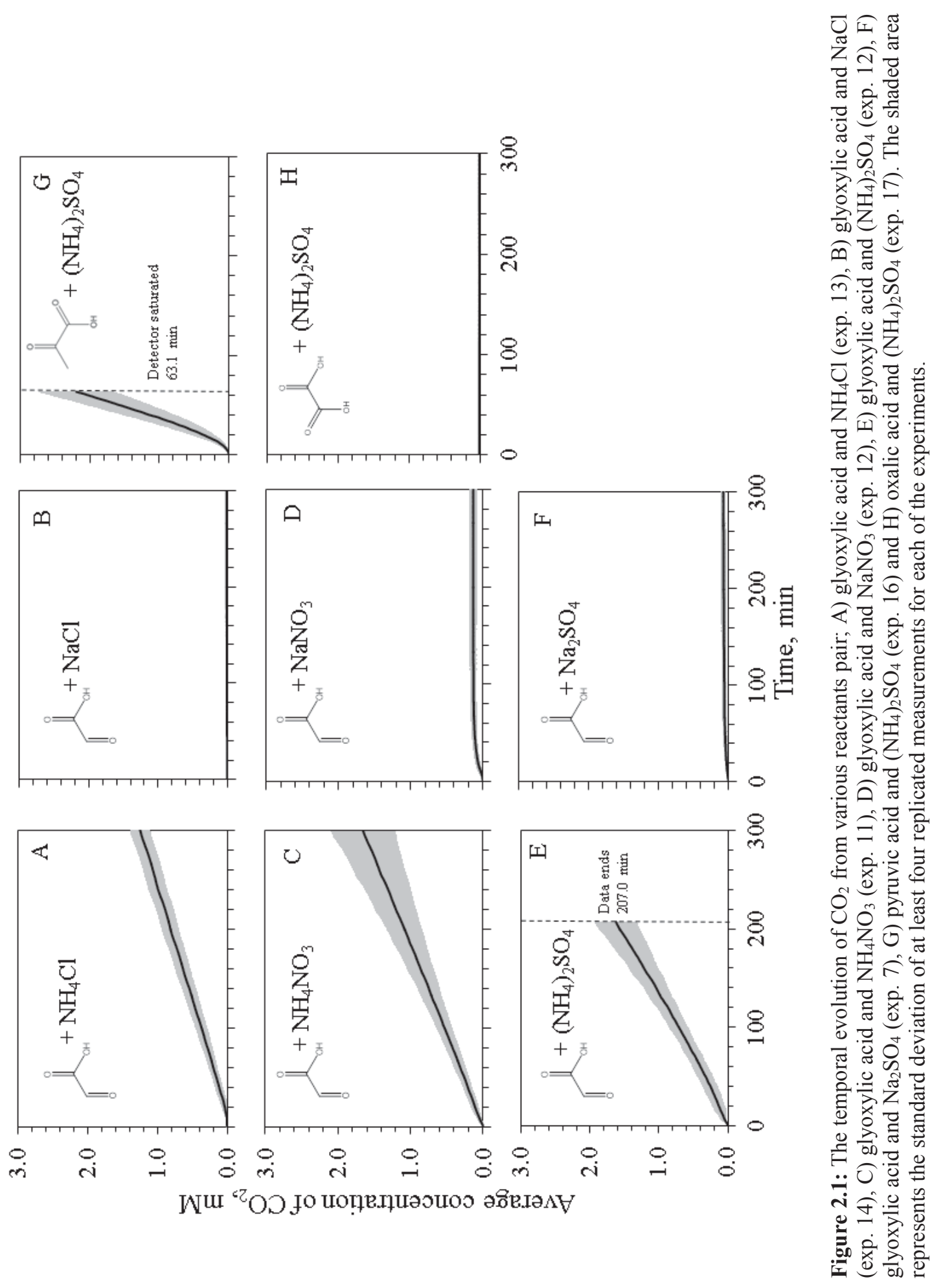




\subsection{Results and Discussion}

\subsubsection{Decarboxylation from glyoxylic and pyruvic acid}

Glyoxylic, pyruvic and oxalic acids were studied in the presence of aqueous ammonium and aqueous sodium salt solutions simulating dark and radical free atmospheric aqueous aerosol conditions. The evolution of the averaged $\mathrm{CO}_{2}$ concentration with respect to reaction time is shown in Figure 2.1 for selected experiments. The reaction appears to have an 'initial induction' period and the rate appeared to be slower at the beginning of the reaction. Although the exact reason for the initial induction is not understood, all of the chemical reactions and their equilibrium along with other physical processes likely contribute to the initial induction period. However after the initial induction period, the production of $\mathrm{CO}_{2}$ becomes faster and linear. It is possibly due to the chosen time scale or it could be that the reaction reached to a 'quasi steady state'. In each experiment, the $\mathrm{pH}$ of the solutions dropped sharply upon the addition of the organic acid and kept decreasing over time at a very slow rate (Appendix A.1.6) indicating a steady increase in the hydronium ion concentration from either the organic acid or the ammonium ion. Overall the $\mathrm{CO}_{2}$ concentrations steadily increased with respect to time for both pyruvic acid and glyoxylic acid in the presence of the ammonium salts, including: ammonium sulfate, ammonium nitrate and ammonium chloride (Figure 2.1A, 2.1C, 2.1H). Negligible amounts of $\mathrm{CO}_{2}$ were observed in the control experiments using the corresponding sodium salts (Figures 2.1B, 2.1D and 2.1E). The initial $\mathrm{pH}$ of the sodium salt solution was higher compared to the ammonium salt solution. At the higher $\mathrm{pH}$ values $(>6)$, the solution

contains considerably higher $\mathrm{HCO}_{3}{ }^{-}$ion and upon addition of the organic acids, the ionic 
equilibrium of the solution quickly shifts such that $\mathrm{HCO}_{3}^{-}$converts to gaseous $\mathrm{CO}_{2}$ and contributes to a minor increase in the gas phase $\mathrm{CO}_{2}$ mixing ratio. Moreover, the major increase in the concentration of $\mathrm{CO}_{2}$ with time for all sodium salts takes place within the first half an hour upon the addition of the organic acids and no further increase in the concentration of $\mathrm{CO}_{2}$ was observed beyond the first hour. This indicates the observed increase is mainly due to a shift in the equilibrium between aqueous $\mathrm{HCO}_{3}{ }^{-}$and gaseous $\mathrm{CO}_{2}$. Trace impurities in the ACS grade salts may also play a minor role, for example in the case of nitrate experiments (Figure 2.1C, 2.1D), nitrate salt can contain minute amount of nitrite and can contribute to the negligible decarboxylation. However, it is expected that all ACS grade salts contain similar impurities but decarboxylation was only observed in the presence of the ammonium salts (Figure 2.1). This implies the fragmentation of $\mathrm{C}-\mathrm{C}$ bond between the carbonyl group and carboxylic acid group leading to decarboxylation of pyruvic and glyoxylic acid is facilitated by the ammonium cation (or its conjugate base ammonia) and not from self-dissociation or any trace impurities. To explore this further, we carried out experiments to evaluate the rate of decarboxylation with respect to: (i) precursor acids, (ii) inorganic salts, (iii) concentration and (iv) ionic strength. The determination of the rate of decarboxylation and other experiments are discussed in the following sections.

\subsubsection{Rate of the Decarboxylation and Order of the Reaction}

\subsubsection{Derivation of the Rates of Decarboxylation}

Despite initial induction periods, the time profile of $\mathrm{CO}_{2}$ is approximately linear meaning the reaction reached to a 'quasi steady state' in the studied time periods. Therefore, we can 
apply an initial rate method to determine the orders and rate constant of the reaction past the induction period. The induction period may be due to required time to bring all the processes to a 'quasi steady state'. However, it is very much possible that the processes involved in the decarboxylation are more complex than thought and involve multiple equilibriums, which awaits further study. We plotted the data points for the variation of the concentration of $\mathrm{CO}_{2}$ with respect to time between $100.0 \mathrm{~min}$ to $199.9 \mathrm{~min}$ (or till end of data points) and then using a liner equation, curve fitted the data and took the value of the slope as the rate of decarboxylation (Figure 2.2 and Table 2.2). The advantage of using this method was it will reduce if not remove completely any contribution from dissolved impurities (i.e., $\mathrm{HCO}_{3}{ }^{-}$, etc.) and also the measured rate will be for the period when the processes appears to be at a 'quasi steady state'. It may be noted, in the case of experiment number 16 (pyruvic acid 1.0 M and ammonium sulfate $2.0 \mathrm{M}$ ) those data points were not available and the range used to determine the rate of decarboxylation was between 40.0 $\min$ and $63.3 \mathrm{~min}$. The derivation of the reaction rate was shown for experiment number 13 (glyoxylic aicd 1.0 M and ammonium sulfate $4.0 \mathrm{M}$ ) in the Figure 2.2 and tabulated in Table 2.2. 


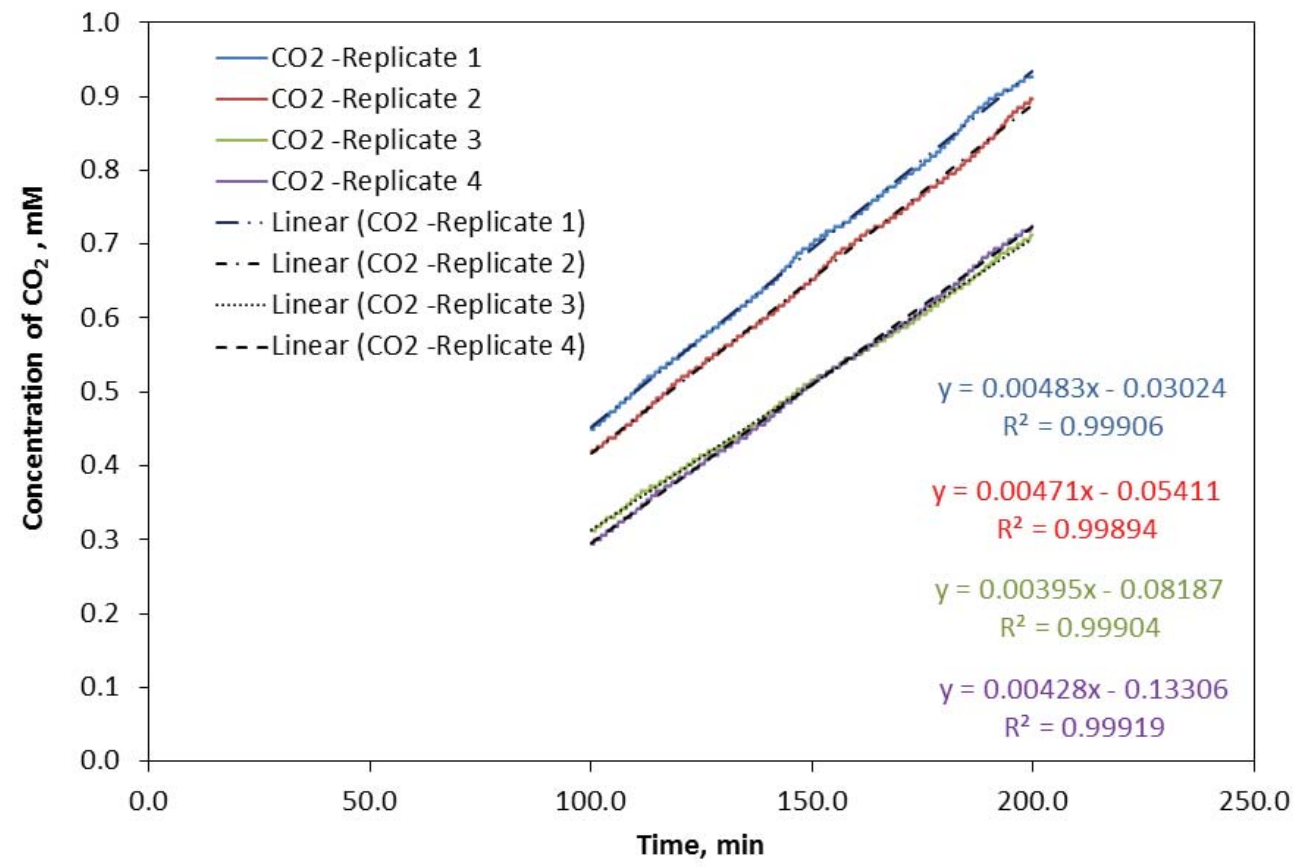

Figure 2.2: The variation of concentration of $\mathrm{CO}_{2}$ with respect to time in experiment number 13 (ammonium chloride 4.00 M and glyoxylic acid $1.00 \mathrm{M}$ ) between $100.0 \mathrm{~min}$ and $199.9 \mathrm{~min}$. The plot of all data points may be found in Figure A.1.2. The data points (Figure 2.2) were fitted with a liner equation. The optimized equation and parameters were presented in the lower right hand side of the figure and are colored coded according to the color of the replicate analysis. The slope of each equation represents the rate of decarboxylation for each replicate and tabulated accordingly in Table 2.2.

Table 2.2: Derived data of rate of decarboxylation for experiment number 13. (Rate of decarboxylation is the slope of the fitted data in Figure 2.2)

\begin{tabular}{|c|c|c|}
\hline Exp. 13 & $\begin{array}{l}\text { Rate of decarboxylation, } \\
\qquad \mathrm{mM} \min ^{-1}\end{array}$ & $\begin{array}{l}\text { Rate of decarboxylation } \\
\times 10^{8}, \mathrm{M} \mathrm{s}^{-1}\end{array}$ \\
\hline Replicate 1 & 0.004825 & 8.04 \\
\hline Replicate 2 & 0.004714 & 7.86 \\
\hline Replicate 3 & 0.003950 & 6.58 \\
\hline Replicate 4 & 0.004279 & 7.13 \\
\hline
\end{tabular}

\subsubsection{Derivation of the Order of the Reaction}

Let us consider the following reaction:

$$
\begin{gathered}
\mathrm{H}(\mathrm{CO}) \mathrm{COOH}+\mathrm{NH}_{4}^{+} \stackrel{\text { Other ions }}{\longrightarrow} \mathrm{CO}_{2}+\text { other products } \\
v_{\text {rate }}=\mathrm{k} \times\left[\mathrm{NH}_{4}^{+}\right]^{\alpha} \times[\text { Glyoxylic acid }]^{\beta} \ldots \ldots \ldots(\mathrm{E} 2.1)
\end{gathered}
$$


Where, $\alpha, \beta$ is the order with respect to ammonium and glyoxylic acid and $\mathrm{k}$ is the rate constant

Now, if the concentration of $\mathrm{NH}_{4}^{+}$is varied keeping concentration of glyoxylic acid constant then the equation E2.1 reduces to:

$$
\begin{gathered}
v_{\text {rate }}=\mathrm{k}_{1} \times\left[\mathrm{NH}_{4}^{+}\right]^{\alpha} \ldots \ldots \ldots(\mathrm{E} 2.2) \\
\text { where, } \mathrm{k}_{1}=\mathrm{k} \times[\text { Glyoxylic acid }]^{\beta}
\end{gathered}
$$

Taking natural logarithm of the equation E2.2 we get,

$$
\ln \left(v_{\text {rate }}\right)=\ln \left(\mathrm{k}_{1}\right)+\alpha \times \ln \left(\left[\mathrm{NH}_{4}{ }^{+}\right]\right) \ldots \ldots \ldots(\mathrm{E} 2.3)
$$

Now, A plot of $\ln \left(v_{\text {rate }}\right)$ vs. $\ln \left(\left[\mathrm{NH}_{4}{ }^{+}\right]\right)$would be a straight line and the slope of the line should be the order of the reaction with respect to $\mathrm{NH}_{4}{ }^{+}$ion.

Similarly order of the reaction with respect to the other species may be derived.

\subsection{Determination of the Order with Respect to the $\mathrm{NH}_{4}^{+}$Ion}

The experiment sets of 1,2,3 and 9,10,11 kept the initial concentration glyoxylic acid constant but varied the initial concentration of ammonium ion. In these two cases we can apply equation E2.3 to obtain the order with respect to $\mathrm{NH}_{4}{ }^{+}$. The derived data were tabulated in Table 2.3 and Table 2.4. The natural logarithm of the rate of decarboxylation and the molar initial concentration of the ammonium ion were plotted in Figure 2.3. No corrections for activity were made and should be addressed in future investigation. The order with respect to ammonium is determined to be 0.8 and 1.1 in ammonium sulfate and ammonium nitrate experiment. For practical purposes, first order with respect to the ammonium ion will be used in the further calculations. 
Table 2.3: Derived kinetic data for the reaction between ammonium sulfate and glyoxylic acid (experiment number 1,2 and 3).

\begin{tabular}{|c|c|c|c|c|c|c|}
\hline $\begin{array}{l}\text { Exp } \\
\text { no. }\end{array}$ & $\begin{array}{l}\text { Replicate } \\
\text { Number }\end{array}$ & $\begin{array}{c}{\left[\mathrm{NH}_{4}^{+}\right],} \\
\mathrm{M}\end{array}$ & $\ln \left(\left[\mathrm{NH}_{4}{ }^{+}\right]\right)$ & $\begin{array}{c}\text { [glyoxylic } \\
\text { acid], } \mathrm{M}\end{array}$ & $\begin{array}{c}\text { Reaction } \\
\text { rate } \times 10^{8} \text {, } \\
\mathrm{M} \mathrm{s}^{-1}\end{array}$ & $\ln$ (rate) \\
\hline \multirow{4}{*}{1} & 1 & 2.00 & 0.693147 & 1.00 & 7.7565 & -16.3721 \\
\hline & 2 & 2.00 & 0.693147 & 1.00 & 7.7151 & -16.3775 \\
\hline & 3 & 2.00 & 0.693147 & 1.00 & 7.8146 & -16.3647 \\
\hline & 4 & 2.00 & 0.693147 & 1.00 & 7.0767 & -16.4639 \\
\hline \multirow{4}{*}{2} & 1 & 4.00 & 1.386294 & 1.00 & 14.0076 & -15.7811 \\
\hline & 2 & 4.00 & 1.386294 & 1.00 & 11.9426 & -15.9406 \\
\hline & 3 & 4.00 & 1.386294 & 1.00 & 19.1444 & -15.4687 \\
\hline & 4 & 4.00 & 1.386294 & 1.00 & 12.0906 & -15.9283 \\
\hline \multirow{5}{*}{3} & 1 & 6.00 & 1.791759 & 1.00 & 15.1573 & -15.7022 \\
\hline & 2 & 6.00 & 1.791759 & 1.00 & 21.0429 & -15.3741 \\
\hline & 3 & 6.00 & 1.791759 & 1.00 & 26.1295 & -15.1576 \\
\hline & 4 & 6.00 & 1.791759 & 1.00 & 16.8648 & -15.5954 \\
\hline & 5 & 6.00 & 1.791759 & 1.00 & 14.1392 & -15.7717 \\
\hline
\end{tabular}

Table 2.4: Derived kinetic data for the reaction between ammonium nitrate and glyoxylic acid (experiment number 9,10 and 11).

\begin{tabular}{|c|c|c|c|c|c|c|}
\hline \multirow{2}{*}{$\begin{array}{c}\text { Exp } \\
\text { no. }\end{array}$} & $\begin{array}{c}\text { Replicate } \\
\text { Number }\end{array}$ & $\begin{array}{c}{\left[\mathrm{NH}_{4}{ }^{+}\right],} \\
\mathrm{M}\end{array}$ & $\ln \left(\left[\mathrm{NH}_{4}{ }^{+}\right]\right)$ & $\begin{array}{c}\text { [glyoxylic } \\
\text { acid], } \mathrm{M}\end{array}$ & $\begin{array}{c}\text { Reaction rate } \\
\times 10^{8}, \mathrm{M} \mathrm{s}^{-1}\end{array}$ & $\ln$ (rate) \\
\hline \multirow{4}{*}{9} & 1 & 3.00 & 1.098612 & 1.00 & 4.1576 & -16.9957 \\
\cline { 2 - 7 } & 2 & 3.00 & 1.098612 & 1.00 & 4.0960 & -17.0107 \\
\cline { 2 - 7 } & 3 & 3.00 & 1.098612 & 1.00 & 4.5732 & -16.9005 \\
\cline { 2 - 7 } & 4 & 3.00 & 1.098612 & 1.00 & 4.7335 & -16.8660 \\
\hline \multirow{4}{*}{10} & 1 & 4.00 & 1.386294 & 1.00 & 5.8393 & -16.6561 \\
\cline { 2 - 7 } & 2 & 4.00 & 1.386294 & 1.00 & 5.3405 & -16.7454 \\
\cline { 2 - 7 } & 3 & 4.00 & 1.386294 & 1.00 & 4.3643 & -16.9472 \\
\hline \multirow{4}{*}{11} & 4 & 4.00 & 1.386294 & 1.00 & 5.7212 & -16.6765 \\
\cline { 2 - 7 } & 1 & 6.00 & 1.791759 & 1.00 & 7.8491 & -16.3603 \\
\cline { 2 - 7 } & 2 & 6.00 & 1.791759 & 1.00 & 7.0465 & -16.4681 \\
\cline { 2 - 7 } & 3 & 6.00 & 1.791759 & 1.00 & 11.4262 & -15.9848 \\
\hline & 4 & 6.00 & 1.791759 & 1.00 & 7.1391 & -16.4551 \\
\hline \multirow{2}{*}{} & 5 & 6.00 & 1.791759 & 1.00 & 12.6122 & -15.8860 \\
\hline
\end{tabular}




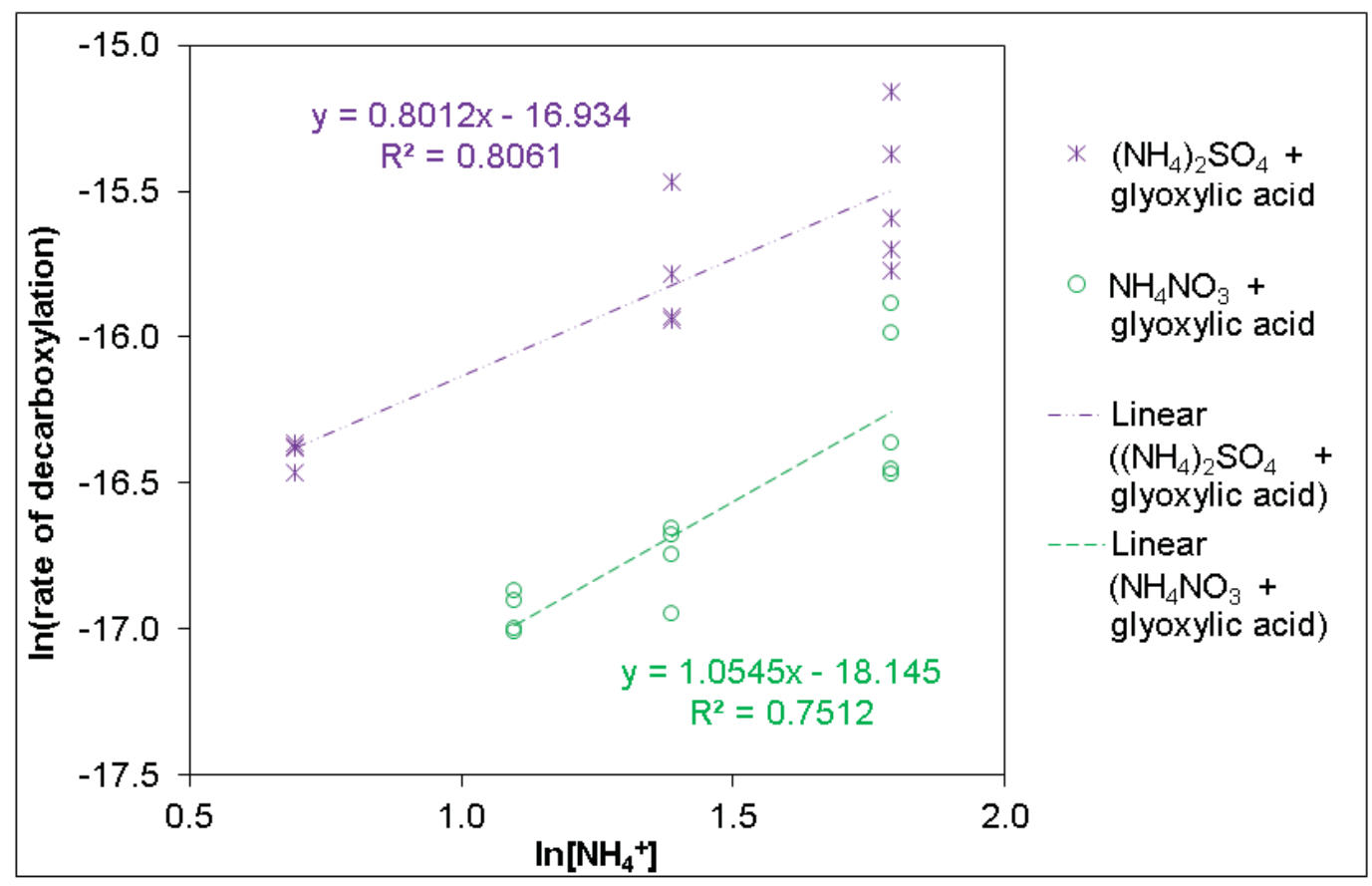

Figure 2.3: The natural logarithm of the rate of decarboxylation vs. the natural logarithm of the molar initial concentration of ammonium ion for experiment sets of 1,2,3 (ammonium sulfate and glyoxylic acid) and 9, 10, 11(ammonium nitrate and glyoxylic acid). The linear fit of the data points was made and from the optimized parameters the slope was determined. The reaction order with respect to the ammonium ion is 0.8 for the ammonium sulfate experiments and 1.1 for the ammonium nitrate experiments from the slopes.

\subsection{Determination of the Order with Respect to Glyoxylic Acid}

A plot of the natural logarithm of the rate of decarboxylation versus the natural logarithm of the initial concentration of glyoxylic acid was made for experiment numbers 2, 4 and 5

(Figure 2.4). The derived order with respect to glyoxylic acid is 1.1 and is very close to 1.

Thus, we used the first order with respect to glyoxylic acid for further calculations. 


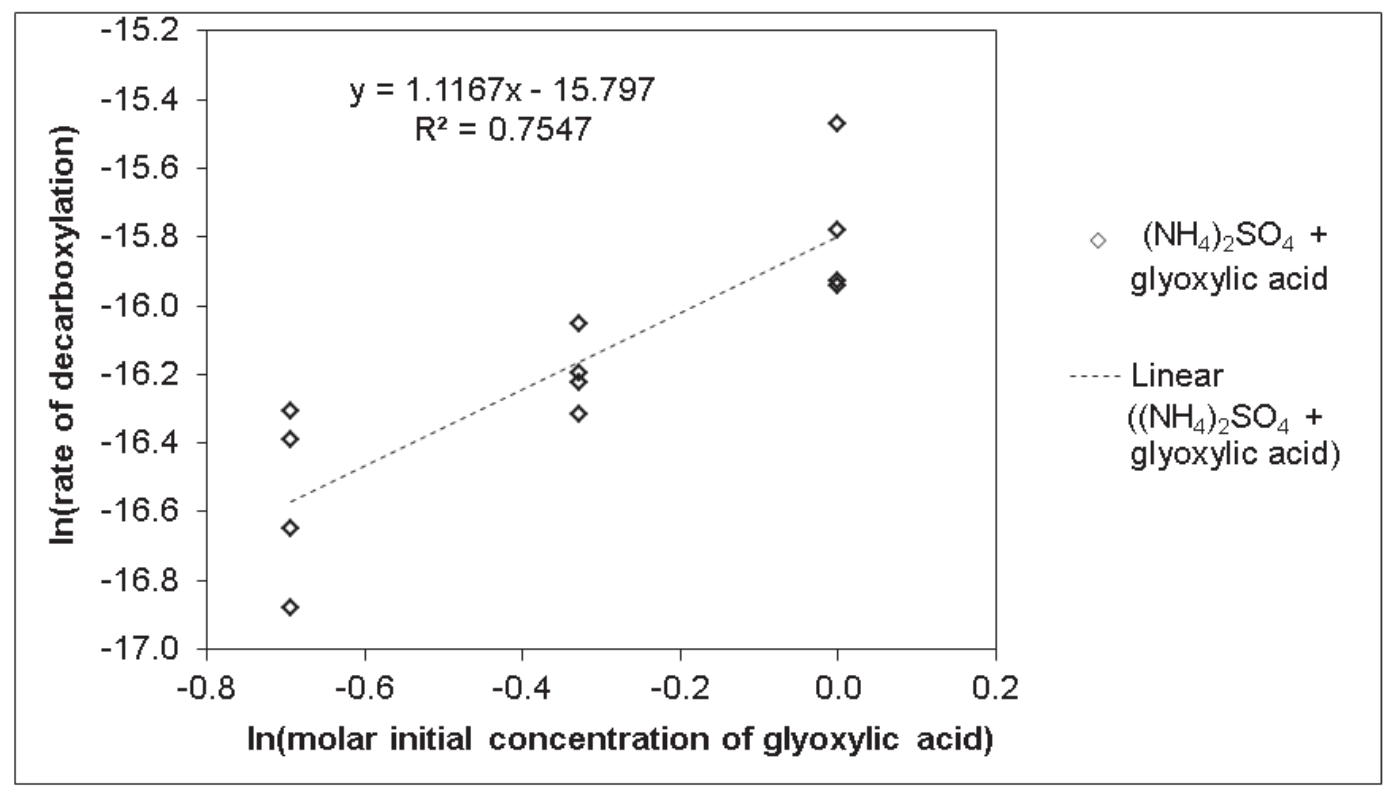

Figure 2.4: Plot of the natural logarithm of the rate of decarboxylation vs. the natural logarithm of the molar initial concentration of glyoxylic acid for the experiment set of 2, 4 and 5 (ammonium sulfate and glyoxylic acid). The slope of the fitted line is 1.1 and thus the reaction order with respect to glyoxylic acid is 1.1.

\subsection{Determination of the Order with Respect to Pyruvic Acid}

A plot of the natural logarithm of the rate of decarboxylation versus the natural logarithm of the initial concentration of pyruvic acid was made for the experiment numbers 15 and 16 (Figure 2.5). The experiments were only done at two different concentrations and perhaps in future studies experiments can be performed with more varied concentrations. However, the derived order with respect to pyruvic acid is 1.5 with a clear deviation from an integer value. In congruence with the findings from glyoxylic acid experiments, we will use the first order with respect to pyruvic acid for further calculations. However, the order with respect to pyruvic acid should be reevaluated in future studies. 


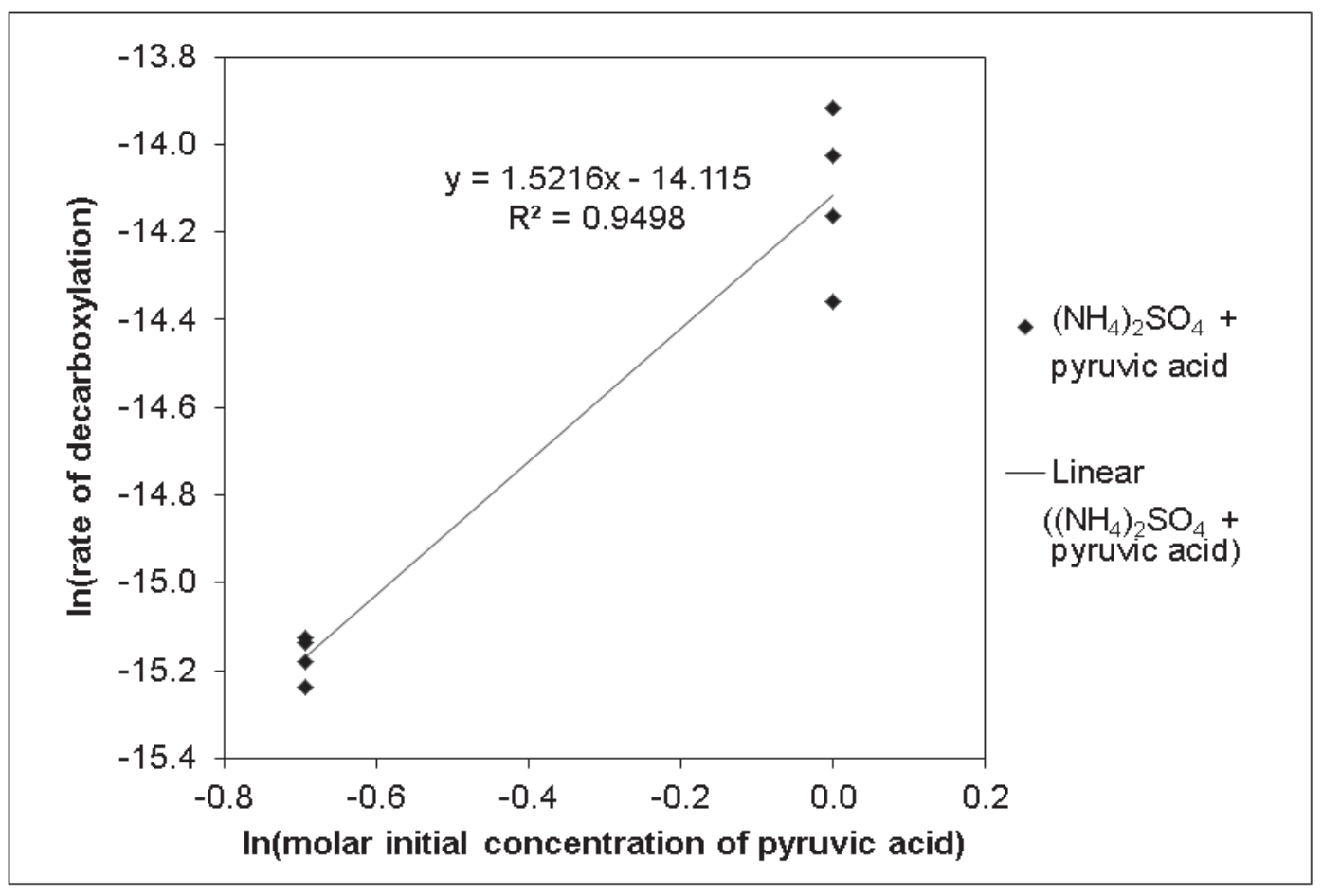

Figure 2.5: A plot of the natural logarithm of the rate of decarboxylation vs. the natural logarithm of the molar initial concentration of pyruvic acid for experiments 15 and 16 (ammonium sulfate and pyruvic acid). The slope of the fitted line is 1.5 .

\subsubsection{Organic Acid Precursors and Concentration}

We studied the decarboxylation of pyruvic acid, glyoxylic acid and oxalic acid in the presence of ammonium and sodium salts. Although decarboxylation was observed for both of the $\alpha$-oxo acids, it was not observed from oxalic acid (Exp. number 17, Figure 2.1H). Therefore, we designed the experiments to study the effect of concentration of the $\alpha$-oxo acids on decarboxylation.

In the experiments 2, 4 and 5 (Table 2.1), the concentration of glyoxylic acid was varied while the concentration of ammonium sulfate was held constant at $2.00 \mathrm{M}$. In general, the rate of $\mathrm{CO}_{2}$ production was increased with the concentration of glyoxylic acid as shown in 
Figure 2.6. The calculated reaction order with respect to glyoxylic acid was 1.1 (Section 2.4.2.2.2) indicating the order of the reaction with respect to glyoxylic acid is a likely one.

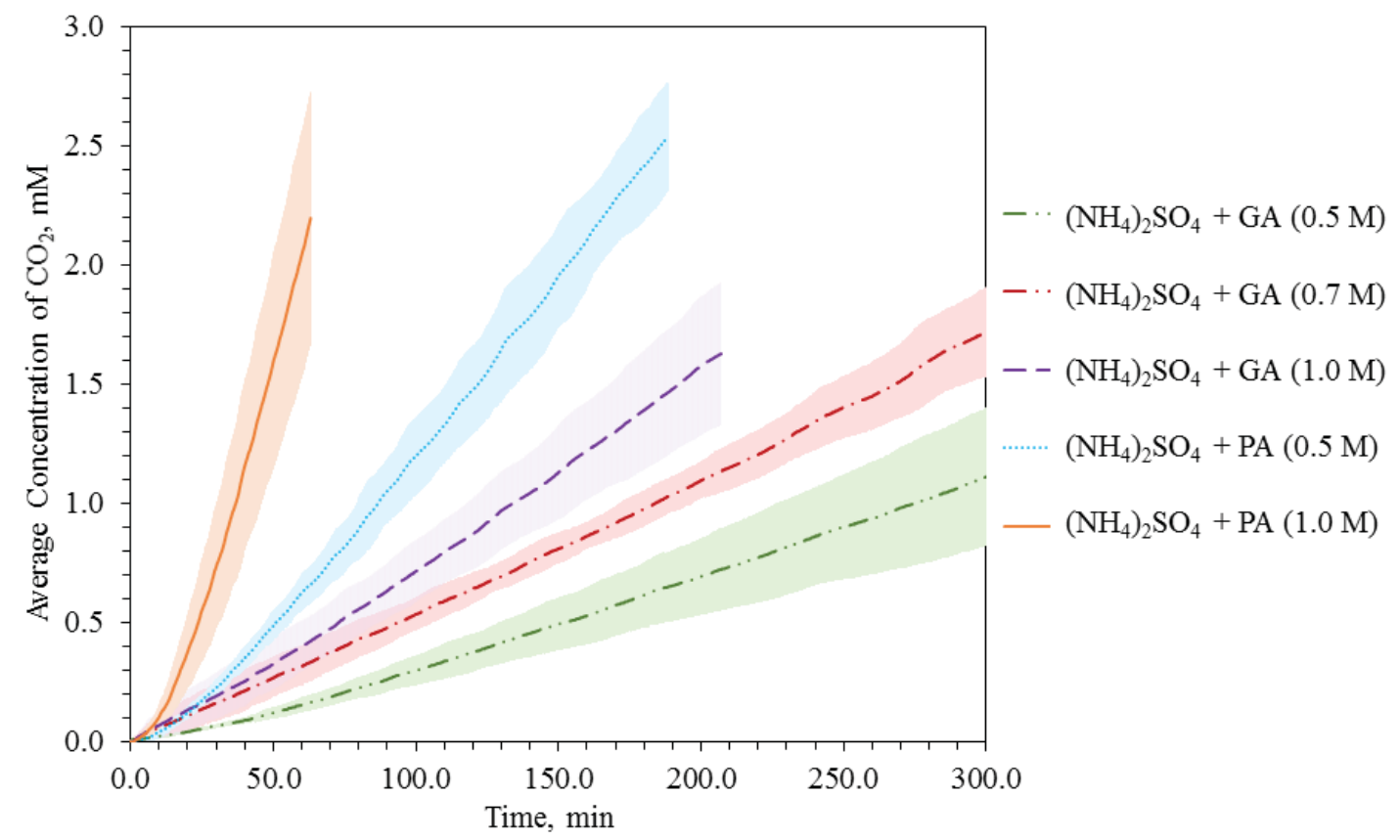

Figure 2.6: Evolution of $\mathrm{CO}_{2}$ production with time with different reaction conditions. The concentration of $\left(\mathrm{NH}_{4}\right)_{2} \mathrm{SO}_{4}$ was $2.00 \mathrm{M}$ in each of the cases here. Faster production of $\mathrm{CO}_{2}$ with increased initial concentrations of pyruvic and glyoxylic acid was observed. Shaded regions represent the standard deviation of the averaged experiments. The gas phase concentration of $\mathrm{CO}_{2}(\mathrm{ppm})$ was converted to the concentration of $\mathrm{CO}_{2}(\mathrm{mM})$ for the volume of the reaction solution. $\mathrm{PA}=$ Pyruvic acid and $\mathrm{GA}=$ Glyoxylic acid.

In the experiments 15 and 16 (Table 2.1), the concentration of pyruvic acid was varied and the concentration of ammonium sulfate was held constant at 2.0 M. Similar to the experiments with glyoxylic acid, the production of $\mathrm{CO}_{2}$ varied almost linearly with the concentration of pyruvic acid (Figure 2.6, Table 2.1). However, the determination of the reaction order was not as straightforward as it was for glyoxylic acid. The reaction order with respect to pyruvic acid was determined to be 1.5 indicating the possibility of a more complex process than previously described (Section 2.4.2.2.3). However in congruence with the observation of first order with respect to glyoxylic acid, we approximated the reaction order 
with respect to pyruvic acid also to be 1 and perhaps future study will provide clarification on this issue.

Pyruvic acid undergoes decarboxylation at a faster rate than glyoxylic acid (Figure 2.6). Specifically, for the reactions with ammonium sulfate the rate constant for pyruvic acid is at least 4 times faster than that of glyoxylic acid (Table 2.1). This indicates the molecular structure of the acid affects the rate of decarboxylation. In the aqueous solutions of both pyruvic and glyoxylic acid, the oxo group is anticipated to be hydrated. The predicted hydration of glyoxylic acid in aqueous solution was $99.9 \%$ and for pyruvic acid $70 \%$ [Kerber and Fernando, 2010]. However, the hydration equilibrium constant for the carbonyl group depends on the inductive effect of adjacent groups [Buschmann et al., 1980] and is a function of the solution $\mathrm{pH}$, temperature, concentration and other conditions [Pocker and Meany, 1970; Pocker et al., 1969]. Pyruvic acid is anticipated to be less hydrated than glyoxylic acid, because of the adjacent methyl group compared to the hydrogen atom of glyoxylic acid under similar conditions. This suggests the decarboxylation reaction likely proceeds via nucleophilic attack of the oxo group, which may be retarded by hydration of the carbonyl moiety forming a geminal diol (the hydrated form of the carbonyl group). This indicates the oxo group plays an important role in the observed decarboxylation. The necessity of activation of the carbonyl moiety in the $\alpha$-oxo acids leading to decarboxylation is further bolstered by the observations of no decarboxylation in the experiments with oxalic acid and ammonium sulfate (Figure 2.1). A set of potential reaction pathways of decarboxylation is given in section 2.4.6 (Scheme 2.1). 


\subsubsection{Inorganic Salts and Concentration}

As discussed earlier, decarboxylation takes place in the reactions between $\alpha$-oxo acids and ammonium salts in the absence of any other known oxidants at the dark conditions. The observed changes in the $\mathrm{CO}_{2}$ concentrations from the reactions with sodium salts were at least one order of magnitude lower than the observed changes from the ammonium salt solutions (Figure 2.1) indicating the ammonium ion (or free ammonia) is involved in the decarboxylation reaction steps. The dependence of decarboxylation on the ammonium salts was explored in the next few experiments.

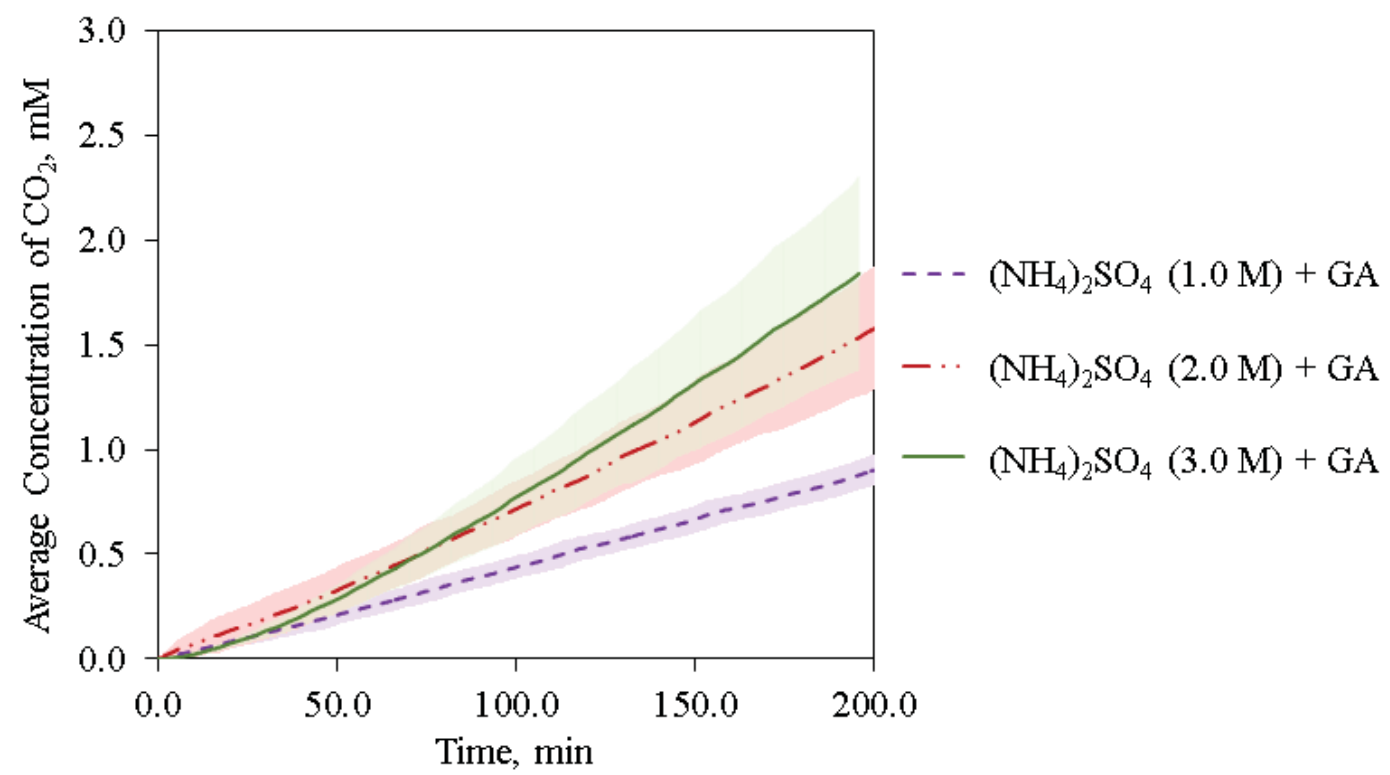

Figure 2.7: The temporal production of $\mathrm{CO}_{2}$ from glyoxylic acid at varying concentration of ammonium sulfate. The concentration of glyoxylic acid (GA) is constant (1.00 M) for all experiments. The gas phase concentration of $\mathrm{CO}_{2}$ (ppm) was converted to an aqueous phase concentration of $\mathrm{CO}_{2}$ for the volume of the reaction solution. The shaded region represents the standard deviation of the averaged experiments. 


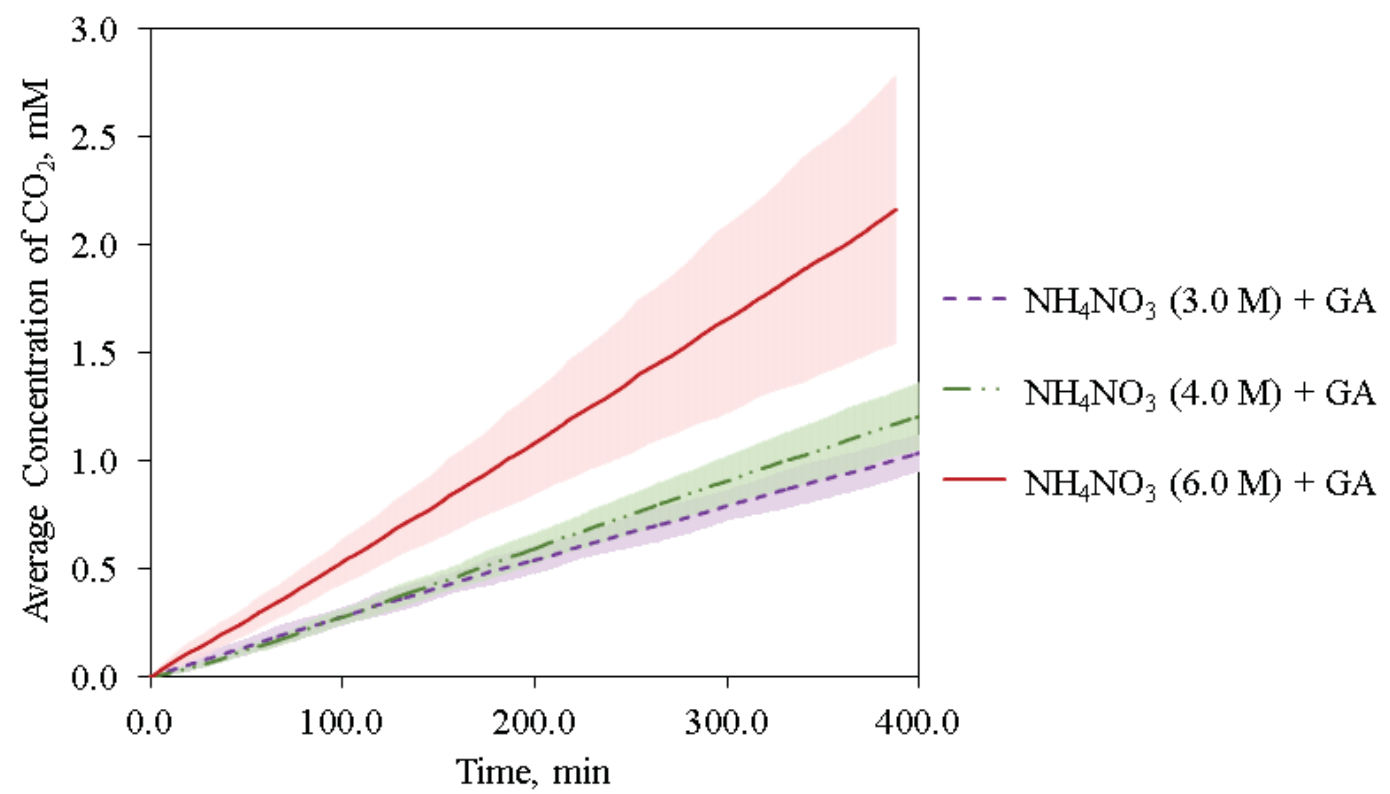

Figure 2.8: Production of $\mathrm{CO}_{2}$ from glyoxylic acid with time at varied concentrations of ammonium nitrate. The concentration of glyoxylic acid (GA) is the same $(1.00 \mathrm{M})$ in all cases. The gas phase concentration of $\mathrm{CO}_{2}$ (ppm) was converted to an aqueous phase concentration of $\mathrm{CO}_{2}$ for the volume of reaction solution. The shaded region represents the standard deviation the averaged experiments.

The concentrations of ammonium sulfate (Experiments 1, 2 and 3) and ammonium nitrate (Experiments 9, 10 and 11) were varied, while the concentration of glyoxylic acid was held constant at 1.0 M. In these experiments, we observed an increase in the rate of decarboxylation with an increase in the ammonium salt concentrations (Figure 2.7 and Figure 2.8). The rate of decarboxylation appeared to vary linearly with the initial concentration of the ammonium ion for each of the ammonium salts (Figure 2.4). No corrections for activity were made. The order of the reaction with respect to the ammonium cation in the reactions between glyoxylic acid and ammonium sulfate (Experiment no. 1, 2 and 3) was determined to be 0.80 (Section 2.4.2.2.1). For the reactions between glyoxylic acid and ammonium nitrate (Exp. 9, 10 and 11) an order of 1.1 with respect to the ammonium concentration was determined (Section 2.4.2.2.1). These calculations and observation indicate that decarboxylation is likely a first order reaction with respect to the ammonium cation. 
Although decarboxylation was predominantly observed in all of the ammonium salts, a negligible increase in the gas phase concentration of $\mathrm{CO}_{2}$ was observed with each of the experiments containing sodium salts (Figure 2.1). As previously mentioned, this increase likely comes from the change in the solution $\mathrm{pH}$ upon the addition of the organic acid, which subsequently changes the solubility of aqueous $\mathrm{CO}_{2}$ (aqueous $\mathrm{HCO}_{3}^{-}$is rapidly converted to aqueous $\mathrm{CO}_{2}$ when the $\mathrm{pH}$ is lowered). Ammonia is known to attack the electron deficit carbonyl carbon because of its capability to donate electrons [Morrison and Boyd, 1992] leading to a nucleophilic addition product, which may initiate the decarboxylation process. The potential reaction pathways were given in section 2.4.6 (Scheme 2.1).

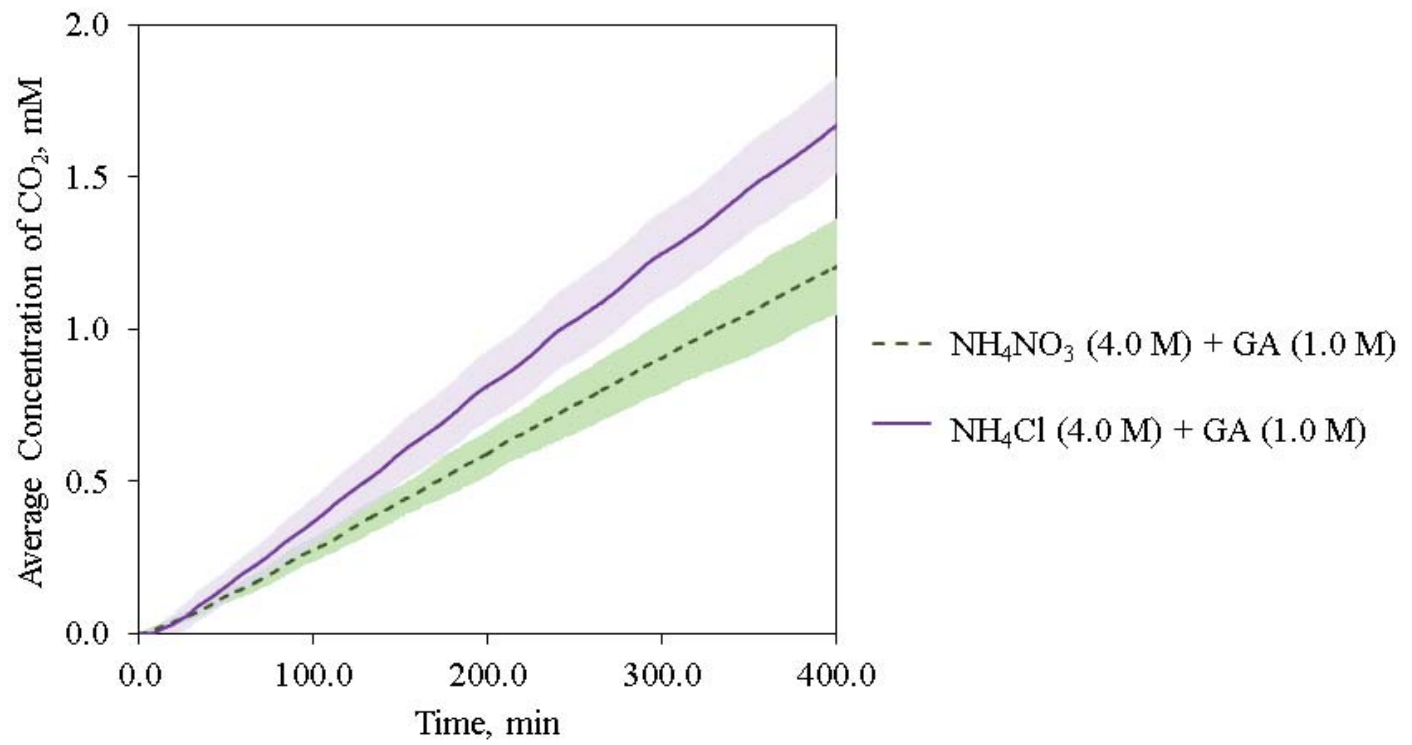

Figure 2.9: Production of $\mathrm{CO}_{2}$ from glyoxylic acid with time and varied inorganic salt composition. The concentration glyoxylic acid (GA) is the same in all cases. The concentrations of ammonium nitrate and ammonium chloride are $4.0 \mathrm{M}$ and both of them are 1:1 electrolyte. The gas phase concentration of $\mathrm{CO}_{2}$ (ppm) was converted to an aqueous phase concentration of $\mathrm{CO}_{2}$ for the volume of the reaction solution. The shaded region represents the standard deviation of the averaged experiments. 
A dissimilar rate of decarboxylation was observed (Figure 2.9) in the experiments with equal molar concentrations of ammonium nitrate (Experiment 10) and ammonium chloride (Experiment 13). A slower rate of $\mathrm{CO}_{2}$ production was observed in the experiments with ammonium nitrate than ammonium chloride (Figure 2.9, Table 2.1). This could arise from one of the following factors: (i) the ionic composition, (ii) the $\mathrm{pH}$ of the reaction solution, and (iii) the concentration of free ammonia. It is likely that the difference in the salt composition most likely causes a difference in the solution environment, the major differences, however, were observed in terms of the $\mathrm{pH}$ and the free ammonia concentration. The $\mathrm{pH}$ of the ammonium nitrate reaction solution was 1.35 and the $\mathrm{pH}$ of ammonium chloride reaction solution was 1.16 , but the impact of the solution $\mathrm{pH}$ on decarboxylation is not known. The concentration of free ammonia in solutions of ammonium nitrate and ammonium chloride were calculated to be $2.1 \times 10^{-8} \mathrm{M}$ and $1.3 \times 10^{-8} \mathrm{M}$ using the aerosol thermodynamic model, E-AIM [Clegg et al., 1998] (as presented in the Appendix Table A.1.3). The amount of free ammonia is higher ( 1.6 fold) in the ammonium nitrate solution. In contrast, we observed a higher rate of decarboxylation ( $\sim 1.4$ times) in the experiments with ammonium chloride compared to the experiments with ammonium nitrate. This suggests that the decarboxylation is not solely controlled by the nucleophilic addition of ammonia to carbonyl moiety, but rather it is likely a function of multiple reaction parameters (i.e., solution $\mathrm{pH}$, ionic strength, etc.) and further study is needed.

\subsubsection{Effect of Ionic Strength}

The rate of decarboxylation of glyoxylic acid was studied at different solution ionic strengths (Experiments 2 and 8). In these experiments, the concentrations of glyoxylic acid 
and ammonium sulfate were kept constant but potassium chloride was added to Experiment 8 to modify the ionic strength of the reaction solution. It should be noted that the $\mathrm{pH}$ of both of the solutions are not the same after addition of the acids. However, potassium chloride is a neutral electrolyte and is not expected to participate in the decarboxylation reaction since no decarboxylation was observed in case of $\mathrm{NaCl}$ (Figure 2.1B). The ionic strength was calculated using the following equation

$$
\mu=\frac{1}{2} \sum C_{i} z_{i}^{2}
$$

where, $C_{i}$ is the molar concentration of ' $i$ ' ion and $z$ is the number of charges of the ' $i$ ' ion.

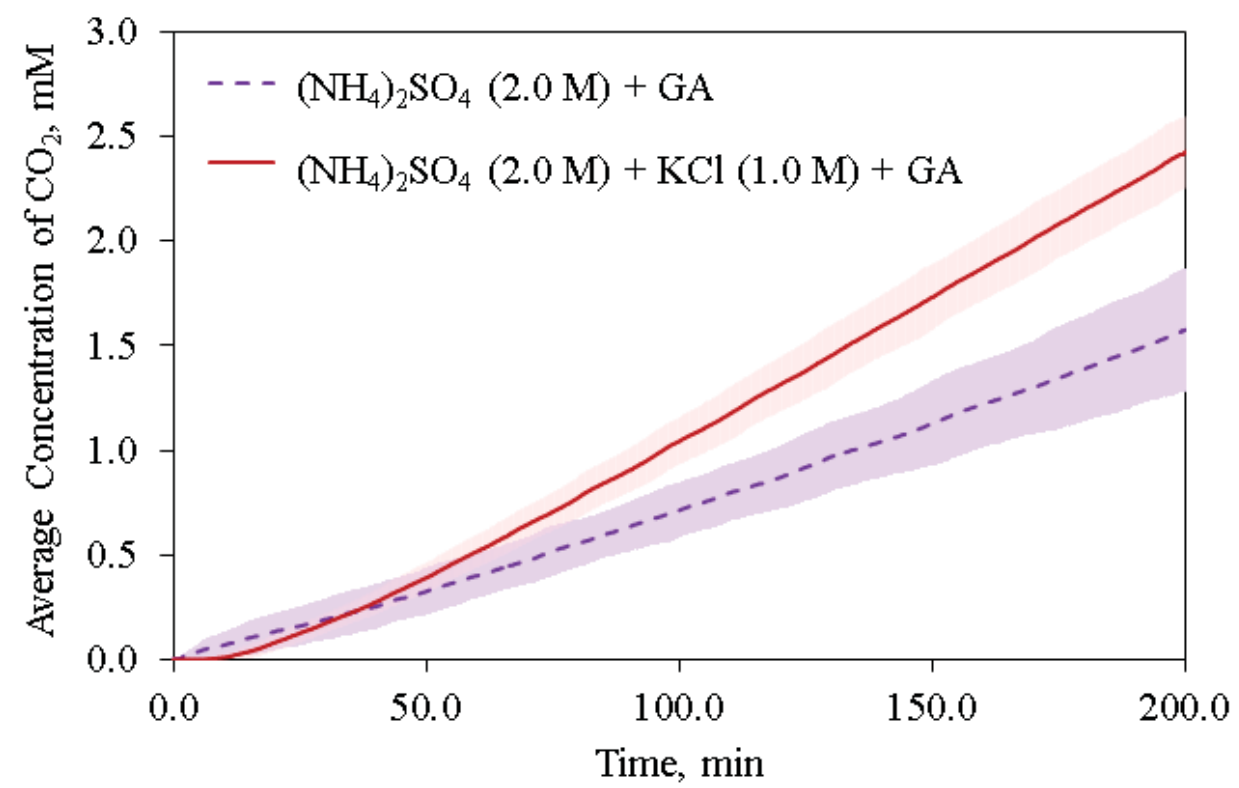

Figure 2.10: Temporal production of $\mathrm{CO}_{2}$ from glyoxylic acid at varied ionic strengths with ammonium sulfate. The concentration of ammonium sulfate and glyoxylic acid (GA) is the same (2.00 M and $1.00 \mathrm{M})$ in both cases. The gas phase concentration of $\mathrm{CO}_{2}(\mathrm{ppm})$ was converted to an aqueous phase concentration of $\mathrm{CO}_{2}$ for the volume of the reaction solution. The shaded region represents the standard deviation of the averaged experiments.

The ionic strengths of the experimental solutions are 6.0 $\mathrm{M}$ and 7.0 $\mathrm{M}$ for Experiment 2 and Experiment 8, respectively. We have taken the major ions of the solution into consideration and contribution from hydronium ions and organic anions were neglected. The 
$\mathrm{pH}$ of the solution was generally $\sim 2$ and thus the concentration of $\mathrm{H}_{3} \mathrm{O}^{+}$was $\sim 0.01 \mathrm{M}$ which is much lower than that of ammonium or other major ions. The organic acids in the present study have low dissociation constants (i.e., $\mathrm{pK}_{\mathrm{a}}$ of glyoxylic acid and pyruvic are 3.19 and 2.39 [Kerber and Fernando, 2010]), therefore, the contribution in the total ionic strength from the organic anions is likely much lower. However, from the comparison shown in Figure 2.6, it is evident that an increased ionic strength leads to a faster rate of decarboxylation (Table 2.1). In addition, a faster rate of decarboxylation was observed in the experiments with ammonium sulfate compared to the other ammonium salt solutions studied here for a given ammonium ion concentration. The experiments 2, 10 and 13 have the same ammonium ion concentration $(4.00 \mathrm{M})$, but the ionic strength is higher for the ammonium sulfate solution $(6.0 \mathrm{M})$ compared to ionic strength of ammonium chloride or ammonium nitrate (4.0 M) (Table A.1.2). The faster rate of decarboxylation as observed in the experiments with ammonium sulfate (Experiment 2, Table $2.1 \&$ A.1.2) could be a result of the increased ionic strength. This indicates the involvement of ionic species in the rate limiting reaction step [Laidler, 1987]. This rate limiting step is likely either a reaction between two same charge ionic species or a reaction between an ionic species and a neutral species [Laidler, 1987]. However, we are not certain whether the increased rate is due to stabilization of a transition state or the increased availability of the active reactants at higher ionic strength. Further studies are required to answer these questions. 


\subsubsection{Mechanism of Decarboxylation}

Free ammonia is present in the ammonium salt solution and it can react with the carbonyl functional group via nucleophilic reaction. Recently, the formation of imidazole compounds from glyoxal (the corresponding $\alpha$-dicarbonyl for glyoxylic acid) in aqueous ammonium sulfate was reported and it is believed that the imidazole is formed via di-imine pathways [Galloway et al., 2009; Kua et al., 2011]. Even if the formation of a mono-imine compound is possible for the $\alpha$-oxo acids, it is not clear how this can cause carbon-carbon bond cleavage leading to decarboxylation.

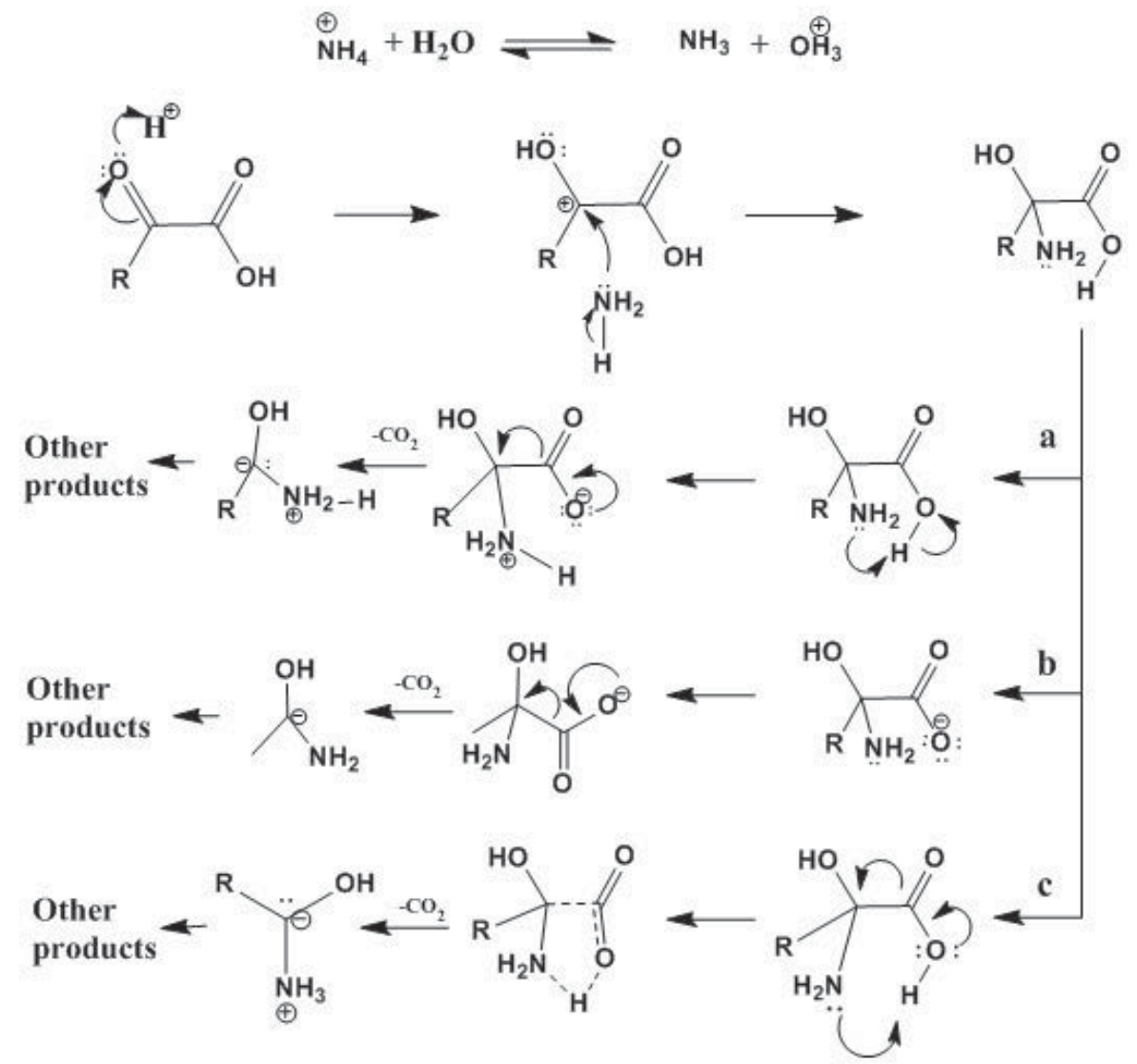

Scheme 2.1: The potential pathways of carbon-carbon bond fragmentation in dark radical free aqueous solutions. A) Zwitterion intermediate, B) stable C-N bond formation and C) Concerted proton transfer toward C$\mathrm{C}$ bond cleavage 
Takahashi and co-workers [Takahashi et al., 2008] reported that gas phase vibrationally excited pyruvic acid (trans-cis configuration) undergoes a unimolecular decarboxylation via hydrogen atom chattering. However, we anticipate the solution phase reaction mechanism to be different than the gas phase reaction mechanism. Moreover, we did not observe any significant decarboxylation with any of the sodium salts, therefore, the documented mechanism for gas phase decarboxylation [Takahashi et al., 2008] is unlikely to be applicable to the aqueous phase decarboxylation in the presence of the ammonium salts. One of the studies of gas phase thermal dissociation of pyruvic acid showed that decarboxylation happens through a transition state with a 5-member ring formation [Saito et al., 1994], but it is not very clear how ammonium/ammonia can contribute to that kind of pathway. However the observations of $\mathrm{CO}_{2}$ production from pyruvic acid and glyoxylic acid with the ammonium salts and the negligible decarboxylation with the sodium salts indicates, the active participation of ammonium or ammonia in the decarboxylation process. The absence of decarboxylation in the case of oxalic acid with ammonium sulfate (Experiment No. 17, Figure 2.1H) indicates decarboxylation requires the carbonyl group. Thus, we conclude that decarboxylation of $\alpha$-oxo carboxylic acid proceeds via nucleophilic attack on the carbonyl carbon by ammonia. Apart from the role of ammonium/ammonia, other reaction parameters also affect the decarboxylation and further study is warranted. Some potential reaction mechanisms of decarboxylation involving the nucleophilic attack of ammonia on the carbonyl carbon leading to carbon-carbon bond fragmentation between the carbonyl carbon and carboxyl carbon are given in Scheme 2.1. Scheme 2.1A involves the formation of a 'zwitterion' intermediate via 'hydrogen chattering', which consecutively weakens the $\mathrm{C}-\mathrm{C}$ bond leading to fragmentation. Scheme 2.1B shows the potential 
formation of a stable C-N bond leading to carbon-carbon bond scission. Scheme 2.1C shows a potential concerted pathway of the transfer of hydrogen and cleavage of the carbon-carbon bond. It should be noted that at present, these are speculative reaction schemes and it is yet to be proved which pathway is most likely responsible for decarboxylation. Further studies are needed in order to understand the pathway through which decarboxylation proceeds in dark and radical free aqueous ammonium salt solutions.

\subsection{Atmospheric Relevance}

A recent study of the gas and particle phase concentrations of the carboxylic acids at a suburban location showed that up to $65 \%$ of the total pyruvic acid and up to $85 \%$ of the total glyoxylic acid was present in the particle phase with some diurnal and seasonal variability [Bao et al., 2012]. In addition, these $\alpha$-oxo acids are structurally very similar to other atmospherically relevant compounds namely $\alpha$-dicarbonyls. Thus, knowledge of the condensed phase processing of glyoxylic and pyruvic acid is necessary to increase the understanding of the overall properties of atmospheric aerosol.

The aqueous phase chemistry of ammonium/ammonia with carbonyl compounds has received much attention recently and the reason for this is its participation in the formation of light absorbing accretion products [Ervens et al., 2011]. However, it is still not certain how ammonium or ammonia is participating in the formation new products possibily contributing to changes in aerosol physical properties. This study indicates ammonium/ammonia is facilitating carbon-carbon bond cleavage leading to a decarboxylation of $\alpha$-oxo acids. Since the $\alpha$-oxo carboxylic acids and $\alpha$-dicarbonyls are 
very similar classes of compounds, similar carbon-carbon bond cleavage may possible in the reactions between the $\alpha$-dicarbonyls and ammonium salt.

Organic oxygen content is often represented by the elemental ratio of oxygen to carbon $(\mathrm{O} / \mathrm{C})$ and is an important parameter to determine physicochemical properties of the organic fraction of aerosol [Pang et al., 2006]. It has been widely shown and accepted that atmospheric functionalization reactions of organic compounds in the gas or condensed phases will increase the oxygen content, which can be translated into increased particulate organic oxygen content [Aiken et al., 2008; Kroll et al., 2009; Presto et al., 2009]. In addition, multigenerational heterogeneous $\mathrm{OH}$ radical oxidation of organic aerosol can lead to fragmentation of organic compounds leading to a loss of particulate carbon keeping the particulate oxygen content unchanged leading to an increased O/C [Kroll et al., 2009]. Similar results are anticipated with other radical reactions. Particulate organic oxygen content can be reduced by condensation reactions such as esterification and aldol condensation [Kundu et al., 2012], whereas accretion reactions such as aldol addition and acetal formation are unlikely to have an effect on the organic oxygen content. This study of dark radical free aqueous phase decarboxylation of $\alpha$-oxo carboxylic acids in the presence of ammonium indicates removal of 1 carbon and 2 oxygen atoms upon decarboxylation producing less oxygenated organic species compared to the parent $\alpha$-oxo carboxylic acid. Thus, these reactions will likely lead to a reduction in the $\mathrm{O} / \mathrm{C}$ ratio of aqueous organic aerosol.

Atmospheric aqueous phase $\alpha$-oxo acids are likely subjected to UV-Vis photolysis or $\mathrm{OH}$ radical oxidation. Using a simple box model, Reed Harris et al. (2014) estimated the major 
loss pathway of atmospheric pyruvic acid is via aqueous phase UV-Vis photolysis and reaction with hydroxyl radical under high water loading condition (cloud, fog, etc.). The rate constant for aqueous phase oxidation of pyruvic acid by $\mathrm{OH}$ radicals was reported to be $1 \times 10^{8} \mathrm{M}^{-1} \mathrm{~s}^{-1}$ at $298 \mathrm{~K}$ [Ervens et al., 2003], but the concentration of $\mathrm{OH}$ radicals in the atmospheric condensed phase is expected to be highly variable ranging between $8.0 \times 10^{-12}$ $\mathrm{M}$ and $2.9 \times 10^{-16} \mathrm{M}$ [Herrmann et al., 2010]. Conversely, ammonium may be present in the aqueous phase at its saturation concentration $\left(\sim 8 \mathrm{M}\right.$ in a deliquesced $\left(\mathrm{NH}_{4}\right)_{2} \mathrm{SO}_{4}$ particle) to sub-milimolar concentration (rain drop). This indicates the loss rate of pyruvic acid in the aqueous phase via reactions with ammonium can be greater than one order of magnitude compared to the reactions with hydroxyl radicals (see more details in Appendix A.1.5). Where our comparison was for a $1.5 \mathrm{M}$ ammonium sulfate aqueous aerosol at a given aqueous phase concentration of pyruvic acid and low concentration of hydroxyl radical (during night time). Therefore, during the night time (in the absence of photolysis) and under reduced availability of hydroxyl radicals, the ammonium salt pathway presented here represents a major sink for pyruvic acid and other $\alpha$-oxo carboxylic acids.

\subsection{Conclusions}

The $\alpha$-oxo carboxylic acids are oxidation products of isoprene and other hydrocarbons and are abundant both in gas and particle phases. Their processing in the aqueous phase can affect the physicochemical properties of atmospheric aerosol. We studied the aqueous aerosol processing of two $\alpha$-oxo carboxylic acids in three ammonium salt solutions and three sodium salt solutions in the absence of UV-Vis radiation and hydroxyl radicals. A cleavage of the carbon-carbon bond leading to the decarboxylation from both pyruvic and glyoxylic 
acid was observed in the presence of ammonium salts. The empirical rate constants for decarboxylation of each of the reactant pairs were calculated and presented in Table 2.1 and Table A.1.2. Pyruvic acid was observed to undergo faster decarboxylation indicating the structure contributes to the rate of the reactions resulting in decarboxylation. In addition, the ionic strength of the solution contributed to a considerable increase in the rate of decarboxylation. The decarboxylation was found to be first order with respect to the oxo-acids and a similar relationship was observed with respect to the ammonium ion concentration. Negligible production of $\mathrm{CO}_{2}$ was observed in the experiments with sodium salts indicating ammonium facilitates the carbon-carbon bond cleavage leading to decarboxylation. Similar carbon-carbon bond cleavage is anticipated for the $\alpha$-dicarbonyl compounds, which are structurally close to $\alpha$-oxo carboxylic acids and abundant in the atmospheric gas and condensed phases. Comparison of reaction rates indicates in the absence of UV-Vis photolysis and under limited availability of $\mathrm{OH}$ radical, the reaction with ammonium salts is likely to be a major sink for the $\alpha$-oxo carboxylic acids. A potential set of reaction mechanisms for the decarboxylation of $\alpha$-oxo carboxylic acids based on the current observations was presented. This reaction is likely initiated by nucleophilic attack on the unhydrated carbonyl carbon by ammonia leading to a multiple potential way of carbon-carbon bond scission. The reaction mechanism of decarboxylation in ammonium salt solutions and other effects of the reaction conditions (i.e., $\mathrm{pH}$, temperature, activity in concentrated solution, etc.) however, are not well understood and further investigation is required. 


\subsection{Acknowledgements}

We thank Paul Charlesworth for lending us the Vernier probes; M. Muhibur Rahman, Tony N. Rogers, Heather A. Rypkema and Marina Tanasova for valuable discussion on the reaction kinetics and reaction mechanism and Dean Seppala for help with the reaction setup. We also thank the funding sources for the support.

\subsection{Supplemental Information}

Treatment of data, other kinetic calculations and additional figures are given in Appendix A.1. 


\section{Chapter 3: Ultrahigh Resolution FT-ICR Mass Spectrometry Characterization of Aqueous SOA Formed in Dark Reaction of Methylglyoxal and Ammonium Sulfate*}

Approved by Co-author/advisor Dr. Lynn R. Mazzoleni

* This chapter represents a manuscript draft to be submitted for publication. The experiments and interpretation were completed by D. M. Ashraf Ul Habib with the supervision of Dr. Lynn R. Mazzoleni. 


\subsection{Abstract}

Aerosols are trace but important constituents of our atmosphere containing variable amounts of inorganic salts, organic and refractory carbon and liquid water. The composition of atmospheric aerosol is expected to significantly change with partitioning and aqueous chemical reactions in the presence of liquid water. To evaluate this, the molecular composition of aqueous secondary organic aerosol (Aq-SOA) formed in the dark aqueous reactions between methylglyoxal and ammonium sulfate in a simulated aqueous aerosol solution was studied. Electrospray ionization Fourier transform ion cyclotron resonance (FT-ICR) mass spectrometry was used to identify the Aq-SOA products. Overall, the AqSOA is a complex mixture of products indicating a complex array of aqueous chemical reactions. Elemental compositions of $\mathrm{CHO}, \mathrm{CHNO}, \mathrm{CHOS}$ and $\mathrm{CHNOS}$ species were identified. Out of 448 species, $47 \%$ are $\mathrm{CHNO}$ compounds, $43 \%$ are $\mathrm{CHO}$ compounds and rest are organo-sulfur species. In congruence with earlier studies, a fraction of the Aq-SOA products are likely formed through accretion reactions such as: aldol, acetal and hydration reaction. However, a significant fraction of Aq-SOA products suggest there is additional processing and it is likely contributing to the formation of complex array of products. In the atmosphere, such reactions could modify physicochemical properties of aerosol in a much more complex way and is needed to be studied further. 


\subsection{Introduction}

Atmospheric aerosol plays an important role in the earth's climate [IPCC, 2013], air quality [Fiore et al., 2012], nutrient cycles [Mahowald et al., 2011] and human health [Cassee et al., 2013]. Aerosol interacts in complex ways with the incoming radiation and thus, their composition and microphysical properties are important climate parameters [IPCC, 2013]. Unraveling the molecular composition of aerosol is one of the key analytical challenges that preclude the quantification of aerosol's impacts [Pöschl, 2005; Seinfeld and Pandis, 2006]. Organic aerosol (OA) is a complex mixture of numerous individual compounds [Goldstein et al., 2008; Hamilton et al., 2004; Kalberer et al., 2004; Reemtsma et al., 2006] and is highly variable in temporal and spatial scales [Zhang et al., 2007]. The incorporation of organics into aerosol involves chemical transformation of volatile organic compounds (VOCs) of biogenic or anthropogenic origins [Hallquist et al., 2009]. Gas phase oxidation and functionalization reactions of VOCs lead to such products which can partition to the particle phase and contribute in the aerosol organic mass [Hallquist et al., 2009]. Some of the products from oxidation of VOCs have fewer carbons than the parent compounds but higher oxygen content (i.e., glyoxal, methylglyoxal, glycoaldehyde, glyoxylic acid, etc.) and are highly water soluble (high Henry's law constant) that they can contribute to aqueous secondary organic aerosol [Carlton et al., 2009]. In the aqueous phase, organic compounds can react further and contribute to the modification of physicochemical properties of aerosol [Ervens et al., 2011; Galloway et al., 2009; Nozière and Esteve, 2005; Sareen et al., 2013]. Unfortunately, aqueous phase processing of water soluble organic compounds and subsequent physicochemical modification of aerosol is still a largely unknown phenomena (i.e., molecular identity, quantification) and further studies were 
warranted to address the aqueous phase processing leading to the production of Aq-SOA [Ervens et al., 2011; Hallquist et al., 2009].

Methylglyoxal (2-oxopropanal) is a semi-volatile water-soluble oxidation product of iso-

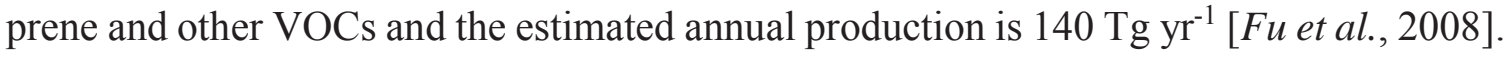
It has been detected in the aerosol phase of various ambient samples from remote to urban locations [Kawamura et al., 1996; Kawamura et al., 2013; Kundu et al., 2010; Wang et al., 2006]. Its highly reactive nature and effective Henry's law constant of $3.7 \times 10^{3} \mathrm{M} \mathrm{atm}^{-1}$ [Betterton and Hoffmann, 1988] make it important to study of its aqueous phase dynamics and production of Aq-SOA. Photochemical oxidation of methylglyoxal in the aqueous phase was shown to produce low volatile organic acids [Altieri et al., 2008; Tan et al., 2010] and oligomer species [Altieri et al., 2008] leading to Aq-SOA. Several studies suggested that methylglyoxal can produce higher molecular weight low volatility species via acetal/hemiacetal and aldol condensation pathways in the absence of photochemical oxidation [De Haan et al., 2009; Kalberer et al., 2004; Zhao J et al., 2006] (See also Table A.2.1). However, the molecular identity of the products only was partially documented using infrared spectrometry [Loeffler et al., 2006], low-resolution mass spectrometry (i.e., ESI-MS [De Haan et al., 2009; Kalberer et al., 2004; Yasmeen et al., 2010]) and aerosol mass spectrometry (e.g. Aerosol-CIMS [Sareen et al., 2010] and HR-ToF-AMS [De Haan et al., 2009]). The studies of glyoxal and methylglyoxal in the ammonium salt solution suggest (i) the formation of organo-nitrogen species [Galloway et al., 2009; Nozière et al., 2008; Sareen et al., 2010; Shapiro et al., 2009] and (ii) light absorbing species [Sareen et al., 2010; Shapiro et al., 2009], although the species responsible for increased light absorption are not very well understood. In addition, comprehensive experimental 
determination of identities of the high molecular weight Aq-SOA products (from processing of glyoxal and methylglyoxal in aqueous phase) is still missing in the literature. Therefore, the detailed molecular level characterization will be useful to enhance our knowledge about the nonradical aqueous aerosol processing (absence of photolysis, $\mathrm{OH}$, $\mathrm{H}_{2} \mathrm{O}_{2}, \mathrm{O}_{3}$, etc.) of methylglyoxal in the presence of aqueous ammonium sulfate solution.

Mass spectrometry (MS) is a robust analytical technique for analyzing complex samples. Fourier transform ion cyclotron resonance (FT-ICR) provides ultrahigh resolution $(>100,000$ at $\mathrm{m} / \mathrm{z} 400)$ in the mass measurement of ions enabling unequivocal assignment of molecular formula of an ion and is described in detail in the literature [Marshall et al., 1998; Xian et al., 2012]. Electrospray ionization (ESI) coupled with FT-ICR has been widely used to analyze complex mixture of organic compounds due to its high sensitivity and superior mass measurement accuracy [Altieri et al., 2009a; D'Andrilli et al., 2010; Koch et al., 2005; Kujawinski et al., 2001; Kundu et al., 2012; Mazzoleni et al., 2010; Putman et al., 2012; Schmitt-Kopplin et al., 2010; Sleighter and Hatcher, 2008; Stenson et al., 2003; Zhao Y et al., 2013]. ESI is a soft ionization method in which intact quasimolecular ions of polar species are produced from solution [Bruins, 1998; Cech and Enke, 2001; Gross, 2011]. Subsequent data analysis using different tools such as van Krevelen diagram, Kendrick mass defect analysis, etc. provide insight of the array of the compounds [Reemtsma, 2009] and product formation [Kundu et al., 2012].

Aqueous phase reactions of methylglyoxal are still not very well understood and the AqSOA formed from methylglyoxal in aqueous phase requires detailed molecular characterization in order to understand the dark aqueous phase processing. For this reason, 
we studied the Aq-SOA composition from the reaction between methylglyoxal and ammonium sulfate in bulk solutions using ESI FT-ICR MS. Here, we present the molecular characterization of the complex array of high molecular weight products formed from the reaction between methylglyoxal and ammonium sulfate in dark aqueous phase.

\subsection{Methods}

\subsubsection{Glassware and Chemicals}

All glassware was thoroughly washed, dried and baked overnight at $500{ }^{0} \mathrm{C}$. Ammonium sulfate with $99.9 \%$ purity was obtained from VWR International (West Chester, PA). Methylglyoxal, 40\% w/w (5.6 M), was obtained from Sigma-Aldrich (St. Louis, MO) and was used without further purification. Methylglyoxal was stored in a refrigerator $\left(4-8{ }^{0} \mathrm{C}\right)$ until the time of use. The LC-MS grade $\left(\right.$ Optima $\left.^{\mathrm{TM}}\right)$ water, methanol, acetonitrile $(\mathrm{ACN})$ were obtained from Fisher Scientific (Fair Lawn, NJ). Solid phase extraction (SPE) cartridges $(6 \mathrm{~mL})$ consisting of $100 \mathrm{mg}$ Strata-X reversed phase polymer were obtained from Phenomenex (Torrance, CA).

\subsubsection{Aqueous SOA Sample Preparation}

A 4.0 M ammonium sulfate solution was prepared as a stock solution and used for the reactions. Methylglyoxal solution was taken out of the refrigerator and allowed to come to room temperature before use. $5.0 \mathrm{~mL}$ of $4.0 \mathrm{M}$ ammonium sulfate solution and $3.2 \mathrm{~mL}$ water (ACS grade, Sigma-Aldrich, St. Louis, MO) was taken inside of a $15 \mathrm{~mL}$ dark brown amber glass vial. To avoid photolysis, the amber vials were wrapped with aluminum foil. Methylglyoxal was added $(1.8 \mathrm{~mL})$ and the final concentrations of methylglyoxal and 
ammonium sulfate became $1.0 \mathrm{M}$ and $2.0 \mathrm{M}$, respectively. The reactions took place in the dark at room temperature for $24 \mathrm{hrs}$. After $24 \mathrm{hrs}, 1.0 \mathrm{~mL}$ of the reaction solution was taken and diluted with $9.0 \mathrm{~mL}$ of water for the extraction of the high molecular weight products using the reverse phase SPE procedure from Mazzoleni et al., 2012. The SPE cartridges were pre-conditioned with $2 \mathrm{~mL}$ ACN, $2 \mathrm{~mL}$ methanol and $3 \mathrm{~mL}$ water (Optima ${ }^{\mathrm{TM}}$ ) in sequence. After the introduction of the reaction solution to the SPE cartridge, the cartridge was rinsed with $3 \mathrm{~mL}$ of water. Then $2.0 \mathrm{~mL}$ of aqueous $\mathrm{ACN}(90 \% \mathrm{v} / \mathrm{v}$ in water) was applied to extract the retained high molecular weight products into a $2 \mathrm{~mL}$ prebaked vial. Usage of methanol during extraction was avoided because it can lead to modified product by reacting with carbonyl functional group [Bateman et al., 2008]. The sample was kept at $\sim-20{ }^{0} \mathrm{C}$ until ESI FT-ICR MS analysis. The SPE procedure was necessary to remove inorganic ions and unreacted methylglyoxal from the sample to avoid ESI artifacts. Two

control experiments were performed by taking (i) only methylglyoxal at $1.0 \mathrm{M}$ and (ii) only ammonium sulfate at 2.0 M. The control experiments also went through the same experimental procedure as mentioned above before ESI FT-ICR MS analyses were carried out.

\subsubsection{Ultrahigh Resolution ESI FT-ICR MS Analysis}

Ultrahigh resolution mass spectrometry was performed at the Woods Hole Oceanographic Institution using a 7 T hybrid FT-ICR MS (LTQ FT Ultra, Thermo Scientific) equipped with an ESI source using the procedure described in an earlier work [Mazzoleni et al., 2010]. ESI was optimized to yield a stable current with a 20 times sample dilution using aqueous acetonitrile (contains $10 \% \mathrm{v} / \mathrm{v}$ water). The solution was directly infused at $5 \mu \mathrm{L}$ 
$\min ^{-1}$ into the ESI interface. The applied voltage of ESI was $-3.6 \mathrm{kV}$ and negatively charged quasi-molecular ions were generated. The sample delivery apparatus was flushed after each run with a minimum of $500 \mu \mathrm{L}$ of $100 \%$ acetonitrile and aqueous acetonitrile (contains $10 \% \mathrm{v} / \mathrm{v}$ water). The flushing of the ESI interface was necessary to avoid sample carry over and to attain background noise level. Negative ion mass spectra were collected in the range of $100<\mathrm{m} / \mathrm{z}<1000$ with the mass resolving power set at 400,000 (defined at $\mathrm{m} / \mathrm{z} 400$ ). Automatic gain control was used to consistently fill the instrument with the same number of ions $\left(n=1 \times 10^{6}\right)$ for each acquisition to avoid space charge effects from over filling the mass analyzer. The instrument was externally calibrated in negative ion mode with a standard solution of sodium dodecyl sulfate and taurocholic acid, and the resulting mass accuracy was better than 2 ppm. Over 200 individual mass spectra were collected and stored as time domain transients by use of Thermo Xcalibur software.

\subsubsection{Assignment of Molecular Formulas}

Ultrahigh resolution FT-ICR MS transients were post-processed using Composer software (Sierra Analytics, Modesto, CA) as previously described [Mazzoleni et al., 2010]. Briefly, $\sim 200$ transient files for each of the analyses were co-added to increase the analyte $\mathrm{S} / \mathrm{N}$ [Stenson et al., 2003]. The molecular formula calculator was set to allow 2-70 carbon atoms, 2-140 hydrogen atoms, 1-30 oxygen atoms, 0-3 nitrogen atoms, 0-1 sulfur atom with up to 25 double bond equivalents (DBE) for the negative ion analysis. DBE is a metric for measurement of unsaturation of a species and is the number of double bonds and rings in a molecule. The DBE of a species is determined using the following equation:

$$
\mathrm{DBE}=\mathrm{c}-\mathrm{h} / 2+\mathrm{n} / 2+1
$$


where $\mathrm{c}, \mathrm{h}$ and $\mathrm{n}$ comes from each elemental composition, $\mathrm{C}_{\mathrm{c}} \mathrm{H}_{\mathrm{h}} \mathrm{N}_{\mathrm{n}} \mathrm{O}_{\mathrm{O}} \mathrm{S}_{\mathrm{s}}$

Two formula extensions $\left(\mathrm{CH}_{2} \mathrm{O}\right.$ and $\left.\mathrm{CH}_{2}\right)$ and a de novo cut off at $\mathrm{m} / \mathrm{z} 500$ were used. Where de novo cutoff at $\mathrm{m} / \mathrm{z} 500$ means formulas will not be assigned to the detected masses above $\mathrm{m} / \mathrm{z} 500$ unless the formula is an extension of the formulas $\left(\mathrm{CH}_{2} \mathrm{O}\right.$ or $\left.\mathrm{CH}_{2}\right)$, assigned below $\mathrm{m} / \mathrm{z} 500$.

We obtained molecular formulas and classified them as $\mathrm{CHO}, \mathrm{CHNO}, \mathrm{CHOS}$ and CHNOS compounds, where each letter in the compound classes represents the elements of the molecular formulas. Molecular formula were assigned only to the peaks which had a signalto-noise ratio $>10$. The assigned monoisotopic molecular formulas were confirmed by the presence of ${ }^{13} \mathrm{C}$ and ${ }^{34} \mathrm{~S}$ containing molecular formulas. For example, the existence of the molecular formula ${ }^{12} \mathrm{C}_{\mathrm{c}} \mathrm{H}_{\mathrm{h}} \mathrm{O}_{o}$ was confirmed by the presence of ${ }^{13} \mathrm{C}_{1}{ }^{12} \mathrm{C}_{\mathrm{c}-1} \mathrm{H}_{\mathrm{h}} \mathrm{O}_{o}$ and likewise for the molecular formula ${ }^{12} \mathrm{C}_{\mathrm{c}} \mathrm{H}_{\mathrm{h}} \mathrm{N}_{\mathrm{n}} \mathrm{O}_{\mathrm{o}}{ }^{32} \mathrm{~S}$, was confirmed by the presence of both ${ }^{13} \mathrm{C}_{1}{ }^{12} \mathrm{C}_{\mathrm{c}}$ ${ }_{1} \mathrm{H}_{\mathrm{h}} \mathrm{N}_{\mathrm{n}} \mathrm{O}_{\mathrm{o}}{ }^{32} \mathrm{~S}$ and ${ }^{12} \mathrm{C}_{\mathrm{c}} \mathrm{H}_{\mathrm{h}} \mathrm{N}_{\mathrm{n}} \mathrm{O}_{\mathrm{o}}{ }^{34} \mathrm{~S}$. To increase the confidence in the assignment of molecular formula, the relative intensity for the peaks with ${ }^{13} \mathrm{C}$ and ${ }^{34} \mathrm{~S}$ atom was set to be $100 \%( \pm$ $40 \%$ ) of the theoretical abundance. The absolute relative error of the formulas was better than 3 ppm (Figure A.2.1). Every molecular formula reported in this study satisfied these stringent methods. The final list of the molecular formulas was prepared after subtracting common molecular formulas identified in the control samples (methylglyoxal control and ammonium sulfate control). A total of 448 new molecular formulas were identified in the dark aqueous experimental solution of ammonium sulfate and methylglyoxal. 


\subsection{Results and Discussion}

\subsubsection{Overview and Mass Spectra}

Overall, 448 new individual molecular formulas were detected in the reaction between ammonium sulfate and methylglyoxal from the ultrahigh resolution mass spectrometry analyses. These new formulas were not detected in any of the control experiments allowing us to study the Aq-SOA composition resulting from the bulk phase reactions of methylglyoxal in presence of ammonium sulfate. The majority of the detected compounds are $\mathrm{CHNO}$ compounds (47\%) followed by $\mathrm{CHO}(43 \%)$, CHOS $(9 \%)$ and $\mathrm{CHNOS}(1 \%)$. The reconstructed mass spectra of monoisotopic species are shown in Figure 3.1. The detected species ranges between m/z 100 and m/z 900 and are negative ions. The spectrum indicates a complex array of Aq-SOA from the aqueous phase processing of methylglyoxal in bulk aqueous phase. The detection of negative ions indicates an abundance of electronegative functional groups involving oxygen, which are easily deprotonated during ionization. As shown in Figure 3.1 most of the detected species are $\mathrm{CHO}$ and $\mathrm{CHNO}$ compounds (purple and light green color bars in the figure) and will be discussed in the next sections. 


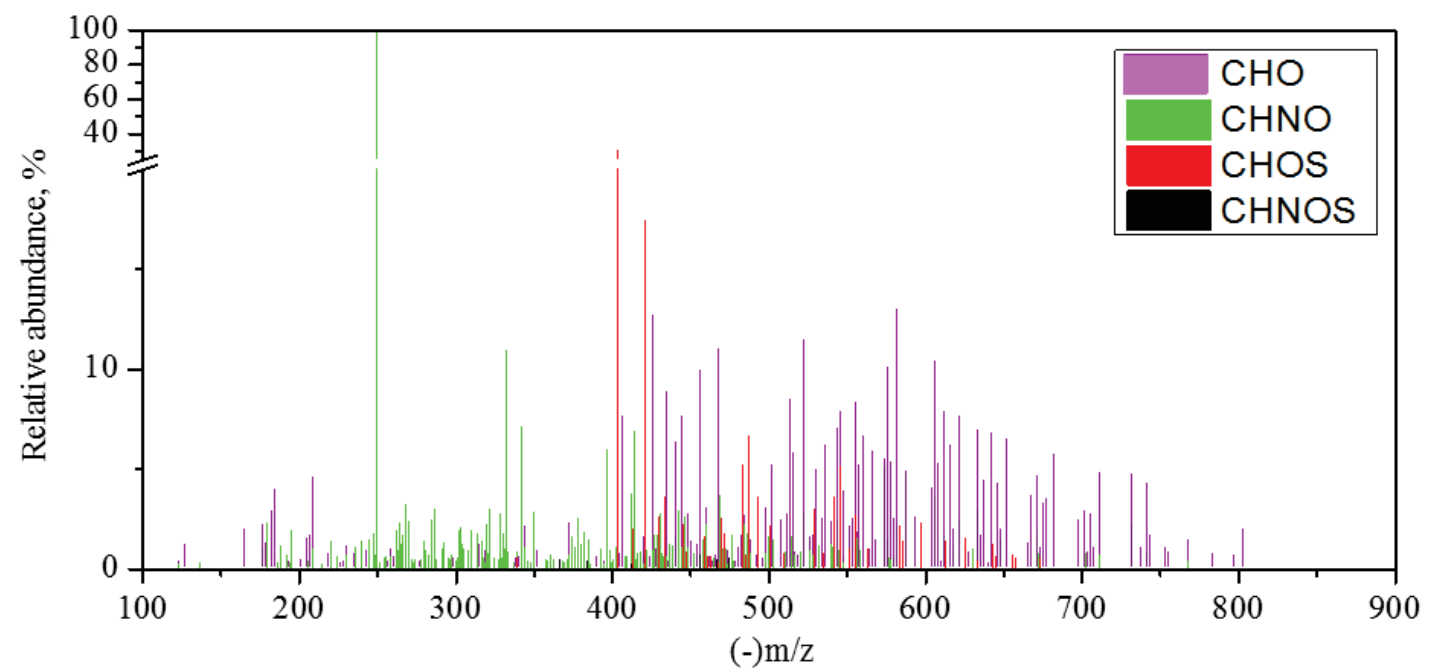

Figure 3.1: Reconstructed mass spectra of Aq-SOA formed from methylglyoxal in the presence of ammonium sulfate. The Aq-SOA formed in the dark reaction and detected as negative quasi-molecular ions in ESI FT-ICR MS experiments. The mass window ranges from m/z 100 to $\mathrm{m} / \mathrm{z} 900$. Note the broken scale at vertical axis. All peaks which were also detected in the control experiments were removed. The color represents the compound class and same color scheme is used throughout the text.

The presence of $\mathrm{H}_{2} \mathrm{O}, \mathrm{CH}_{2} \mathrm{O}$ homologous series were observed in the analysis of respective Kendrick mass (KM) (Figure 3.2). All of the species in one homologous series have an identical Kendrick mass defect (KMD) when that homologue base is chosen as the Kendrick Mass Base. Thus, one can study an array of products for the presence of more than one homologous series. It may be noted 'homologous series' in our discussion merely indicates a relationship of the extension unit in the molecular formula and does not pertain to the structural description of the molecule. The KMDs are a unique property and will be constant when they are plotted against any variables. This means if $\mathrm{KMD}_{\mathrm{a}}(\mathrm{KMD}$ taking ' $\mathrm{a}$ ' as the Kendrick Mass base) is plotted against $\mathrm{KMD}_{\mathrm{b}}$ then we can easily visualize the presence of more than one homologous series, which may be done by two different plots otherwise. 


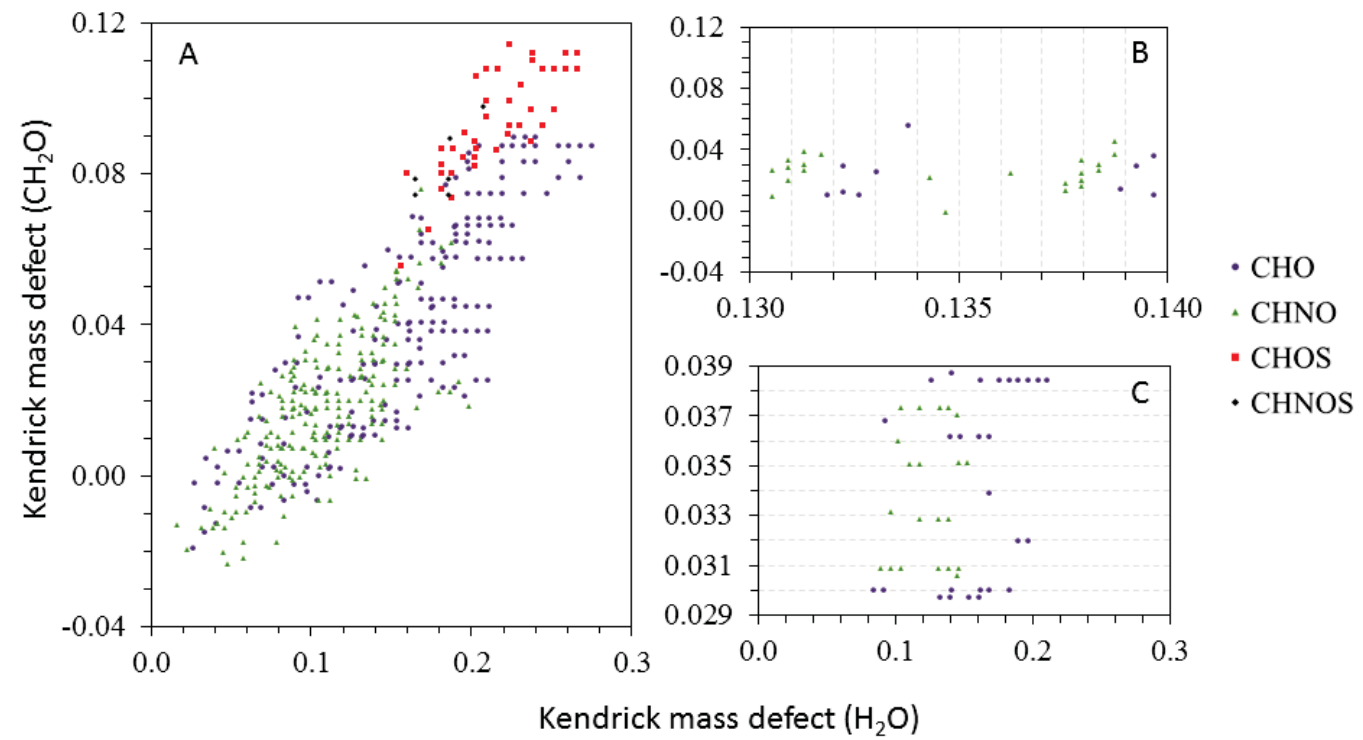

Figure 3.2: Kendrick analysis plot of Aq-SOA formed form methylglyoxal in the presence of ammonium sulfate in a dark aqueous solution. The horizontal axis represents the Kendrick mass defect with $\mathrm{H}_{2} \mathrm{O}$ as the Kendrick base and vertical axis represents the Kendrick mass defect with $\mathrm{CH}_{2} \mathrm{O}$ as the Kendrick base. (Panel A) All of the species are shown. (Panel B) Zoomed in to a subsection of the horizontal axis to show the $\mathrm{H}_{2} \mathrm{O}$ homologous series. The species aligned and parallel to the y-axis have the same Kendrick mass defect and hence are related by an integer number of $\mathrm{H}_{2} \mathrm{O}$ units indicating hydration reactions likely take place. (Panel C) Zoomed in to a subsection of the vertical axis to show the $\mathrm{CH}_{2} \mathrm{O}$ homologous series. The species which are aligned and parallel to the $\mathrm{x}$-axis have the same Kendrick mass defect and hence are related by an integer number of $\mathrm{CH}_{2} \mathrm{O}$ units. (See also Figures A.2.3 \& A.2.4).

Two KMDs are plotted against each other in Figure 3.2. On the x-axis the KMD with $\mathrm{H}_{2} \mathrm{O}$ as the Kendrick base and on the y-axis $\mathrm{KMD}$ with $\mathrm{CH}_{2} \mathrm{O}$ as the Kendrick base. We observe many species to be oriented parallel to the axes (Figure 3.2B and 3.2C). The species that orientate themselves parallel to y-axis (Figure 3.2B) have identical Kendrick mass defects with $\mathrm{H}_{2} \mathrm{O}$ as the Kendrick base. These species represent $\mathrm{H}_{2} \mathrm{O}$ homologous series, meaning there is only an $\mathrm{H}_{2} \mathrm{O}$ group difference between two consecutive species on that line. The $\mathrm{H}_{2} \mathrm{O}$ series suggest hydration of the carbonyl functional groups forming diols (Appendix, Scheme A.2.1). In addition, dehydration of alcohol/acetal groups leads to the formation of carbon-carbon double bonds via condensation pathways (Scheme A.2.2); these species are likely to contribute to the water KMD series as well. The species with the parallel 
orientation to $\mathrm{x}$-axis (Figure 3.2C) have identical KMD using $\mathrm{CH}_{2} \mathrm{O}$ as Kendrick base and represent $\mathrm{CH}_{2} \mathrm{O}$ homologous series. $\mathrm{CH}_{2} \mathrm{O}$ homologous series were observed in rain over northeastern United States [Altieri et al., 2009b] and laboratory generated secondary organic aerosol [Kundu et al., 2012]. However, the chemical reason for observation of $\mathrm{CH}_{2} \mathrm{O}$ series in the Aq-SOA products of the reaction between methylglyoxal and ammonium sulfate is not understood.

The $\mathrm{CH}_{2}$ homologous series were found to be present with shorter extensions than those found in atmospheric fog and cloud water samples [Mazzoleni et al., 2010; Zhao Y et al., 2013] and laboratory generated SOA samples [Kundu et al., 2012]. The presence of a larger carbon backbone hydrocarbon (e.g., isoprene, monoterpene, etc.) and radical reactants likely facilitate the formation of extended series of $\mathrm{CH}_{2}$. However, methylglyoxal has only three carbons and two of them are as carbonyl carbon and thus products with shorter $\mathrm{CH}_{2}$ homologous are expected (Figure A.2.5).

The observation of $\mathrm{O}$ (oxygen) homologous series was reported previously by Kundu and coworkers [Kundu et al., 2012] based on a study of laboratory generated SOA from limonene ozonolysis using ultrahigh resolution FTICR-MS. They suggested it might be associated with oxidation of compounds in the presence of ozone. In our case, although, we do not anticipate oxidation to take place, the presence of O-homologous series is an interesting aspect of this Aq-SOA (Figure A.2.6). In addition, the presence of $\mathrm{O}$ homologous series in the products may be observed from the disproportion reaction of methylglyoxal such as Cannizzaro reaction [De Haan et al., 2009]. The reaction leads to both an alcohol and a carboxylic acid species. Thus oxidized and reduced products are observed at the same time 
from one compound and leading to a generation of O-homologous series. The Cannizzaro reaction typically takes place under strongly basic conditions on the aldehyde functional group in the absence of $\beta$-hydrogen [Carey and Sundberg, 2008]. However, the $\mathrm{pH}$ of our reaction solution was about 3 thus the Cannizzaro reaction is unlikely to take place in this aqueous phase and further study is required.

Table 3.1: Bulk properties of Aq-SOA formed in the dark reaction between ammonium sulfate and methylglyoxal. (Standard deviation or the range is given in the parenthesis)

\begin{tabular}{|c|c|c|c|c|}
\hline Number of species & 193 & 209 & 40 & 6 \\
\hline Average O/C & $\begin{array}{c}0.55 \\
( \pm 0.14)\end{array}$ & $\begin{array}{c}0.51 \\
( \pm 0.16)\end{array}$ & $\begin{array}{c}0.85 \\
( \pm 0.17)\end{array}$ & $\begin{array}{c}0.88 \\
( \pm 0.05)\end{array}$ \\
\hline Average H/C & $\begin{array}{c}1.17 \\
( \pm 0.20)\end{array}$ & $\begin{array}{c}1.24 \\
( \pm 0.18)\end{array}$ & $\begin{array}{c}1.43 \\
( \pm 0.21)\end{array}$ & $\begin{array}{c}1.50 \\
( \pm 0.13)\end{array}$ \\
\hline $\begin{array}{c}\text { Average double bond } \\
\text { equivalent }\end{array}$ & $10( \pm 3)$ & $8( \pm 2)$ & $6( \pm 3)$ & $5( \pm 1)$ \\
\hline $\begin{array}{c}\text { Average number of carbon } \\
\text { atoms in the formulas }\end{array}$ & $\begin{array}{c}22 \\
(6-35)\end{array}$ & $\begin{array}{c}17 \\
(6-34)\end{array}$ & $\begin{array}{c}18 \\
(11-29)\end{array}$ & $\begin{array}{c}14 \\
(12-16)\end{array}$ \\
\hline $\begin{array}{c}\text { Average number of oxygen } \\
\text { atoms in the formulas }\end{array}$ & $\begin{array}{c}12 \\
(2-23)\end{array}$ & $\begin{array}{c}9 \\
(1-18)\end{array}$ & $\begin{array}{c}15 \\
(2-20)\end{array}$ & $\begin{array}{c}12 \\
(10-14)\end{array}$ \\
\hline
\end{tabular}



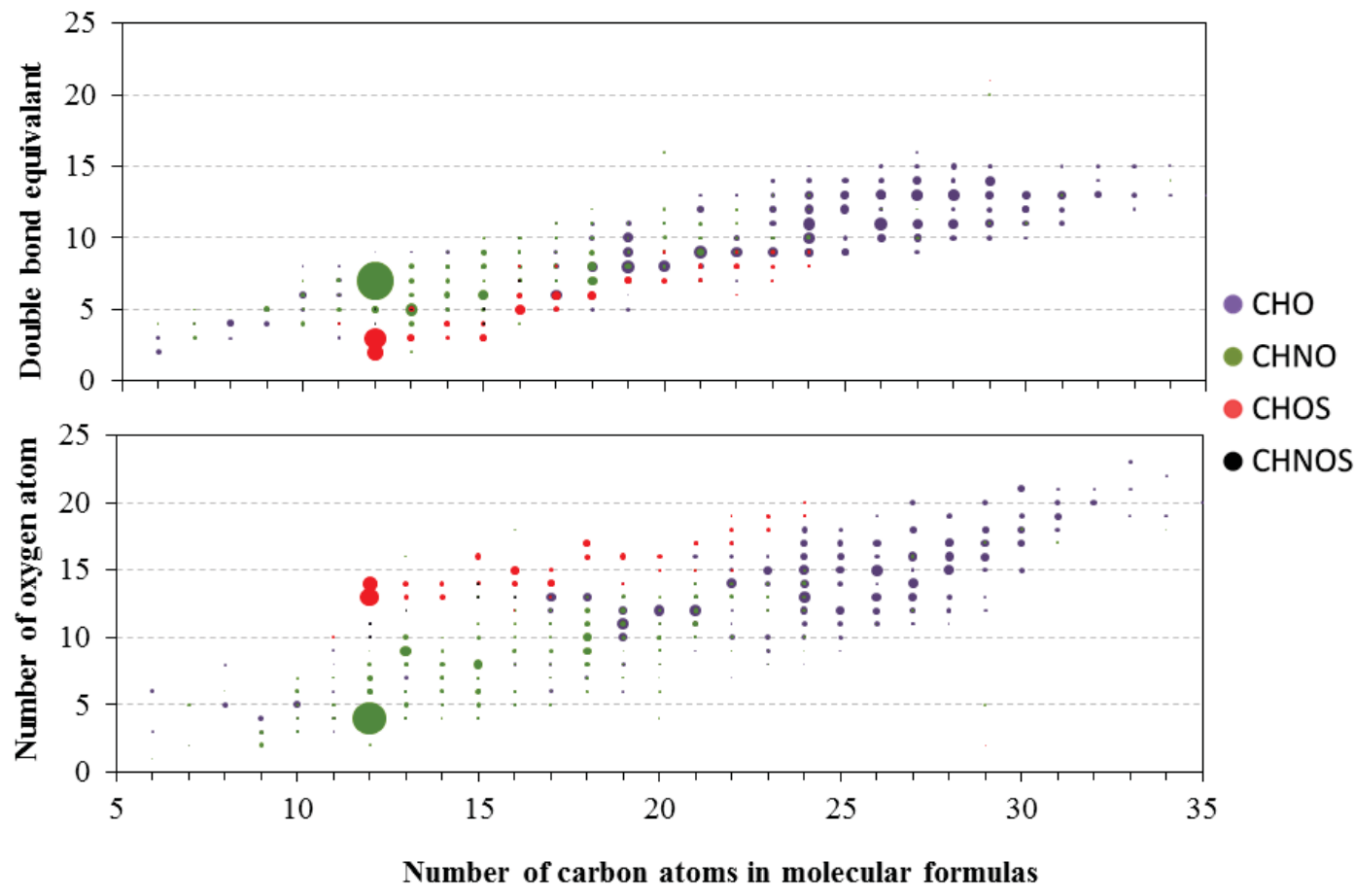

Figure 3.3: Variation of the DBE (top) and oxygen content (bottom) with the number of carbon atoms of the Aq-SOA species detected in ESI FT-ICR MS formed from methylglyoxal in the dark ammonium sulfate solution.

\subsubsection{CHO Compounds}

A total of $193 \mathrm{CHO}$ compound were observed as negative ion in ESI FT-ICR MS analysis of Aq-SOA formed from the reaction between methylglyoxal and ammonium sulfate. Overall, the DBE ranges from 2 to 16 for the $\mathrm{CHO}$ compounds with a range of 6 to 35 carbon atoms in the molecular formulas (Figure 3.3). The number of oxygen atoms in the molecular formulas varies from 2 to 23 across the $\mathrm{CHO}$ compounds (Figure 3.3). These indicate the degree of unsaturation and the oxygen content are increasing with the number of carbon atoms (Figure 3.3), which is consistent with accretion reactions of methylglyoxal. In addition, we observed the degree of oxidation and hydrogenation varies for each carbon 
number (Figure A.2.9) suggesting multiple reaction pathways have occurred including accretion, hydration, dehydration, and oxidation.

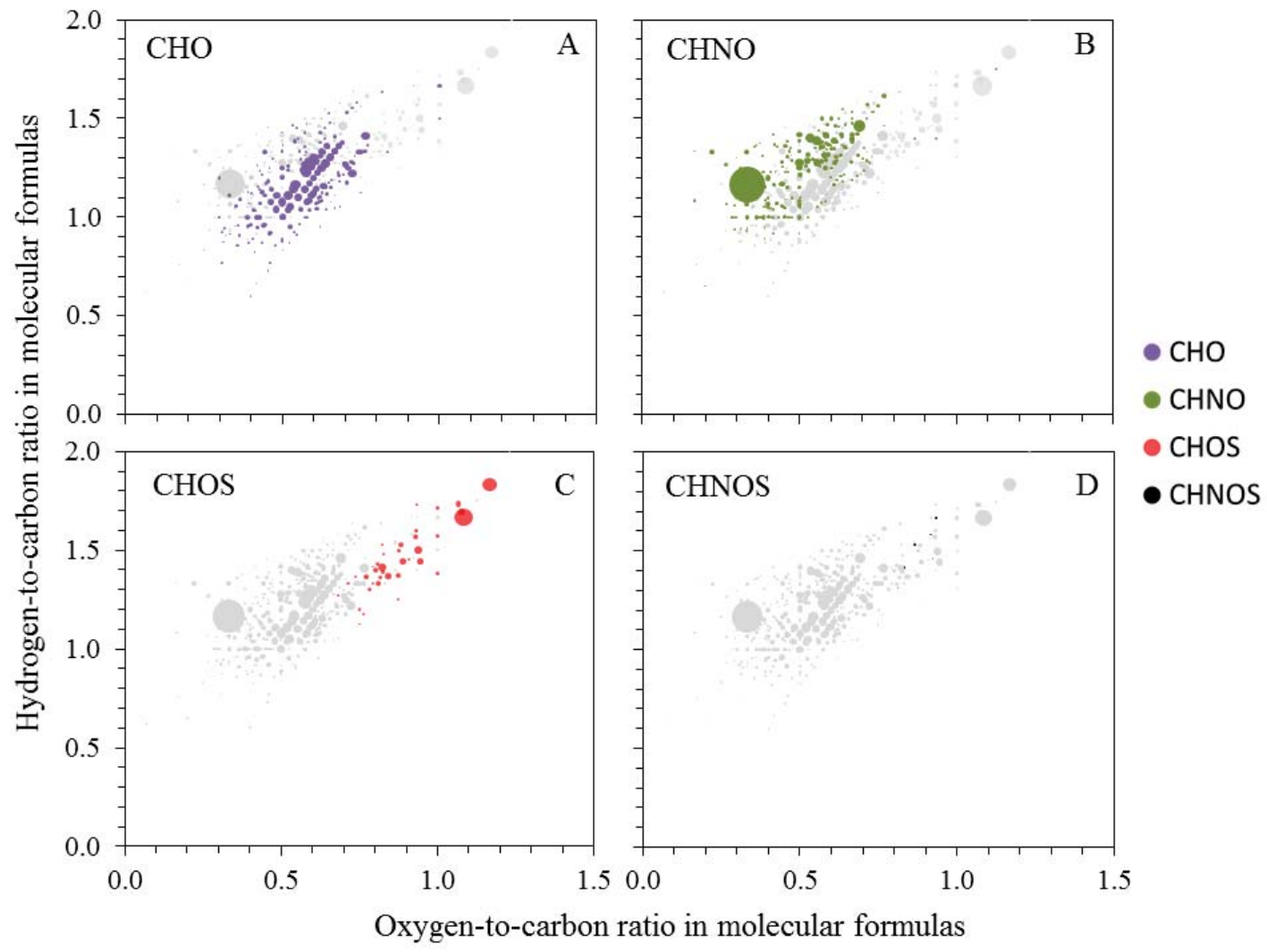

Figure 3.4: van Krevelen plot of the Aq-SOA formed from methylglyoxal in dark ammonium sulfate solution. CHO, CHNO, CHOS and CHNOS are presented in the panel A, B, C and D, respectively. In each panel each of the compounds were presented in colors while others are in gray scale for comparison. The size of the bubble represents the analyte relative abundance. (See also Figure A.2.8)

The $\mathrm{CHO}$ compounds are presented as the ratio of their consisting elements in Figure 3.4A, commonly called van Krevelen diagram. The oxygen-to-carbon ratios $(\mathrm{O} / \mathrm{C})$ for each of the molecular formula range between 0.25 and 1.0 (Figure 3.4A) with an average $\mathrm{O} / \mathrm{C}$ value of $0.55 \pm 0.14$ (Table 3.1). Most of the higher relative abundance species are in the range of 0.4 to 0.8 . From ultrahigh resolution analyses, a varying distribution of $\mathrm{O} / \mathrm{C}$ were reported for various atmospheric samples (e.g., 0.35 for HULIS fraction of PM 2.5 [Lin et 
al., 2012], 0.62 for cloud water sample [Zhao Y et al., 2013], 0.7 for continental rain water [Altieri et al., 2009a]). However, Altieri and coworkers [2008] reported average O/C to be 0.69 , where they conducted photochemical oxidation of methylglyoxal. Lower $\mathrm{O} / \mathrm{C}(0.55$ \pm 0.14 ) was expected in our products due to the absence of any photochemical oxidant $\left(\mathrm{OH}, \mathrm{NO}_{3}\right.$, etc.). The hydrogen-to-carbon ratio $(\mathrm{H} / \mathrm{C})$ ranges from 0.6 to 1.7 (Figure 3.4A) with the averages of $1.17 \pm 0.20$ (Table 3.1) for $\mathrm{CHO}$ compounds. The lower $\mathrm{H} / \mathrm{C}$ values could be a consequence of having carbonyl functional moieties leading to higher $\mathrm{O} / \mathrm{C}$ but lower H/C. Also, highly oxygenated CHO compounds (lower H/C) were likely be detected more efficiently in the negative ion experiment. There are some linear trends apparent in the van Krevelen plots (Figure 3.4). Linearity originates from the quantized valence of the atoms [Kim et al., 2003]. In Figure 3.4, the points that appear to be on a hypothetical line with an intercept of 2 on vertical axis represent $\mathrm{CH}_{2}$ molecular formula extensions [Mazzoleni et al., 2010]. The hydration (or dehydration) series are observed in the points, which may form a line passing through the origin (zero intercept) with a slope of 2 and parallel to it in the van Krevelen diagram. Oxidation and reduction lines are parallel to $\mathrm{x}$ and y-axis, respectively. In Figure 3.4, the point where $\mathrm{O} / \mathrm{C}=0.67$ and $\mathrm{H} / \mathrm{C}=1.33$ represents all of the oligomer species from methylglyoxal formed via classic pathways (i.e., aldol addition, acetal formation, etc.) in ammonium sulfate solution with 'zero' net hydration (no hydration or dehydration). It may be noted again, we had removed the formulas of all species those were present in the two control experiments. Therefore, the existence of this point $(0.67,1.33)$ certainly indicates a higher degree of oligomerization in the presence of ammonium sulfate compared to only methylglyoxal alone in the aqueous phase and is 
consistent with earlier work of Noziere et al. (2010) where they suggested aldol reaction being facilitated by inorganic ions.

A few $\mathrm{CHO}$ compounds are located in the so-called 'aromatic region' $(\mathrm{O} / \mathrm{C}<0.5$ and $\mathrm{H} / \mathrm{C}$ $<1)$ of the van Krevelen plot [Koch et al., 2005]. However, the presence of some species in the aromatic region of the van Krevelen plot can also arise from completely non-aromatic compound [Koch et al., 2005]. For example, $\mathrm{C}_{24} \mathrm{H}_{22} \mathrm{O}_{11}$ was assigned to $\mathrm{m} / \mathrm{z}$ 485.1097 and has an $\mathrm{H} / \mathrm{C}$ value of 0.92 and an $\mathrm{O} / \mathrm{C}$ value of 0.45 and is located in the 'aromatic region' of van Krevelen plot. One of the many potential formation pathways and structure of this species is shown in Scheme A.2.2 (Appendix A.2). It should be noted, we do not rule out the possibility of other reaction pathways leading to the same molecular formulas with different structures. In the structure of $\mathrm{C}_{24} \mathrm{H}_{22} \mathrm{O}_{11}$ multiple carbon-carbon double bonds are proposed from aldol condensation reaction. Aldol condensation reactions were reported to be catalyzed by ammonium ions [Noziere et al., 2010]. Similar reactions could lead to the formation of the polyunsaturated aliphatic species and may appear in the 'aromatic region' of the van Krevelen plot.

Earlier studies reported acetal and aldol reactions are responsible for the formation of higher molecular weight compounds and summarized in Appendix (Table A.2.1). If we consider hydration, aldol, acetal pathways are responsible for the product formation from methylglyoxal in presence of ammonium sulfate, these pathways are equally applicable in case of blank methylglyoxal solution from a qualitative perspective. That is why we removed the molecular formulas detected in the methylglyoxal control mass spectrometric experiment. This indicates, in the presence of ammonium sulfate there should not be any 
CHO compounds if hydration, aldol, acetal pathways are the only product formation pathways. However, we identified 193 new $\mathrm{CHO}$ species and only a few of them are coming from a higher degree of oligomerization as discussed above indicating the existence of additional pathway and is required to study further.

\subsubsection{CHNO Compounds}

CHNO compounds are the major class of species formed in the reaction between methylglyoxal and ammonium sulfate in the range of $100<\mathrm{m} / \mathrm{z}<900$ (Figure 3.1). However, $87 \%$ of all $\mathrm{CHNO}$ species are within $100<\mathrm{m} / \mathrm{z}<500$ indicating fewer molecular formulas beyond $\mathrm{m} / \mathrm{z} 500$. This is a consequence of being conservative in our formula assignment of the $\mathrm{CHNO}$ compounds, where we applied a de novo cutoff at $\mathrm{m} / \mathrm{z} 500$. The Kendrick analysis using $\mathrm{H}_{2} \mathrm{O}$ as a Kendrick mass base indicates that there is a considerable contribution of the hydration reaction to the array of $\mathrm{CHNO}$ compounds (Figure 3.2 and Figure A.2.4). The $>\mathrm{C}=\mathrm{O}$ can undergo hydration at varying degree and presence of multiple $>\mathrm{C}=\mathrm{O}$ will increase the range of hydration. This indicates hydration and dehydration reactions are likely to markedly impact the physicochemical properties of aerosol. Although shorter in elongations compared to the $\mathrm{CHO}$ species, we observed the existence of $\mathrm{CH}_{2} \mathrm{O}, \mathrm{CH}_{2}, \mathrm{O}$ and $\mathrm{C}_{3} \mathrm{H}_{4} \mathrm{O}_{2}$ homologous series (Figures A.2.3 to A.2.7). Because of the presence of fewer species across the mass range, only short homologous series were observed in Kendrick plots. The double bond equivalents of CHNO species range from 2 to 20 with a number average of 8 and are lower than average $\mathrm{DBE}$ of $\mathrm{CHO}$ compounds (Table 3.1). This indicates the CHNO is likely more saturated compared to CHO Aq-SOA species. The average hydrogen-to-carbon ratio for CHNO species was $1.24 \pm 0.18$ (Table 
3.1). The van Krevelen diagram representing $\mathrm{CHNO}$ compound class (Figure 3.4B) also indicates $\mathrm{CHNO}$ compounds are much more hydrogenated than the $\mathrm{CHO}$ compounds. This apparent excess hydrogen could come from ammonia-ammonium equilibration, which is likely to be involved in the aqueous production of nitrogen containing species. The average oxygen-to-carbon ratio is $0.51 \pm 0.16$ and is slightly lower than $\mathrm{CHO}$ compounds. The formation of compounds containing nitrogen atoms could come from the reaction of ammonia and carbonyl functional group via nucleophilic addition of ammonia to carbonyl moiety [Carey and Sundberg, 2008]. This addition product could undergo subsequent dehydration to form carbon-nitrogen double bonds to produce imines [Carey and Sundberg, 2008]. Glyoxal (CHO-CHO), a very similar compound to methylglyoxal, was reported to produce nitrogenous species via the formation of imines [Galloway et al., 2009] and similar reactions are anticipated to happen in this study. The formation of imine will convert $>\mathrm{C}=\mathrm{O}$ to $>\mathrm{C}=\mathrm{N}$ - increasing the organic nitrogen content at the expense of oxygen and may explain why we observe decreased oxygen-to-carbon ratio in the CHNO compounds compared to the $\mathrm{CHO}$ compounds (Table 3.1).

About $72 \%$ of all CHNO species contain only one nitrogen atom indicating fewer cases of the incorporation of multiple nitrogen atoms to the Aq-SOA. Out of 59 multiple nitrogen containing CHNO species, 9 contain 3 nitrogen atoms and the rest of them contain 2 nitrogen atoms. Although imidazole formation was suggested from the reaction between glyoxal and ammonia [Galloway et al., 2009; Yu et al., 2011], the detected CHNO compounds are less likely to be imidazole compounds. Imidazole compounds are slightly basic and would more likely be detected as positive ion. Although we do not rule out the possibility of multiple functional group enabling them be ionized and detected in both positive and 
negative ion analysis, the confirmation of the nature of these polynitrogenous $\mathrm{CHNO}$ compounds awaits future study.

\subsubsection{CHOS and CHNOS Compounds}

The organosulfur species represent $10 \%$ of the total detected species and are classified as CHOS and CHNOS compounds. A total of 40 species were detected as CHOS compounds and 6 species as detected as CHNOS compounds. The average hydrogen-to-carbon ratios of CHOS and CHNOS are $1.43 \pm 0.21$ and $1.50 \pm 0.13$, respectively (Table 3.1). In comparison, the average $\mathrm{H} / \mathrm{C}$ of both $\mathrm{CHOS}$ and CHNOS is higher than the other two nonsulfur compound classes but the reason was not understood. The sulfur containing species contain higher oxygen-to-carbon ratios compare to $\mathrm{CHO}$ and $\mathrm{CHNO}$ compounds. The average values of oxygen-to-carbon ratios were $0.85 \pm 0.17$ for CHOS and $0.88 \pm 0.05$ for CHNOS compounds (Table 3.1). This indicates the organosulfur compounds may contain strong electronegative functional moiety such as organosulfate functional group leading to a higher oxygen-to-carbon ratios and also efficient detection as negative ions in the mass spectrometric analysis. In contrast, organosulfate compounds reported to form from glyoxal under UV irradiated conditions and no organosulfur production was observed under dark condition [Galloway et al., 2009]. The abundance of sulfate ions in the aqueous phase should play a role in the production of organosulfur compounds; however, the incorporation of the sulfur containing functional group to an organic moiety should be addressed with further investigations. 


\subsection{Conclusions}

We carried out dark reactions in bulk aqueous phase solutions of methylglyoxal (1.0 M) and ammonium sulfate $(2.0 \mathrm{M})$ mimicking dark aqueous aerosol. We let the reaction run for 24 hours and then separated the products from the reactants using solid phase extraction. Then we acquired accurate mass measurements of the Aq-SOA products using ultrahigh resolution ESI FT-ICR MS. The ultrahigh resolution mass spectrometry analyses show that a large number of high molecular weight species are formed in the dark aqueous phase reactions. A total of 448 new molecular formulas were determined from the negative ion ESI FT-ICR MS spectra. The detected species were classified as $\mathrm{CHO}, \mathrm{CHNO}, \mathrm{CHOS}$ and CHNOS species. The CHNO compounds were the major fraction (47\%) of the Aq-SOA products followed by $\mathrm{CHO}(43 \%)$ compounds (Table 3.1). In addition, 46 organosulfur species (CHOS and CHNOS) were detected as well. Because of the abundance of the electronegative oxygen atoms in the precursor molecule methylglyoxal, the Aq-SOA products also enriched in oxygen content leading to efficient ionization and detection as negative ion in the ESI FT-ICR MS analysis. The diversity of the species of the compound classes indicates multiple reaction pathways leading to a complex array of Aq-SOA products. We observed the presence of multiple homologous series across the Aq-SOA products suggesting complex pathways are involved in the Aq-SOA formation. Ammonium sulfate is highly abundant in the atmosphere. It is apparent ammonium sulfate can lead to a complex array of reactions to produce complex Aq-SOA. The processing of carbonyls in presence of ammonium sulfate will modify the aerosol composition and physical properties much more complex way than currently understood. In order to understand the 
additional formation pathways leading to a complex array of the Aq-SOA products in the absence of any other radical precursor or photolysis, further investigation is needed.

\subsection{Acknowledgements}

The authors thank Dr. Melissa Kido-Soule of the Woods Hole Oceanographic Institution for FT-ICR MS support. The funding for this research was provided by the National Science Foundation (AGS-1039742).

\subsection{Supplemental Information}

Additional schemes, tables and figures for data visualization are given in Appendix A.2 


\section{Chapter 4: Conclusions}

Aerosol in the atmosphere is ubiquitous and plays an important role in the earth's energy balance. The uncertainty in the aerosol chemical composition and dynamics contributes to the uncertainty in our understanding of radiative transfer. The low molecular weight highly oxygenated organic compounds in the current studies are oxidation products of isoprene and other volatile organic compounds and may be present in the atmospheric aqueous phase. Thus aqueous phase processing of these compounds is likely to have a marked impact on the aerosol physicochemical properties but very little are known about these aqueous phase dynamics. The aqueous phase processing of glyoxylic acid, pyruvic acid, oxalic acid and methylglyoxal was studied simulating a dark and radical free aqueous aerosol condition.

Overall, the aqueous phase reactions in the dark and radical free conditions contribute to the chemical evolution of aerosol. A novel carbon-carbon bond cleavage in pyruvic acid and glyoxylic acid leading to their decarboxylation was observed in the presence of ammonium salts but no decarboxylation was observed from oxalic acid. The empirical rate constants of decarboxylation were determined and summarized in Chapter 2. The structure of the acid, ionic environment of solution and concentration of species were found to affect the decarboxylation process. Although not thoroughly understood, a tentative set of reaction mechanisms was proposed involving nucleophilic attack by ammonia on the carbonyl carbon leading to fragmentation of the carbon-carbon bond between the carbonyl and carboxyl carbons. In contrast, formation of nitrogen and/or sulfur containing Aq-SOA 
was observed in case of methylglyoxal. The elemental composition of the Aq-SOA species was determined. It was hypothesized that in addition to the known classical pathways, unknown pathways also likely contribute to the formation of Aq-SOA. Under similar conditions the aqueous phase processing is likely to impact the physicochemical properties of aerosol. However, further studies are required to better understand these complex processes. 


\section{References}

Aiken, A. C., P. F. DeCarlo, J. H. Kroll, D. R. Worsnop, J. A. Huffman, K. S. Docherty, I. M. Ulbrich, C. Mohr, J. R. Kimmel, D. Sueper, Y. Sun, Q. Zhang, A. Trimborn, M. Northway, P. J. Ziemann, M. R. Canagaratna, T. B. Onasch, M. R. Alfarra, A. S. H. Prevot, J. Dommen, J. Duplissy, A. Metzger, U. Baltensperger, J. L. Jimenez (2008), O/C and OM/OC Ratios of Primary, Secondary, and Ambient Organic Aerosols with High-Resolution Time-of-Flight Aerosol Mass Spectrometry, Environmental Science \& Technology, 42(12), 4478-4485.

Altieri, K. E., B. J. Turpin, and S. P. Seitzinger (2009a), Oligomers, organosulfates, and nitrooxy organosulfates in rainwater identified by ultra-high resolution electrospray ionization FT-ICR mass spectrometry, Atmos. Chem. Phys., 9(7), 2533-2542.

Altieri, K. E., B. J. Turpin, and S. P. Seitzinger (2009b), Composition of Dissolved Organic Nitrogen in Continental Precipitation Investigated by Ultra-High Resolution FTICR Mass Spectrometry, Environmental Science \& Technology, 43(18), 69506955.

Altieri, K. E., S. P. Seitzinger, A. G. Carlton, B. J. Turpin, G. C. Klein, and A. G. Marshall (2008), Oligomers formed through in-cloud methylglyoxal reactions: Chemical composition, properties, and mechanisms investigated by ultra-high resolution FTICR mass spectrometry, Atmospheric Environment, 42(7), 1476-1490.

Atkinson, R. (2007), Rate constants for the atmospheric reactions of alkoxy radicals: An updated estimation method, Atmospheric Environment, 41(38), 8468-8485.

Atkinson, R., and J. Arey (2003), Atmospheric Degradation of Volatile Organic Compounds, Chemical Reviews, 103(12), 4605-4638.

Baduel, C., D. Voisin, and J. L. Jaffrezo (2010), Seasonal variations of concentrations and optical properties of water soluble HULIS collected in urban environments, Atmos. Chem. Phys., 10(9), 4085-4095.

Bao, L., M. Matsumoto, T. Kubota, K. Sekiguchi, Q. Wang, and K. Sakamoto (2012), Gas/particle partitioning of low-molecular-weight dicarboxylic acids at a suburban site in Saitama, Japan, Atmospheric Environment, 47(0), 546-553.

Bateman, A. P., M. L. Walser, Y. Desyaterik, J. Laskin, A. Laskin, and S. A. Nizkorodov (2008), The Effect of Solvent on the Analysis of Secondary Organic Aerosol Using Electrospray Ionization Mass Spectrometry, Environmental Science \& Technology, 42(19), 7341-7346.

Betterton, E. A., and M. R. Hoffmann (1988), Henry's law constants of some environmentally important aldehydes, Environmental Science \& Technology, 22(12), 1415-1418. 
Boris, A. J., Y. Desyaterik, and J. L. Collett Jr (2014), How do components of real cloud water affect aqueous pyruvate oxidation?, Atmospheric Research, 143(0), 95-106.

Bruins, A. P. (1998), Mechanistic aspects of electrospray ionization, Journal of Chromatography A, 794(1-2), 345-357.

Buschmann, H.-J., H.-H. Füldner, and W. Knoche (1980), The Reversible Hydration of Carbonyl Compounds in Aqueous Solution. Part I, The Keto/Gem-diol Equilibrium, Berichte der Bunsengesellschaft für physikalische Chemie, 84(1), 41-44.

Carey, F. A., and R. J. Sundberg (2008), Advanced Organic Chemistry: Part A, 5th Edition ed., 1212 pp., Springer, New York, NY 10013, USA.

Carlton, A. G., C. Wiedinmyer, and J. H. Kroll (2009), A review of Secondary Organic Aerosol (SOA) formation from isoprene, Atmos. Chem. Phys., 9(14), 4987-5005.

Carlton, A. G., B. J. Turpin, H.-J. Lim, K. E. Altieri, and S. Seitzinger (2006), Link between isoprene and secondary organic aerosol (SOA): Pyruvic acid oxidation yields low volatility organic acids in clouds, Geophys. Res. Lett., 33(6), L06822.

Cassee, F. R., M. E. Heroux, M. E. Gerlofs-Nijland, and F. J. Kelly (2013), Particulate matter beyond mass: recent health evidence on the role of fractions, chemical constituents and sources of emission, Inhalation toxicology, 25(14), 802-812.

Cech, N. B., and C. G. Enke (2001), Practical implications of some recent studies in electrospray ionization fundamentals, Mass Spectrometry Reviews, 20(6), 362-387.

Clegg, S. L., P. Brimblecombe, and A. S. Wexler (1998), The Extended Aerosol Inorganics Model (http://www.aim.env.uea.ac.uk/aim/aim.php), edited.

D'Andrilli, J., T. Dittmar, B. P. Koch, J. M. Purcell, A. G. Marshall, and W. T. Cooper (2010), Comprehensive characterization of marine dissolved organic matter by Fourier transform ion cyclotron resonance mass spectrometry with electrospray and atmospheric pressure photoionization, Rapid Communications in Mass Spectrometry, 24(5), 643-650.

De Haan, D. O., A. L. Corrigan, M. A. Tolbert, J. L. Jimenez, S. E. Wood, and J. J. Turley (2009), Secondary Organic Aerosol Formation by Self-Reactions of Methylglyoxal and Glyoxal in Evaporating Droplets, Environmental Science \& Technology, 43(21), 8184-8190.

Decesari, S., et al. (2006), Characterization of the organic composition of aerosols from Rondônia, Brazil, during the LBA-SMOCC 2002 experiment and its representation through model compounds, Atmos. Chem. Phys., 6(2), 375-402.

Ervens, B., S. Gligorovski, and H. Herrmann (2003), Temperature-dependent rate constants for hydroxyl radical reactions with organic compounds in aqueous solutions, Physical Chemistry Chemical Physics, 5(9), 1811-1824. 
Ervens, B., B. J. Turpin, and R. J. Weber (2011), Secondary organic aerosol formation in cloud droplets and aqueous particles (aqSOA): a review of laboratory, field and model studies, Atmos. Chem. Phys., 11(21), 11069-11102.

Ervens, B., G. Feingold, G. J. Frost, and S. M. Kreidenweis (2004), A modeling study of aqueous production of dicarboxylic acids: 1. Chemical pathways and speciated organic mass production, Journal of Geophysical Research: Atmospheres, 109(D15), D15205.

Fiore, A. M., et al. (2012), Global air quality and climate, Chemical Society Reviews, 4l(19), 6663-6683.

Fu, P., K. Kawamura, K. Usukura, and K. Miura (2013), Dicarboxylic acids, ketocarboxylic acids and glyoxal in the marine aerosols collected during a round-theworld cruise, Marine Chemistry, 148(0), 22-32.

Fu, T.-M., D. J. Jacob, F. Wittrock, J. P. Burrows, M. Vrekoussis, and D. K. Henze (2008), Global budgets of atmospheric glyoxal and methylglyoxal, and implications for formation of secondary organic aerosols, J. Geophys. Res.,

Galloway, M. M., P. S. Chhabra, A. W. H. Chan, J. D. Surratt, R. C. Flagan, J. H. Seinfeld, and F. N. Keutsch (2009), Glyoxal uptake on ammonium sulphate seed aerosol: reaction products and reversibility of uptake under dark and irradiated conditions, Atmos. Chem. Phys., 9(10), 3331-3345.

Goldstein, A. H., D. R. Worton, B. J. Williams, S. V. Hering, N. M. Kreisberg, O. Panić, and T. Górecki (2008), Thermal desorption comprehensive two-dimensional gas chromatography for in-situ measurements of organic aerosols, Journal of Chromatography A, 1186(1-2), 340-347.

Graham, B., et al. (2003), Composition and diurnal variability of the natural Amazonian aerosol, Journal of Geophysical Research: Atmospheres, 108(D24), 4765.

Griffith, E. C., B. K. Carpenter, R. K. Shoemaker, and V. Vaida (2013), Photochemistry of aqueous pyruvic acid, Proceedings of the National Academy of Sciences, 110(29), 11714-11719.

Gross, J. H. (2011), Mass Spectrometry, in A text book, edited, ISBN 978-3-642-10709-2.

Guzmán, M. I., A. J. Colussi, and M. R. Hoffmann (2006a), Photoinduced Oligomerization of Aqueous Pyruvic Acid, The Journal of Physical Chemistry A, 110(10), 3619-3626.

Guzmán, M. I., A. J. Colussi, and M. R. Hoffmann (2006b), Photogeneration of Distant Radical Pairs in Aqueous Pyruvic Acid Glasses, The Journal of Physical Chemistry A, 110(3), 931-935.

Hallquist, M., et al. (2009), The formation, properties and impact of secondary organic aerosol: current and emerging issues, Atmos. Chem. Phys., 9(14), 5155-5236. 
Hamilton, J. F., P. J. Webb, A. C. Lewis, J. R. Hopkins, S. Smith, and P. Davy (2004), Partially oxidised organic components in urban aerosol using GCXGC-TOF/MS, Atmos. Chem. Phys., 4(5), 1279-1290.

Herrmann, H., D. Hoffmann, T. Schaefer, P. Bräuer, and A. Tilgner (2010), Tropospheric Aqueous-Phase Free-Radical Chemistry: Radical Sources, Spectra, Reaction Kinetics and Prediction Tools, ChemPhysChem, 11(18), 3796-3822.

IPCC (2013), Climate Change 2013: The Physical Science Basis: Contribution of Working Group I to the Fifth Assessment Report of the Intergovernmental Panel on Climate Change Stocker, T.F., D. Qin, G.-K. Plattner, M. Tignor, .K. Allen, J. Boschung, A. Nauels, Y. Xia, V. Bex and P.M. Midgley (eds.)], Cambridge University Press, Cambridge, United Kingdom and New York, NY, USA, 1935 pp.

Kalberer, M., et al. (2004), Identification of Polymers as Major Components of Atmospheric Organic Aerosols, Science, 303(5664), 1659-1662.

Kanakidou, M., et al. (2005), Organic aerosol and global climate modelling: a review, Atmos. Chem. Phys., 5(4), 1053-1123.Kawamura, K., H. Kasukabe, and L. A. Barrie (1996), Source and reaction pathways of dicarboxylic acids, ketoacids and dicarbonyls in arctic aerosols: One year of observations, Atmospheric Environment, 30(10-11), 1709-1722.

Kawamura, K., and O. Yasui (2005), Diurnal changes in the distribution of dicarboxylic acids, ketocarboxylic acids and dicarbonyls in the urban Tokyo atmosphere, Atmospheric Environment, 39(10), 1945-1960.

Kawamura, K., K. Okuzawa, S. G. Aggarwal, H. Irie, Y. Kanaya, and Z. Wang (2013), Determination of gaseous and particulate carbonyls (glycolaldehyde, hydroxyacetone, glyoxal, methylglyoxal, nonanal and decanal) in the atmosphere at Mt. Tai, Atmos. Chem. Phys., 13(10), 5369-5380.

Kerber, R. C., and M. S. Fernando (2010), $\alpha$-Oxocarboxylic Acids, Journal of Chemical Education, 87(10), 1079-1084.

Kim, S., R. W. Kramer, and P. G. Hatcher (2003), Graphical Method for Analysis of Ultrahigh-Resolution Broadband Mass Spectra of Natural Organic Matter, the Van Krevelen Diagram, Analytical Chemistry, 75(20), 5336-5344.

Koch, B. P., M. Witt, R. Engbrodt, T. Dittmar, and G. Kattner (2005), Molecular formulae of marine and terrigenous dissolved organic matter detected by electrospray ionization Fourier transform ion cyclotron resonance mass spectrometry, Geochimica et Cosmochimica Acta, 69(13), 3299-3308.

Krizner, H. E., D. O. De Haan, and J. Kua (2009), Thermodynamics and Kinetics of Methylglyoxal Dimer Formation: A Computational Study, The Journal of Physical Chemistry A, 113(25), 6994-7001. 
Kroll, J. H., and J. H. Seinfeld (2008), Chemistry of secondary organic aerosol: Formation and evolution of low-volatility organics in the atmosphere, Atmospheric Environment, 42(16), 3593-3624.

Kroll, J. H., J. D. Smith, D. L. Che, S. H. Kessler, D. R. Worsnop, and K. R. Wilson (2009), Measurement of fragmentation and functionalization pathways in the heterogeneous oxidation of oxidized organic aerosol, Physical Chemistry Chemical Physics, 11(36), 8005-8014.

Kua, J., H. E. Krizner, and D. O. De Haan (2011), Thermodynamics and Kinetics of Imidazole Formation from Glyoxal, Methylamine, and Formaldehyde: A Computational Study, The Journal of Physical Chemistry A, 115(9), 1667-1675.

Kujawinski, E. B., P. G. Hatcher, and M. A. Freitas (2001), High-Resolution Fourier Transform Ion Cyclotron Resonance Mass Spectrometry of Humic and Fulvic Acids: Improvements and Comparisons, Analytical Chemistry, 74(2), 413-419.

Kundu, S., K. Kawamura, T. W. Andreae, A. Hoffer, and M. O. Andreae (2010), Molecular distributions of dicarboxylic acids, ketocarboxylic acids and \&alpha;-dicarbonyls in biomass burning aerosols: implications for photochemical production and degradation in smoke layers, Atmos. Chem. Phys., 10(5), 2209-2225.

Kundu, S., R. Fisseha, A. L. Putman, T. A. Rahn, and L. R. Mazzoleni (2012), High molecular weight SOA formation during limonene ozonolysis: insights from ultrahigh-resolution FT-ICR mass spectrometry characterization, Atmos. Chem. Phys., 12(12), 5523-5536.

Laidler, K. J. (1987), Chemical Kinetics, Third Edition ed., Harper \& Row.

Larsen, M. C., and V. Vaida (2012), Near Infrared Photochemistry of Pyruvic Acid in Aqueous Solution, The Journal of Physical Chemistry A, 116(24), 5840-5846.

Leermakers, P. A., and G. F. Vesley (1963), The Photochemistry of $\alpha$-Keto Acids and $\alpha$ Keto Esters. I. Photolysis of Pyruvic Acid and Benzoylformic Acid, Journal of the American Chemical Society, 85(23), 3776-3779.

Lim, H.-J., A. G. Carlton, and B. J. Turpin (2005), Isoprene Forms Secondary Organic Aerosol through Cloud Processing: Model Simulations, Environmental Science \& Technology, 39(12), 4441-4446.

Lin, G., S. Sillman, J. E. Penner, and A. Ito (2014), Global modeling of SOA: the use of different mechanisms for aqueous-phase formation, Atmos. Chem. Phys., 14(11), $5451-5475$.

Lin, P., A. G. Rincon, M. Kalberer, and J. Z. Yu (2012), Elemental Composition of HULIS in the Pearl River Delta Region, China: Results Inferred from Positive and Negative Electrospray High Resolution Mass Spectrometric Data, Environmental Science \& Technology, 46(14), 7454-7462. 
Loeffler, K. W., C. A. Koehler, N. M. Paul, and D. O. De Haan (2006), Oligomer Formation in Evaporating Aqueous Glyoxal and Methyl Glyoxal Solutions, Environmental Science \& Technology, 40(20), 6318-6323.

Lund Myhre, C. E., and C. J. Nielsen (2004), Optical properties in the UV and visible spectral region of organic acids relevant to tropospheric aerosols, Atmos. Chem. Phys., 4(7), 1759-1769.

Mahowald, N., D. S. Ward, S. Kloster, M. G. Flanner, C. L. Heald, N. G. Heavens, P. G. Hess, J.-F. Lamarque, and P. Y. Chuang (2011), Aerosol Impacts on Climate and Biogeochemistry, Annual Review of Environment and Resources, 36(1), 45-74.

Marshall, A. G., C. L. Hendrickson, and G. S. Jackson (1998), Fourier transform ion cyclotron resonance mass spectrometry: A primer, Mass Spectrometry Reviews, 17(1), 1-35.

Mazzoleni, L. R., B. M. Ehrmann, X. Shen, A. G. Marshall, and J. L. Collett (2010), WaterSoluble Atmospheric Organic Matter in Fog: Exact Masses and Chemical Formula Identification by Ultrahigh-Resolution Fourier Transform Ion Cyclotron Resonance Mass Spectrometry, Environmental Science \& Technology, 44(10), 3690-3697.

Mellouki, A., and Y. Mu (2003), On the atmospheric degradation of pyruvic acid in the gas phase, Journal of Photochemistry and Photobiology A: Chemistry, 157(2-3), 295300 .

Morrison, R. T., and R. N. Boyd (1992), Organic Chemistry, 6th Edition ed., Prentice-Hall, Inc., Englewood Cliffs, NJ.

Nemet, I., D. Vikić-Topić, and L. Varga-Defterdarović (2004), Spectroscopic studies of methylglyoxal in water and dimethylsulfoxide, Bioorganic Chemistry, 32(6), 560570 .

Noziere, B., P. Dziedzic, and A. Cordova (2010), Inorganic ammonium salts and carbonate salts are efficient catalysts for aldol condensation in atmospheric aerosols, Physical Chemistry Chemical Physics, 12(15), 3864-3872.

Nozière, B., and W. Esteve (2005), Organic reactions increasing the absorption index of atmospheric sulfuric acid aerosols, Geophys. Res. Lett., 32(3), L03812.

Nozière, B., P. Dziedzic, and A. Córdova (2008), Products and Kinetics of the LiquidPhase Reaction of Glyoxal Catalyzed by Ammonium Ions (NH4+), The Journal of Physical Chemistry A, 113(1), 231-237.

Pang, Y., B. J. Turpin, and L. A. Gundel (2006), On the Importance of Organic Oxygen for Understanding Organic Aerosol Particles, Aerosol Science and Technology, 40(2), 128-133. 
Pavuluri, C. M., K. Kawamura, and T. Swaminathan (2010), Water-soluble organic carbon, dicarboxylic acids, ketoacids, and \&\#945;-dicarbonyls in the tropical Indian aerosols, J. Geophys. Res., 115(D11), D11302.

Plath, K. L., K. Takahashi, R. T. Skodje, and V. Vaida (2009), Fundamental and Overtone Vibrational Spectra of Gas-Phase Pyruvic Acid $\dagger$, The Journal of Physical Chemistry A, 113(26), 7294-7303.

Pocker, Y., and J. E. Meany (1970), Reversible hydration of pyruvic acid. II. Metal ion and enzymic catalysis, The Journal of Physical Chemistry, 74(7), 1486-1492.

Pocker, Y., J. E. Meany, B. J. Nist, and C. Zadorojny (1969), Reversible hydration of pyruvic acid. I. Equilibrium studies, The Journal of Physical Chemistry, 73(9), 28792882.

Pöschl, U. (2005), Atmospheric Aerosols: Composition, Transformation, Climate and Health Effects, Angewandte Chemie International Edition, 44(46), 7520-7540.

Presto, A. A., M. A. Miracolo, J. H. Kroll, D. R. Worsnop, A. L. Robinson, and N. M. Donahue (2009), Intermediate-Volatility Organic Compounds: A Potential Source of Ambient Oxidized Organic Aerosol, Environmental Science \& Technology, 43(13), 4744-4749.

Putman, A. L., J. H. Offenberg, R. Fisseha, S. Kundu, T. A. Rahn, and L. R. Mazzoleni (2012), Ultrahigh-resolution FT-ICR mass spectrometry characterization of $\alpha$ pinene ozonolysis SOA, Atmospheric Environment, 46(0), 164-172.

Reed Harris, A. E., B. Ervens, R. K. Shoemaker, J. A. Kroll, R. J. Rapf, E. C. Griffith, A. Monod, and V. Vaida (2014), Photochemical Kinetics of Pyruvic Acid in Aqueous Solution, The Journal of Physical Chemistry A.

Reemtsma, T. (2009), Determination of molecular formulas of natural organic matter molecules by (ultra-) high-resolution mass spectrometry: Status and needs, Journal of Chromatography A, 1216(18), 3687-3701.

Reemtsma, T., A. These, P. Venkatachari, X. Xia, P. K. Hopke, A. Springer, and M. Linscheid (2006), Identification of Fulvic Acids and Sulfated and Nitrated Analogues in Atmospheric Aerosol by Electrospray Ionization Fourier Transform Ion Cyclotron Resonance Mass Spectrometry, Analytical Chemistry, 78(24), 82998304.

Saito, K., G. Sasaki, K. Okada, and S. Tanaka (1994), Unimolecular Decomposition of Pyruvic Acid: An Experimental and Theoretical Study, The Journal of Physical Chemistry, 98(14), 3756-3761.

Sareen, N., A. N. Schwier, E. L. Shapiro, D. Mitroo, and V. F. McNeill (2010), Secondary organic material formed by methylglyoxal in aqueous aerosol mimics, Atmos. Chem. Phys., 10(3), 997-1016. 
Sareen, N., A. N. Schwier, T. L. Lathem, A. Nenes, and V. F. McNeill (2013), Surfactants from the gas phase may promote cloud droplet formation, Proceedings of the National Academy of Sciences.

Schmitt-Kopplin, P., A. Gelencsér, E. Dabek-Zlotorzynska, G. Kiss, N. Hertkorn, M. Harir, Y. Hong, and I. Gebefügi (2010), Analysis of the Unresolved Organic Fraction in Atmospheric Aerosols with Ultrahigh-Resolution Mass Spectrometry and Nuclear Magnetic Resonance Spectroscopy: Organosulfates As Photochemical Smog Constituents $\dagger$, Analytical Chemistry, 82(19), 8017-8026.

Seinfeld, J. H., and S. N. Pandis (2006), Atmospheric Chemistry and Physics: From Air Pollution to Climate Change, 2nd Edition.

Shapiro, E. L., J. Szprengiel, N. Sareen, C. N. Jen, M. R. Giordano, and V. F. McNeill (2009), Light-absorbing secondary organic material formed by glyoxal in aqueous aerosol mimics, Atmos. Chem. Phys. Discuss., 9(1), 59-80.

Sleighter, R. L., and P. G. Hatcher (2008), Molecular characterization of dissolved organic matter (DOM) along a river to ocean transect of the lower Chesapeake Bay by ultrahigh resolution electrospray ionization Fourier transform ion cyclotron resonance mass spectrometry, Marine Chemistry, 110(3-4), 140-152.

Stenson, A. C., A. G. Marshall, and W. T. Cooper (2003), Exact Masses and Chemical Formulas of Individual Suwannee River Fulvic Acids from Ultrahigh Resolution Electrospray Ionization Fourier Transform Ion Cyclotron Resonance Mass Spectra, Analytical Chemistry, 75(6), 1275-1284.

Takahashi, K., K. L. Plath, R. T. Skodje, and V. Vaida (2008), Dynamics of Vibrational Overtone Excited Pyruvic Acid in the Gas Phase: Line Broadening through Hydrogen-Atom Chattering, The Journal of Physical Chemistry A, 112(32), 73217331.

Tan, Y., A. G. Carlton, S. P. Seitzinger, and B. J. Turpin (2010), SOA from methylglyoxal in clouds and wet aerosols: Measurement and prediction of key products, Atmospheric Environment, 44(39), 5218-5226.

Wang, H., K. Kawamura, and K. Yamazaki (2006), Water-Soluble dicarboxylic acids, ketoacids and dicarbonyls in the atmospheric aerosols over the southern ocean and western pacific ocean, Journal of Atmospheric Chemistry, 53(1), 43-61.

Xian, F., C. L. Hendrickson, and A. G. Marshall (2012), High Resolution Mass Spectrometry, Analytical Chemistry, 84(2), 708-719.

Yamamoto, S., and R. A. Back (1985), The photolysis and thermal decomposition of pyruvic acid in the gas phase, Canadian Journal of Chemistry, 63(2), 549-554.

Yasmeen, F., N. Sauret, J. F. Gal, P. C. Maria, L. Massi, W. Maenhaut, and M. Claeys (2010), Characterization of oligomers from methylglyoxal under dark conditions: a pathway to produce secondary organic aerosol through cloud processing during nighttime, Atmos. Chem. Phys., 10(8), 3803-3812. 
Zhang, Q., et al. (2007), Ubiquity and dominance of oxygenated species in organic aerosols in anthropogenically-influenced Northern Hemisphere midlatitudes, Geophys. Res. Lett., 34(13), L13801.

Zhao, J., N. P. Levitt, R. Zhang, and J. Chen (2006), Heterogeneous Reactions of Methylglyoxal in Acidic Media:â€\%o Implications for Secondary Organic Aerosol Formation, Environmental Science \& Technology, 40(24), 7682-7687.

Zhao, Y., A. G. Hallar, and L. R. Mazzoleni (2013), Atmospheric organic matter in clouds: exact masses and molecular formula identification using ultrahigh-resolution FTICR mass spectrometry, Atmos. Chem. Phys., 13(24), 12343-12362. 


\section{Appendix}

\section{A.1 Supplemental Information: Decarboxylation of Pyruvic Acid and Glyoxylic Acid in Ammonium Salt Solutions as Aqueous Aerosol Mimics}

\section{A.1.1 Conversion of Mixing Ratio of $\mathrm{CO}_{2}$}

The mixing ratio of $\mathrm{CO}_{2}$ was measured in gas phase throughout the experiments. Kinetic studies require us to convert the gas phase mixing ratio to concentration of $\mathrm{CO}_{2}$ in per unit volume of reaction solution and shown in subsequent sections.

\section{A.1.1.1 Experimental Parameters}

We have the following experimental parameters at standard temperature and pressure:

1. Volume of air space above solution $=1.4 \mathrm{~L}$ (A calculation was shown using 1.4 L. Actual measured volume of the flasks used were $1.411 \mathrm{~L}$ and $1.388 \mathrm{~L}$ )

2. Temperature $\simeq 25{ }^{0} \mathrm{C}$ (range was 70 to $\left.80{ }^{0} \mathrm{~F}\right)$

3. Volume of solution $=100.0 \mathrm{~mL}$

4. $\mathrm{CO}_{2}$ mixing ratio in the air above solution, measured in ppm with respect to time

\section{A.1.1.2 Conversion of the Measured $\mathrm{CO}_{2}$ in Moles}

Let the mixing ratio of $\mathrm{CO}_{2}$ in ppm $=y \times 10^{-6}$ moles of $\mathrm{CO}_{2}$ in 1 mole of air. Now, we apply the ideal gas law to determine the number of moles of air in the air space above the reaction solution:

$$
n_{\text {air }}=\frac{P V}{R T}=5.7 \times 10^{-2} \mathrm{~mol}
$$


where, $\mathrm{P}=1 \mathrm{~atm}, \mathrm{~V}=1.4 \mathrm{~L}, \mathrm{R}=0.08205746 \mathrm{~atm} \mathrm{~L} \mathrm{~mol}^{-1} \mathrm{~K}^{-1}$ and $\mathrm{T}=298 \mathrm{~K}$.

Similarly, the number of moles of $\mathrm{CO}_{2}$ for $y$ mixing ratio in $1.4 \mathrm{~L}$ air at $1 \mathrm{~atm}$ and $298 \mathrm{~K}$ temperature,

$$
n_{\mathrm{CO}_{2}(g)}=y \times 10^{-6} \times 5.7 \times 10^{-2} \mathrm{~mol}=y \times 5.7 \times 10^{-8} \mathrm{~mol}
$$

where, an increase in the mixing ratio of $\mathrm{CO}_{2}$ up to 5000ppm which is upper limit of our detector causing a negligible increase in the pressure of the system.

\section{A.1.1.3 Calculation of the Total $\mathrm{CO}_{2}$}

The closed system contains both gas and aqueous phases.

$\mathrm{CO}_{2}$ is present in a closed gas-aqueous system according to the following equilibrium:

$\mathrm{CO}_{2}(\mathrm{~g})+\mathrm{H}_{2} \mathrm{O}(l) \rightleftharpoons \mathrm{CO}_{2} \cdot \mathrm{H}_{2} \mathrm{O}(a q) \rightleftharpoons \mathrm{HCO}_{3}^{-}(a q)+\mathrm{H}^{+}(a q) \rightleftharpoons \mathrm{CO}_{3}{ }^{2-}(a q)+\mathrm{H}^{+}(a q)$

i) The aqueous phase concentration of $\mathrm{CO}_{2} \cdot \mathrm{H}_{2} \mathrm{O}(a q)$ is given by

$$
\begin{gathered}
{\left[\mathrm{CO}_{2} \cdot \mathrm{H}_{2} \mathrm{O}(a q)\right]=H_{\mathrm{CO}_{2}}} \\
\times p_{\mathrm{CO}_{2}}=3.4 \times 10^{-2} \mathrm{M} \mathrm{atm}^{-1} \times y \times 10^{-6} \mathrm{~atm} \\
=y \times 3.4 \times 10^{-8} \mathrm{M}
\end{gathered}
$$

where, $\mathrm{H}_{\mathrm{CO}_{2}}=3.4 \times 10^{-2} \mathrm{M} \mathrm{atm}^{-1}$ and $p_{\mathrm{CO}_{2}} \approx y \times 10^{-6} \mathrm{~atm}$.

For a $100 \mathrm{~mL}$ volume, the number of moles of $\mathrm{CO}_{2} \cdot \mathrm{H}_{2} \mathrm{O}(a q)$ is

$$
n_{\mathrm{CO}_{2}(a q)}=y \times 3.4 \times 10^{-8} \times 100 \times 10^{-3} \mathrm{~mol}=y \times 3.4 \times 10^{-9} \mathrm{~mol}
$$

ii) Concentration of $\mathrm{HCO}_{3}^{-}(a q)$ is given by 


$$
\left[\mathrm{HCO}_{3}^{-}(a q)\right]=\frac{\mathrm{H}_{\mathrm{CO}_{2}} \times p_{\mathrm{CO}_{2}} \times K_{1}}{\left[H^{+}\right]}=y \times 1.4 \times 10^{-11} \mathrm{M}
$$

where, $\mathrm{K}_{1}$ is the equilibrium constant $=4.3 \times 10^{-7} \mathrm{M}$ at $298 \mathrm{~K}$ and $\left[\mathrm{H}^{+}\right]=10^{-3} \mathrm{M}($ at $\mathrm{pH}=$ 3.0). $\left[\mathrm{HCO}_{3}^{-}(\mathrm{aq})\right]$ will be lower for lower $\mathrm{pH}$ values.

The number of moles of $\mathrm{HCO}_{3}^{-}(a q)$ is

$$
n_{\mathrm{HCO}_{3}^{-}(a q)}=y \times 1.4 \times 10^{-12} \mathrm{~mol}
$$

iii) Similarly, the number of moles of $\mathrm{CO}_{3}{ }^{2-}$ (aq) is

$$
n_{\mathrm{CO}_{3}^{2-}(a q)}=y \times 6.5 \times 10^{-20} \mathrm{~mol}
$$

Therefore, $n_{\mathrm{CO}_{2}(a q)}>n_{\mathrm{HCO}_{3}^{-}(a q)}>>n_{\mathrm{CO}_{3}^{2-}(a q)}$. Thus, total number of moles of all $\mathrm{CO}_{2}$ species in the aqueous phase can be approximated by

$$
n_{\text {total aqueous } \mathrm{CO} 2} \approx n_{\mathrm{CO}_{2}(a q)}
$$

Now, if we imagine all the $\mathrm{CO}_{2}$ that were produced from decarboxylation reaction remains in the solution (in reality $\mathrm{CO}_{2}$ are distributed between gas and solution phase) and then we can derive an aqueous phase concentration of $\mathrm{CO}_{2}$ and observe the change of concentration of it with time.

We calculate the moles of $\mathrm{CO}_{2}$ in unit volume of reactant (aqueous phase concentration of $\mathrm{CO}_{2}$ if all $\mathrm{CO}_{2}$ would have remained in the solution). This conversion is to calculate the production of $\mathrm{CO}_{2}$ per unit time in per unit volume of reactant solution. That will have all the concentration at the same unit and will be helpful to obtain rate constant of decarboxylation. 
Concentration of $\mathrm{CO}_{2}$ in unit volume of reaction solution $=\frac{\text { Total number of moles of } \mathrm{CO}_{2}}{\text { Volume of the solution }}$

$$
\begin{gathered}
=\frac{\text { Total moles of } \mathrm{CO}_{2} \text { in gas phase }+ \text { Tota moles of } \mathrm{CO}_{2} \text { in aqueoues phase }}{\text { Volume of the solution }} \\
\qquad=\frac{y \times 5.7 \times 10^{-8}+y \times 3.4 \times 10^{-9} \mathrm{~mol}}{100 \times 10^{-3} \mathrm{~L}}=\mathrm{y} \times 6.04 \times 10^{-4} \mathrm{mM}
\end{gathered}
$$

\section{A.1.2 Plot of the Raw and Derived Data for Experiment Number 13 (Table 2.1).}

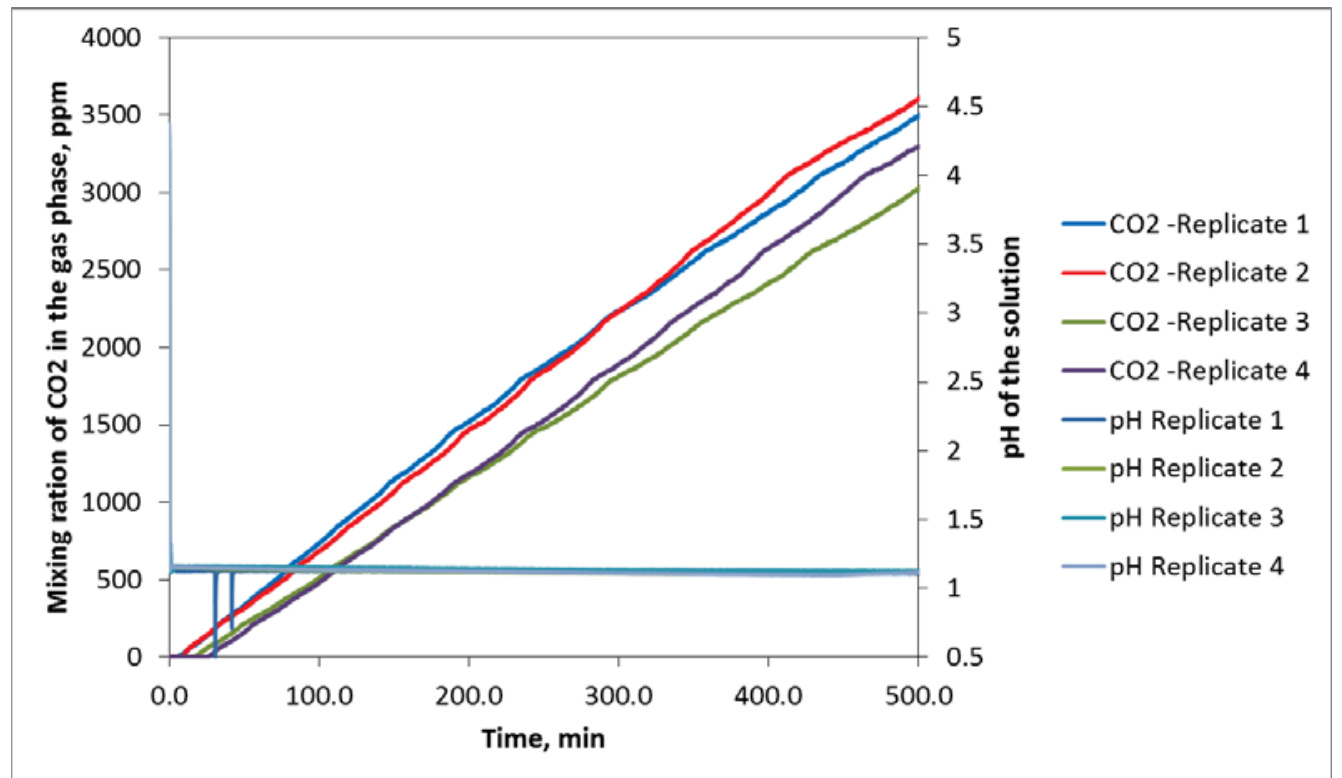

Figure A.1.1: Variation of the $\mathrm{pH}$ of the reaction solution and the mixing ratio of gas phase $\mathrm{CO}_{2}$ above the solution of $1.0 \mathrm{M}$ glyoxylic acid and 3.0 $\mathrm{M} \mathrm{NH}_{4} \mathrm{Cl}$ reaction (Experiment Number 13, raw data). The reaction solution volume is $100.0 \mathrm{~mL}$ and the volume of the air space is $1.41 \mathrm{~L}$. The reaction started at $0.0 \mathrm{~min}$ in all cases when we introduced glyoxylic acid into the solution. As soon as the acid was added the $\mathrm{pH}$ drops sharply. 


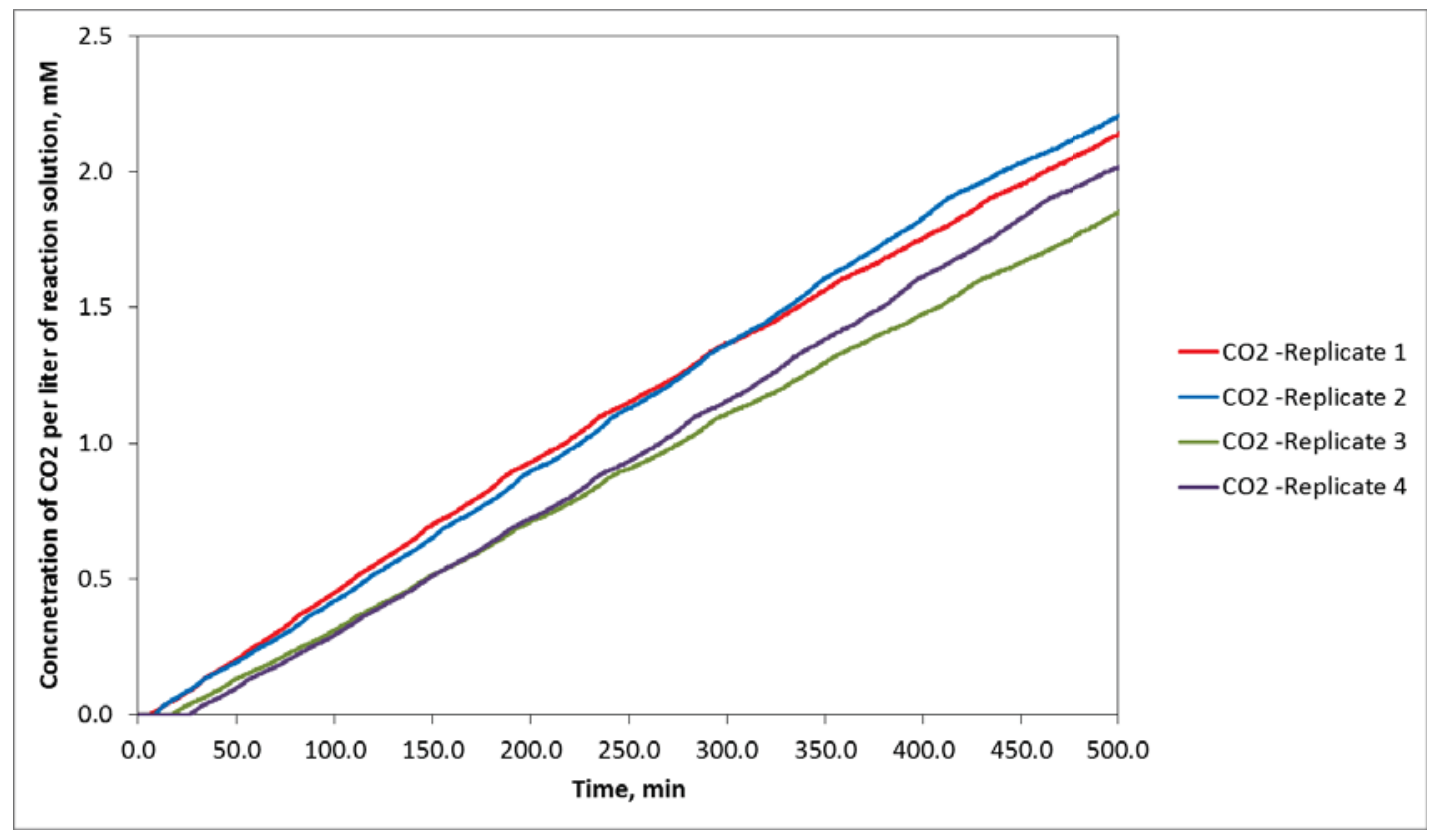

Figure A.1.2: Variation in the concentration of $\mathrm{CO}_{2}$ per liter of the reaction solution (as if all $\mathrm{CO}_{2}$ remains in the aqueous phase) of $1.0 \mathrm{M}$ glyoxylic acid and 3.0 $\mathrm{M} \mathrm{NH}_{4} \mathrm{Cl}$ reaction (Experiment Number 13, processed data).

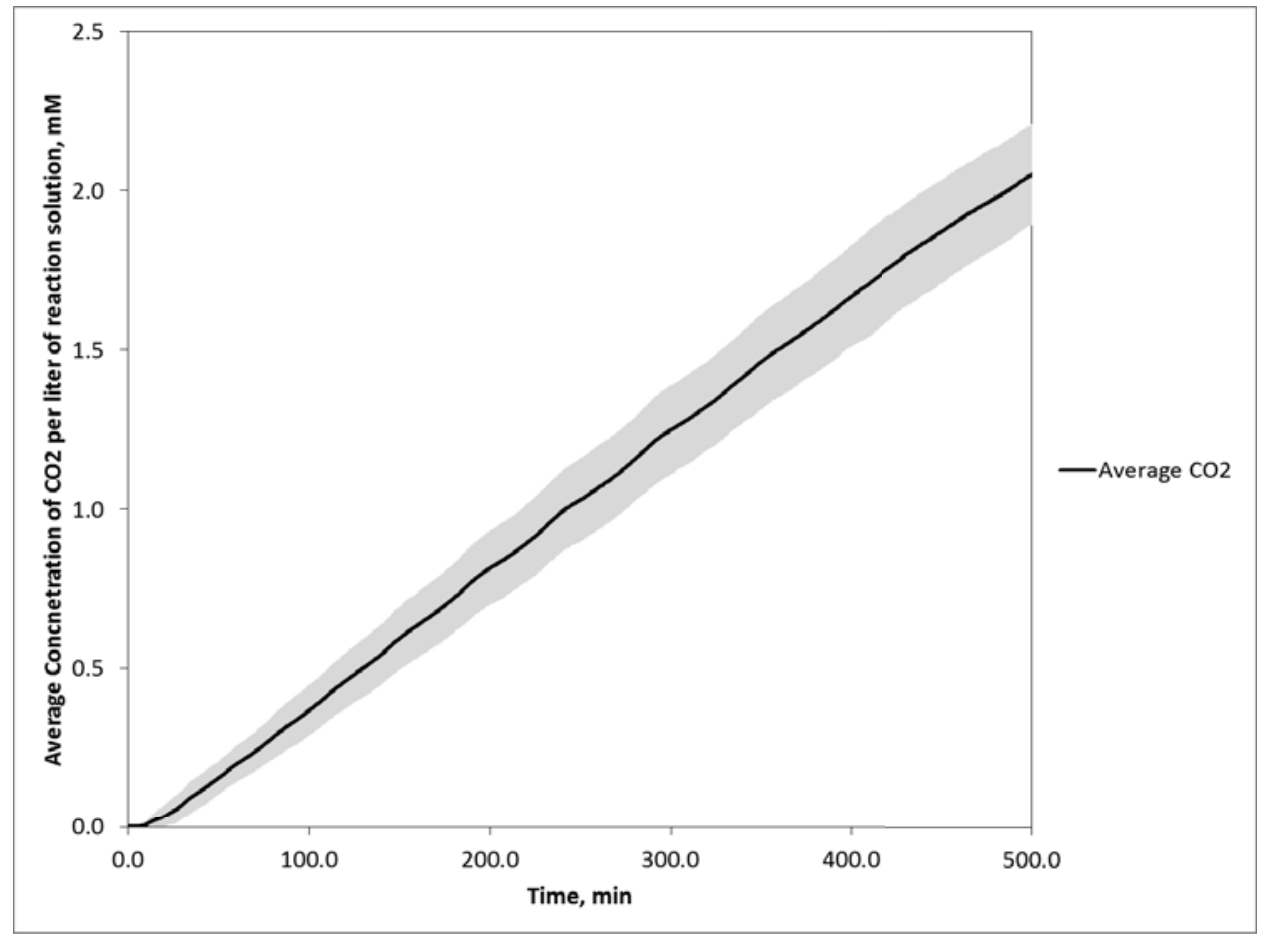

Figure A.1.3: Variation of the average concentration of $\mathrm{CO}_{2}$ in per liter of reaction solution for the experiment with $1.0 \mathrm{M}$ glyoxylic acid and 3.0 $\mathrm{M} \mathrm{NH}_{4} \mathrm{Cl}$ reaction (Experiment Number 13, processed averaged data). The shade represents the standard deviation from the replicate analysis (4 replicate). 


\section{A.1.3 Kinetics of the Phase Transfer of $\mathrm{CO}_{2}$}

$\mathrm{CO}_{2}$ is produced in the solution and it is transported to the gas phase and then we measured its mixing ratio in gas phase. If we can produce all of the $\mathrm{CO}_{2}$ at once in the solution and then allow it to diffuse to the gas phase, then we can observe the kinetics of the phase transfer of $\mathrm{CO}_{2}$ from the aqueous phase to the gas phase. In the phase transfer, $\mathrm{CO}_{2}$ obeys laws of mass transfer through an interface and the equilibrium concentration will be established according to Henry's law. For our reaction setup selected variables remain unchanged (i.e., area, phase, turbulence, etc.) and reduction in the variables allows us to study the phase transfer process of $\mathrm{CO}_{2}$ as a first order process, according to the following equation:

Concentration of $\mathrm{CO}_{2}$ in the gas phase $=a\left(1-e^{-k t}\right) \ldots \ldots$ E-A.1

Where, $\mathrm{a}$ is the maximum concentration; $\mathrm{t}$ is time in minute and $\mathrm{k}$ is the constant of phase transfer process for the present experimental setup and this constant is applicable to the current study only.

$250 \mu \mathrm{L}$ of $1.01 \mathrm{M} \mathrm{Na}_{2} \mathrm{CO}_{3}$ solution was mixed in $100 \mathrm{~mL}$ of water and stirred continuously using Teflon ${ }^{\circledR}$ coated magnetic stir bar $(\sim 2.9 \mathrm{~cm}$ long and $\sim 0.8 \mathrm{~cm}$ thick $)$ at $350 \mathrm{rpm}$. A 3.0 $\mathrm{mL}$ of $1 \mathrm{M}$ sulfuric acid solution was introduced to the sodium carbonate solution so that the $\mathrm{pH}$ of the solution suddenly drops to below 2. The evolution of gas phase $\mathrm{CO}_{2}$ was monitored using $\mathrm{CO}_{2}$ probe same as other experiments. The reason for doing this is because the addition of excess acid will force all of the dissolved $\mathrm{CO}_{3}{ }^{2-}$ and $\mathrm{HCO}_{3}{ }^{-}$to $\mathrm{CO}_{2} \cdot \mathrm{H}_{2} \mathrm{O}(a q)$ as discussed in previous section (A.1.1). The $\mathrm{CO}_{2} \cdot \mathrm{H}_{2} \mathrm{O}$ will be forced to establish equilibrium with the gas phase $\mathrm{CO}_{2}$ according to Henry's law. Then it will allow us to 
study the kinetics of phase transfer of $\mathrm{CO}_{2}$ from aqueous phase to gas phase under experimental condition (i.e., temperature, agitation of the solution from magnetic stir bar spinning at $350 \mathrm{rpm}$, etc.)

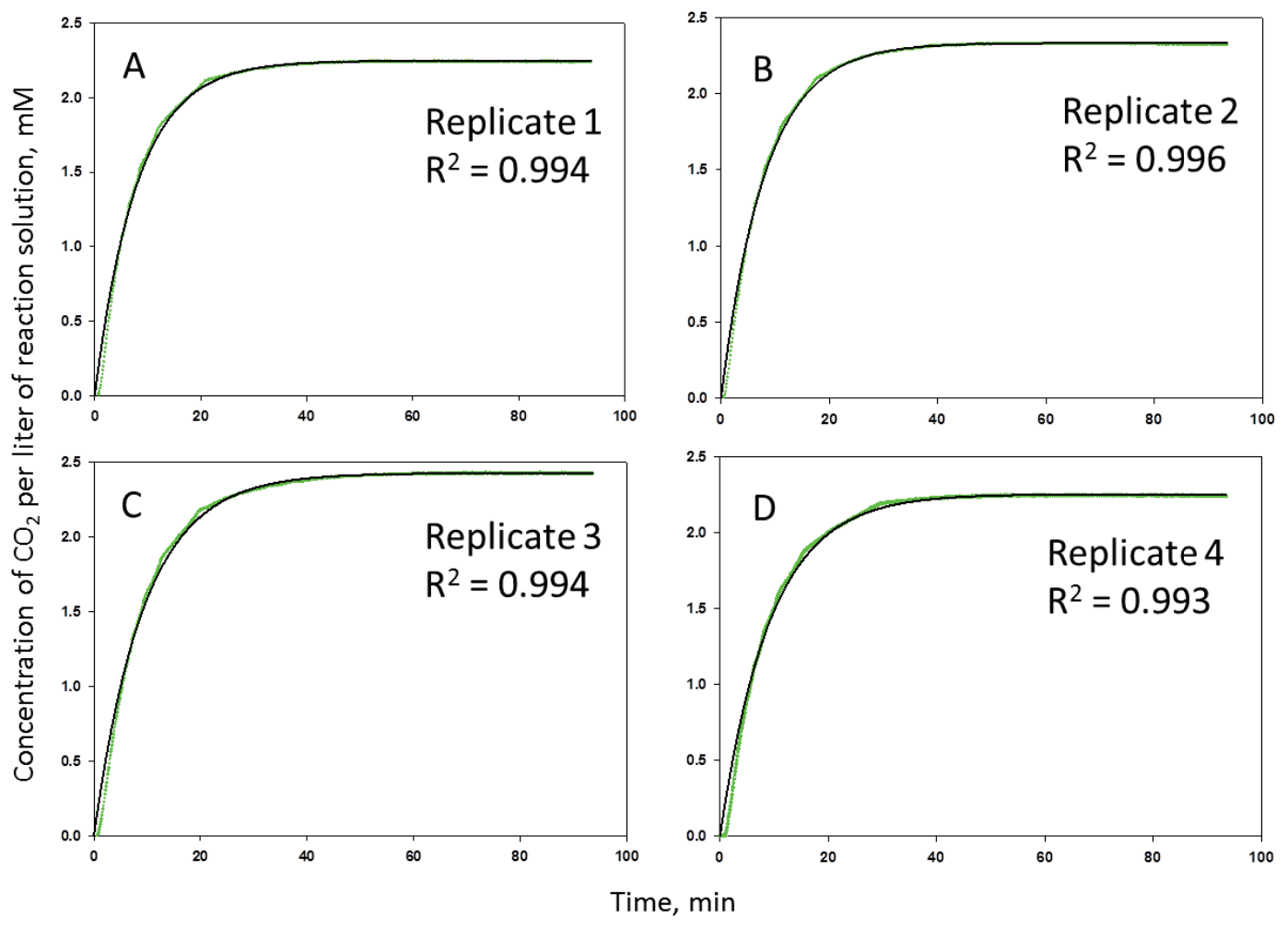

Figure A.1.4: The temporal evolution of the gas phase concentration of $\mathrm{CO}_{2}$ produced from the reaction between sodium carbonate and sulfuric acid. Panel A to D represents indicated replicated analysis profile. The green points represent the observed value and black line is the fitted line according to the equation EA.1. The $\mathrm{R}^{2}$ value for the regression is given in the respective panel.

We monitored the evolution of $\mathrm{CO}_{2}$ in the gas phase and fitted the concentration of $\mathrm{CO}_{2}$ with a first order increment process and obtained the phase transfer process constant from the optimized parameter. In Figure 4, the time profile of the gas phase $\mathrm{CO}_{2}$ was plotted from the reaction between sodium carbonate and sulfuric acid. The green points are the 
measured value and the black lines are fitted curve using the first order increment equation (E-A.1). The optimized phase transfer constant is tabulated in Table A.1.1.

Table A.1.1: Derived kinetic data of the phase transfer of $\mathrm{CO}_{2}$ from the aqueous phase to the gas phase generated from the reaction between sodium carbonate and sulfuric acid

\begin{tabular}{|c|c|c|c|}
\hline $\begin{array}{c}\mathrm{Na}_{2} \mathrm{CO}_{3}+ \\
\mathrm{H}_{2} \mathrm{SO}_{4}\end{array}$ & $\begin{array}{c}\text { Phase transfer } \\
\text { constant, } \mathrm{min}^{-1}\end{array}$ & $\begin{array}{c}\text { Phase transfer } \\
\text { constant, } \mathrm{s}^{-1}\end{array}$ & $\begin{array}{c}\text { Average phase } \\
\text { transfer constant, } \mathrm{s}^{-1}\end{array}$ \\
\cline { 1 - 3 } Replicate 1 & 0.125 & 0.002083 & \\
\cline { 1 - 2 } Replicate 2 & 0.123 & 0.002050 & \multirow{2}{*}{$1.9 \pm 0.2 \times 10^{-3}$} \\
\cline { 1 - 3 } Replicate 3 & 0.106 & 0.001767 & \\
\cline { 1 - 3 } Replicate 4 & 0.108 & 0.00180 & \\
\hline
\end{tabular}

\section{A.1.4 Rate of the Decarboxylation and Order of the Reaction}

Derivation of the rate of the reaction and order with respect to ammonium ion, glyoxylic acid and pyruvic acid was shown in Chapter 2. Here we will show the determination of order with respect to ammonia, which is in equilibrium with ammonium ion. The kinetic data of individual replicate for each experiment are tabulated in Table A.1.2

\section{A.1.4.1 Determination of Order with Respect to Ammonia}

Ammonia is present in minute amounts in the solutions in equilibrium with ammonium ions. Therefore, we calculated the concentration of free ammonia in solution using an aerosol thermodynamic model (E-AIM) and the values are tabulated in Table A.1.3. It may be noted that throughout our experiments we used molar concentration unit but the E-AIM model uses molal concentration unit and hence, the values of concentration of free ammonia is an approximate value not exact value. The natural logarithm of the average rate of decarboxylation versus the natural logarithm of the molar concentration of free ammonia were plotted in Figure A.1.5 for the experiment set 1,2 and 3 (Panel A) and for 
the experiment set 9, 10 and 11 (Panel C). No corrections were made to get the activity of the species. The optimized slopes were 0.5 and -2.1 meaning the order with respect to ammonia is highly deviated from any positive integer value and the reason for this is not understood and awaits clarification with future investigation.
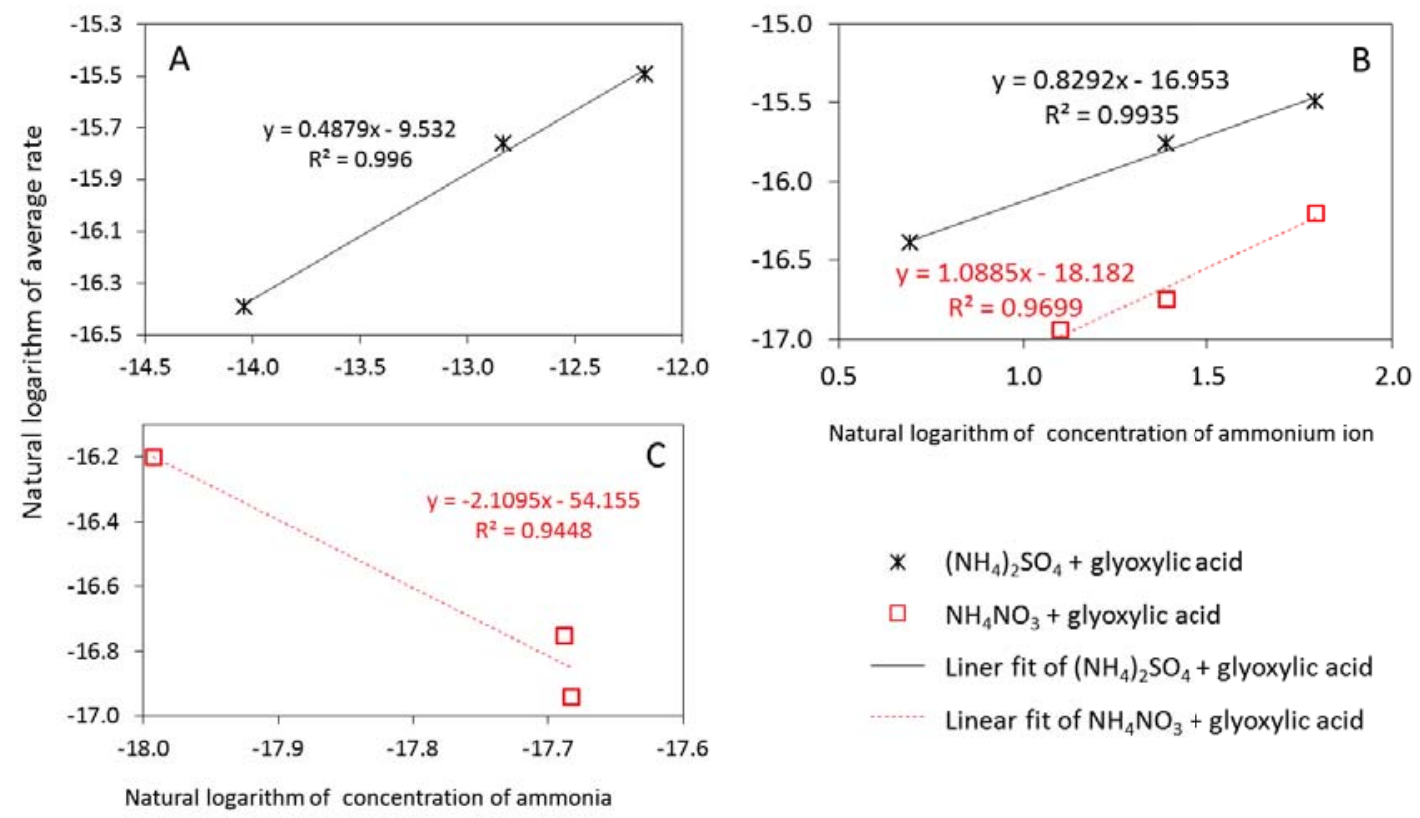

Natural logarithm of concentration of ammonium ion

* $\left(\mathrm{NH}_{4}\right)_{2} \mathrm{SO}_{4}+$ glyoxylic acid

․ $\mathrm{NH}_{4} \mathrm{NO}_{3}+$ glyoxylic acid

- Liner fit of $\left(\mathrm{NH}_{4}\right)_{2} \mathrm{SO}_{4}+$ glyoxylic acid

Linear fit of $\mathrm{NH}_{4} \mathrm{NO}_{3}+$ glyoxylic acid

Figure A.1.5: Plot of the natural logarithm of the average rates of decarboxylation vs. the natural logarithm of the concentration of free ammonia for experiment sets 1, 2, 3 (ammonium sulfate and glyoxylic acid) in the 'panel A' and 9, 10, 11 (ammonium nitrate and glyoxylic acid) in the 'panel C'. Panel B is for the comparison purpose, which is the plot of the natural logarithm of the average rate of decarboxylation vs. natural logarithm of initial concentration of ammonium ion. The linear fit of data points was made and from the optimized parameter the slope was determined to be 0.5 (Panel A) and -2.1 (Panel C) from ammonium sulfate and ammonium nitrate experiments. The slopes in panel B are equivalent with the slopes from Figure 2.3 . 


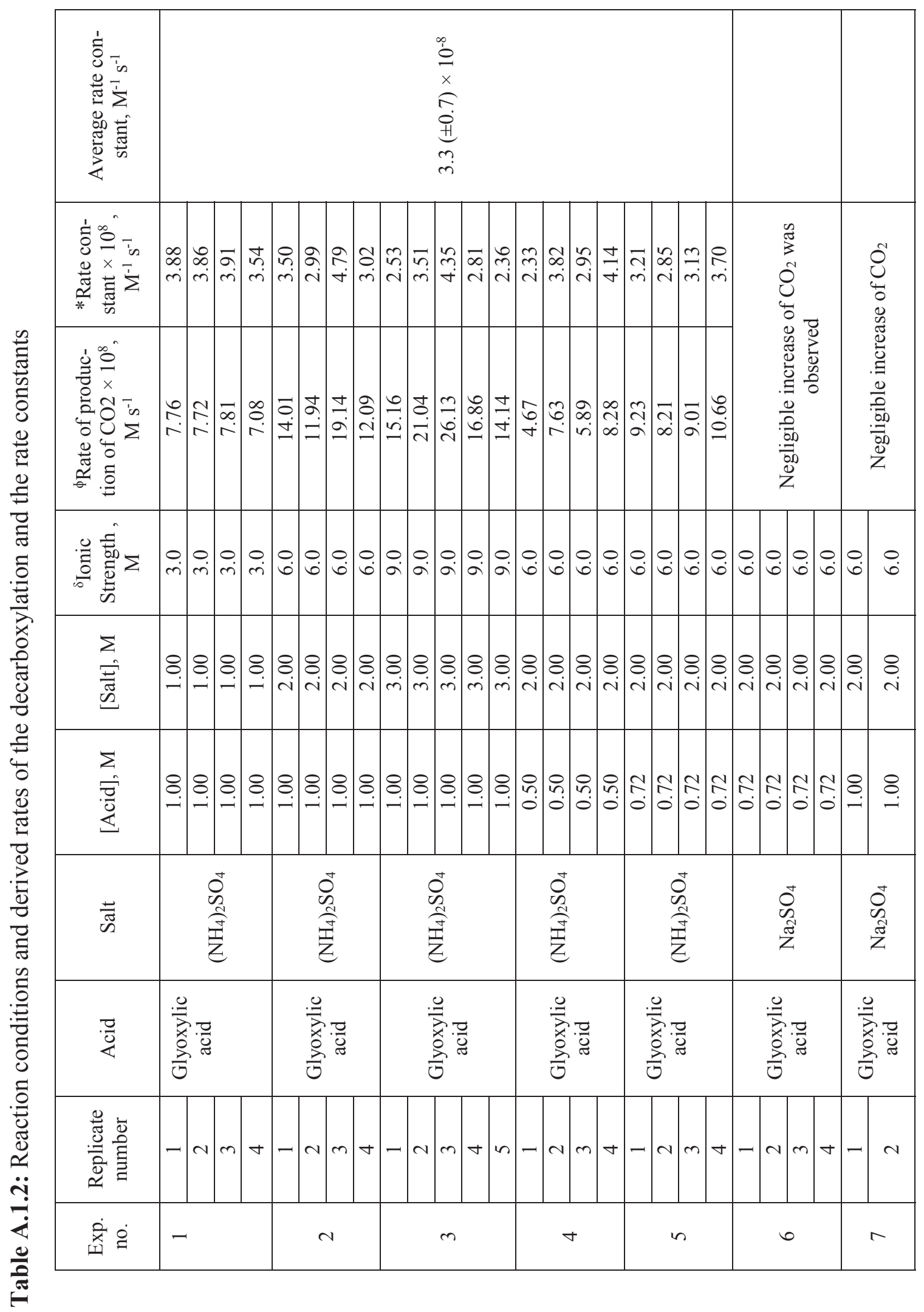




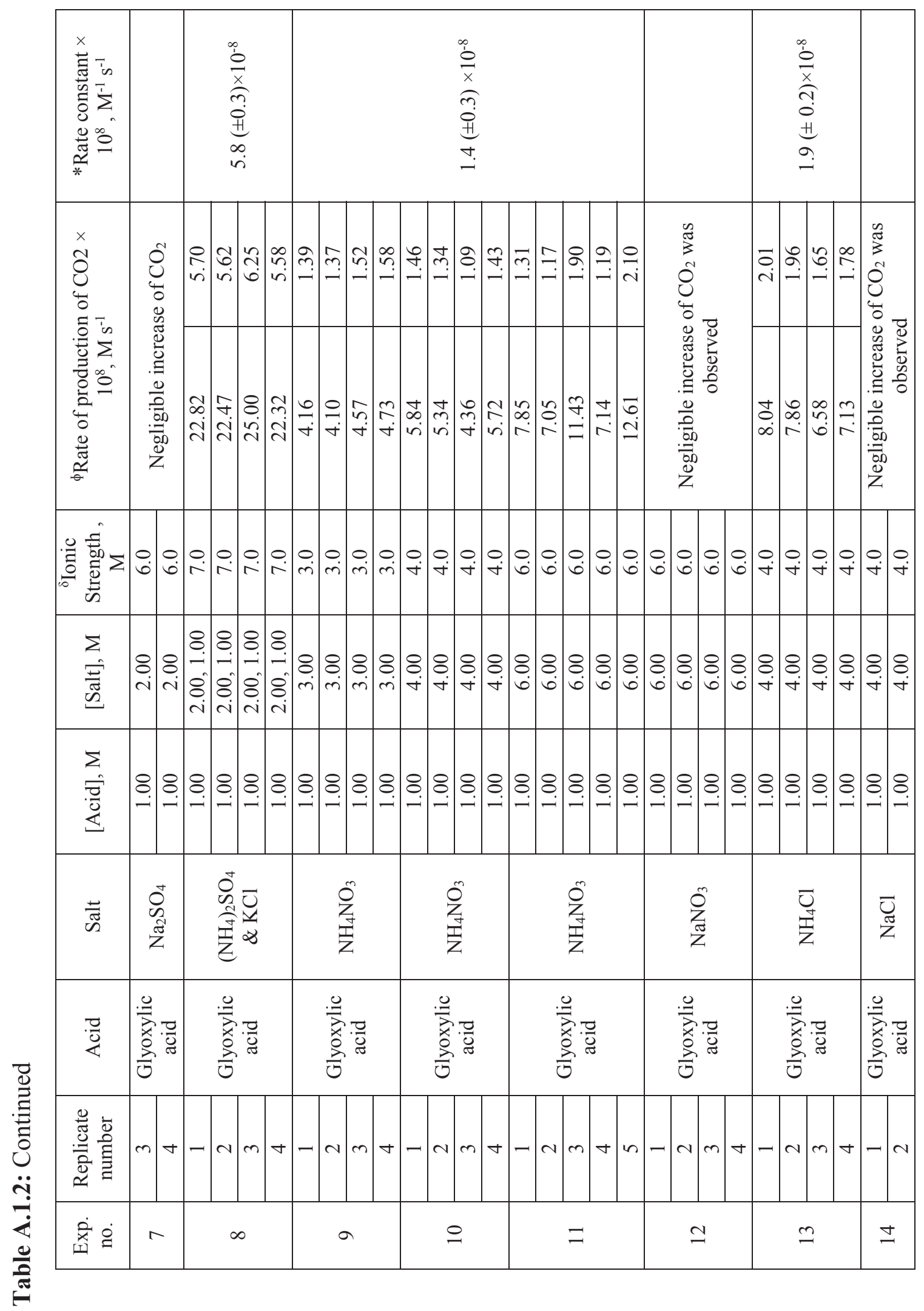




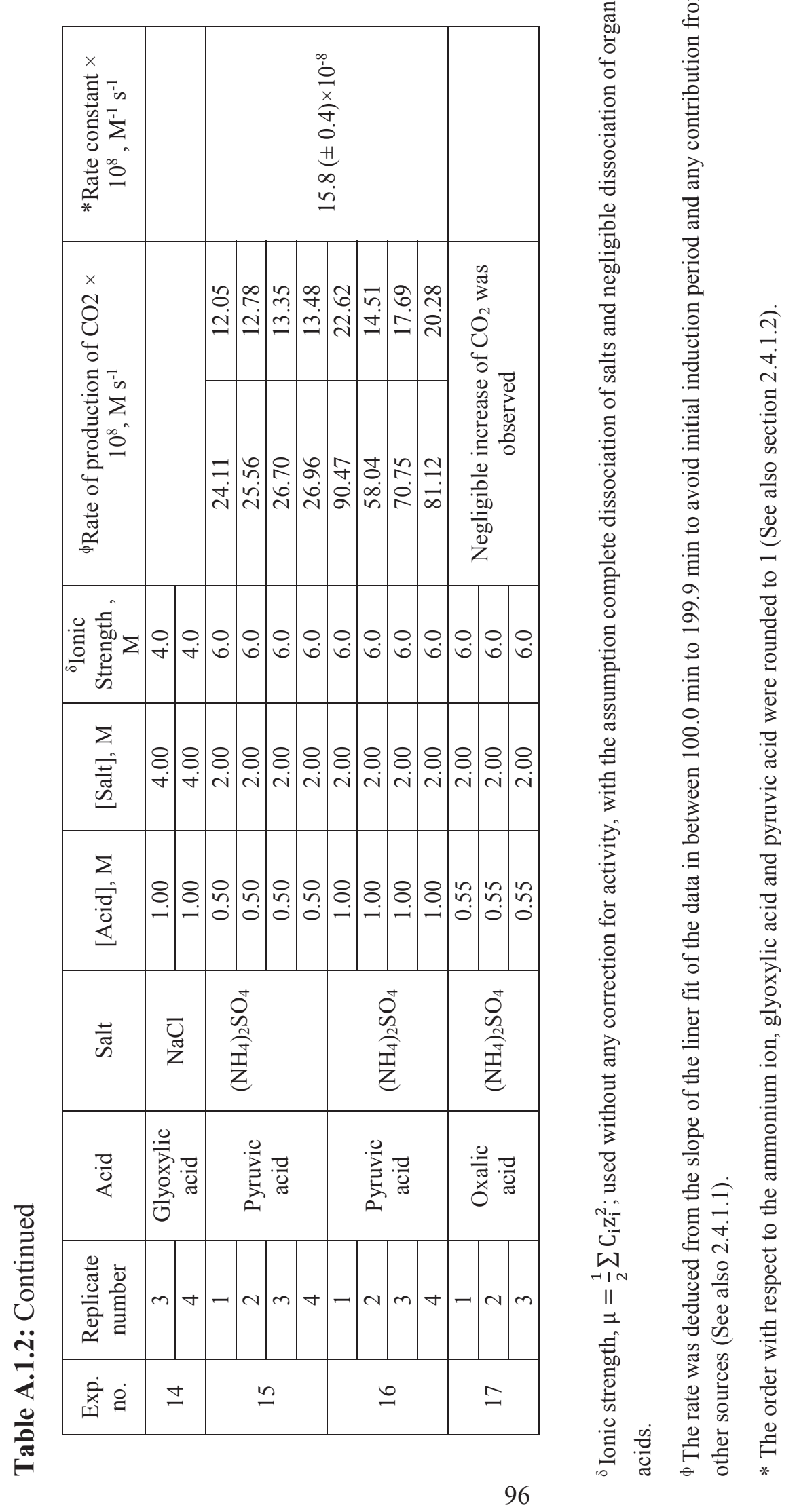




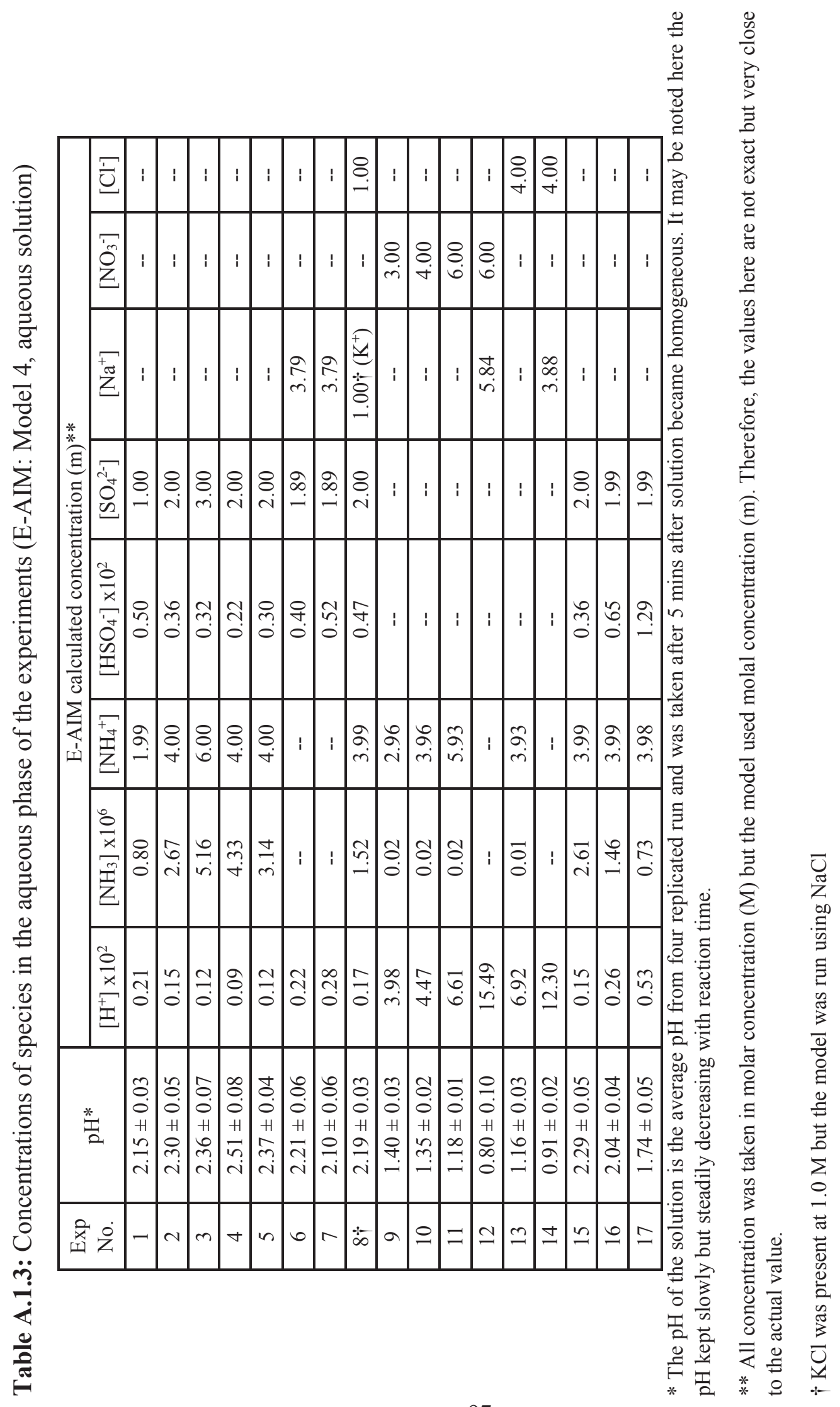




\section{A.1.5 Reaction Rates for Pyruvic Acid: OH Radical Reaction vs. Aqueous Ammo- nium Sulfate Reaction}

The lowest modeled concentration of $\mathrm{OH}$ radical is $2.9 \times 10^{-16} \mathrm{M}$ [Herrmann et al., 2010]. Considering, a concentration of ammonium ion in deliquesced aerosol particles is at least $3 \mathrm{M}$ (note, the saturated concentration of ammonium sulfate is $>4.0 \mathrm{M}$ ).

Rate constant of pyruvic acid with $\mathrm{OH}$ radical, $\mathrm{koH}=1 \times 10^{8} \mathrm{M}^{-1} \mathrm{~s}^{-1}$ [Ervens et al., 2003].

Rate constant of pyruvic acid with ammonium sulfate, $\mathrm{k}_{\mathrm{pa}+(\mathrm{NH} 4) 2 \mathrm{SO} 4}=15.8 \times 10^{-8} \mathrm{M}^{-1} \mathrm{~s}^{-1}$ [This work].

Therefore, for any given concentration of pyruvic acid, $2.9 \times 10^{-16} \mathrm{M} \mathrm{OH}$ radical concentration and $3 \mathrm{M}$ ammonium ion concentration in a deliquesced particle.

The ratio of rate of reaction between them $=\frac{\operatorname{rate}_{(\mathrm{NH} 4) 2 \mathrm{SO} 4}}{\text { rate }_{\mathrm{OH}}}$

$$
=\frac{3 \times 15.8 \times 10^{-8}}{2.9 \times 10^{-16} \times 1 \times 10^{8}}=16.3
$$




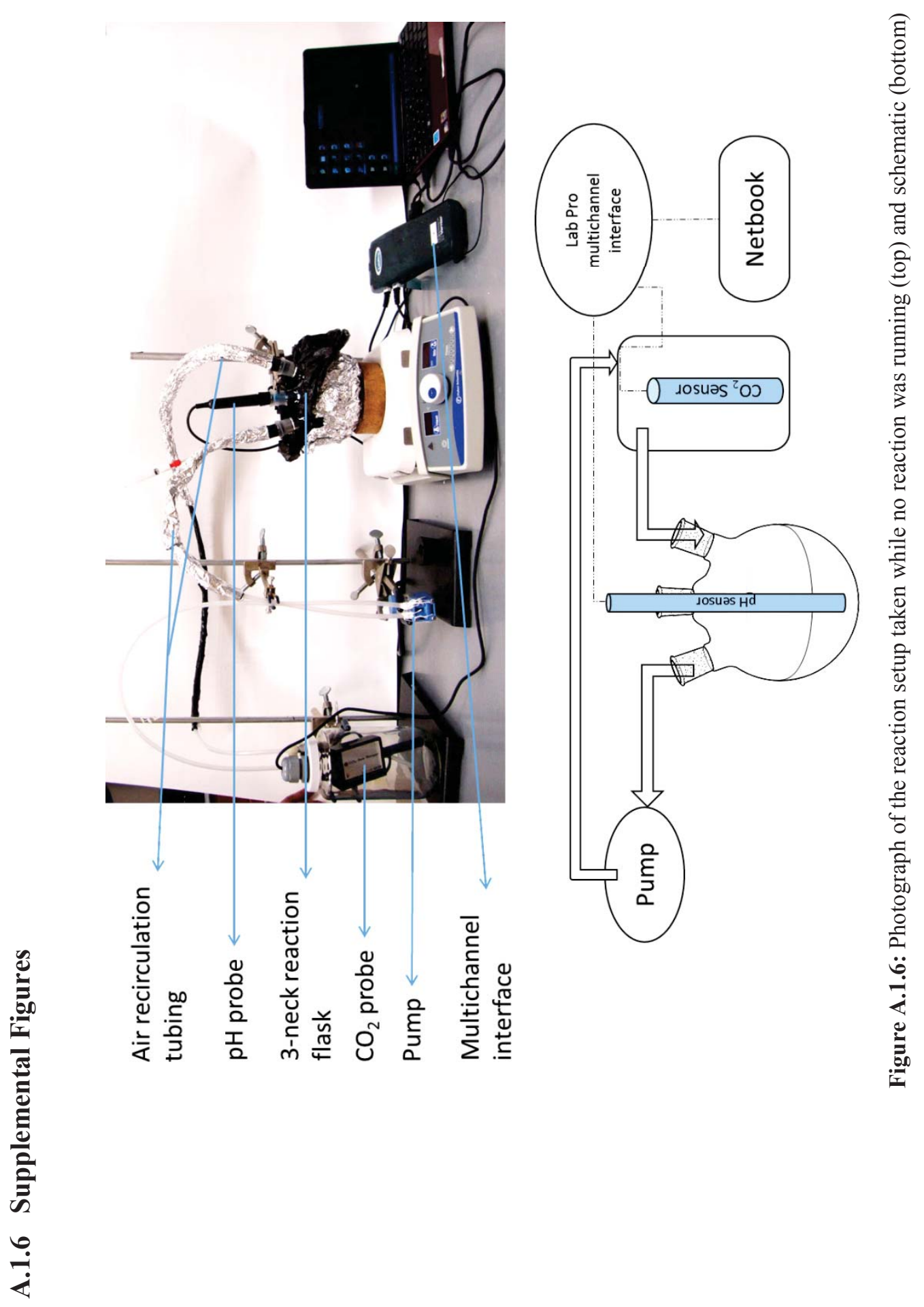




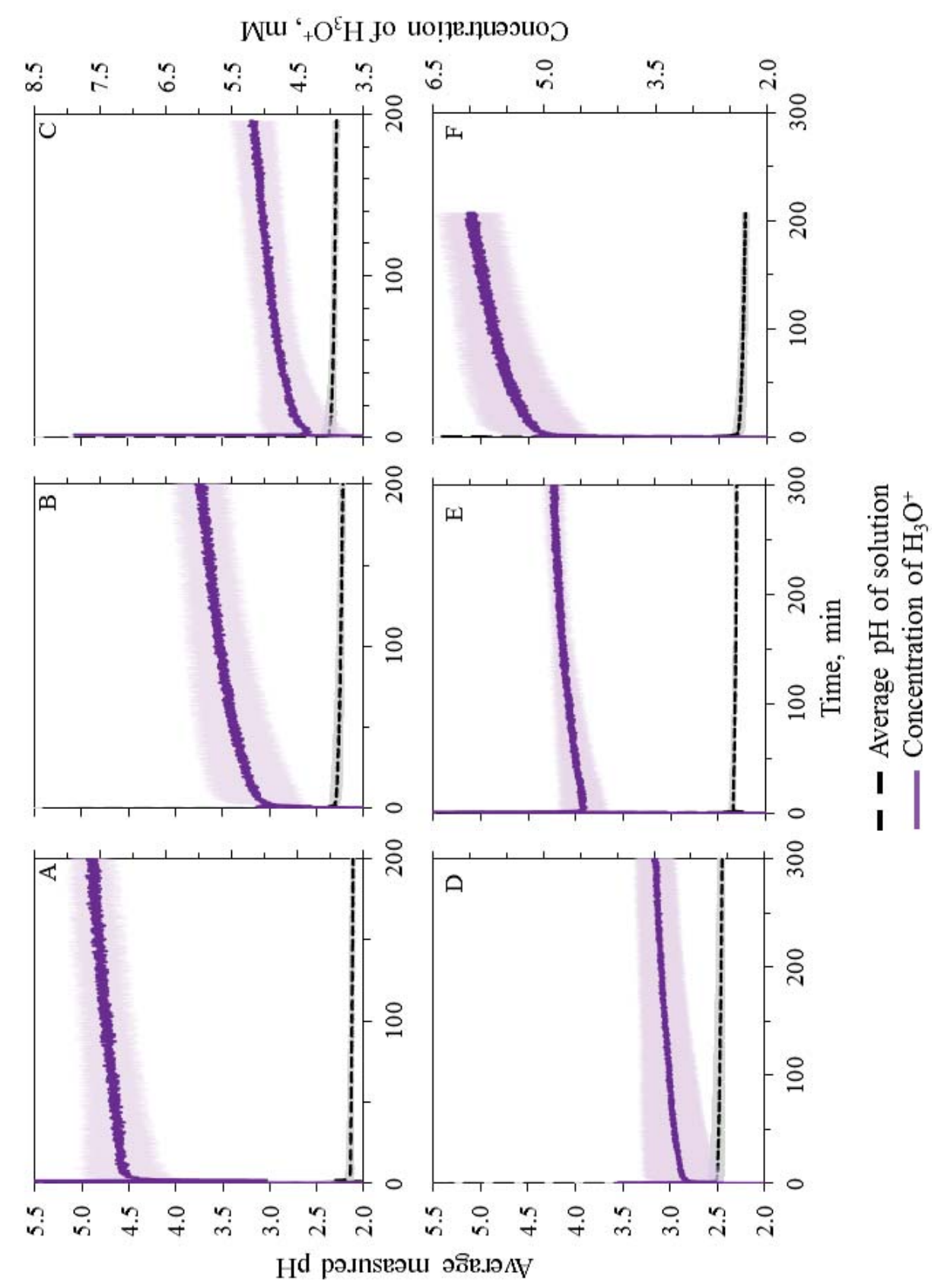

总克

先需

ชิ

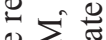

Ð

$\exists-\overline{2}$

可焉

表

능

하요.

.유 है

可可

寻立吾

흥을

更品

O 0

㟧泀

ธิ

퓽

娄

调

ठิ

¿ $\sum_{0}$

웅요

考它告

Q

泣

웅.

㐘㐫

능

造文

$\square$ की

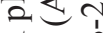

苍造

声宣王

क

导龸

苍泀

. 롱

炡

灭

웅

要曹定

\&.엉

$\ddot{0} \overline{0}$

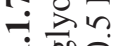

\&

० बृ

量这 


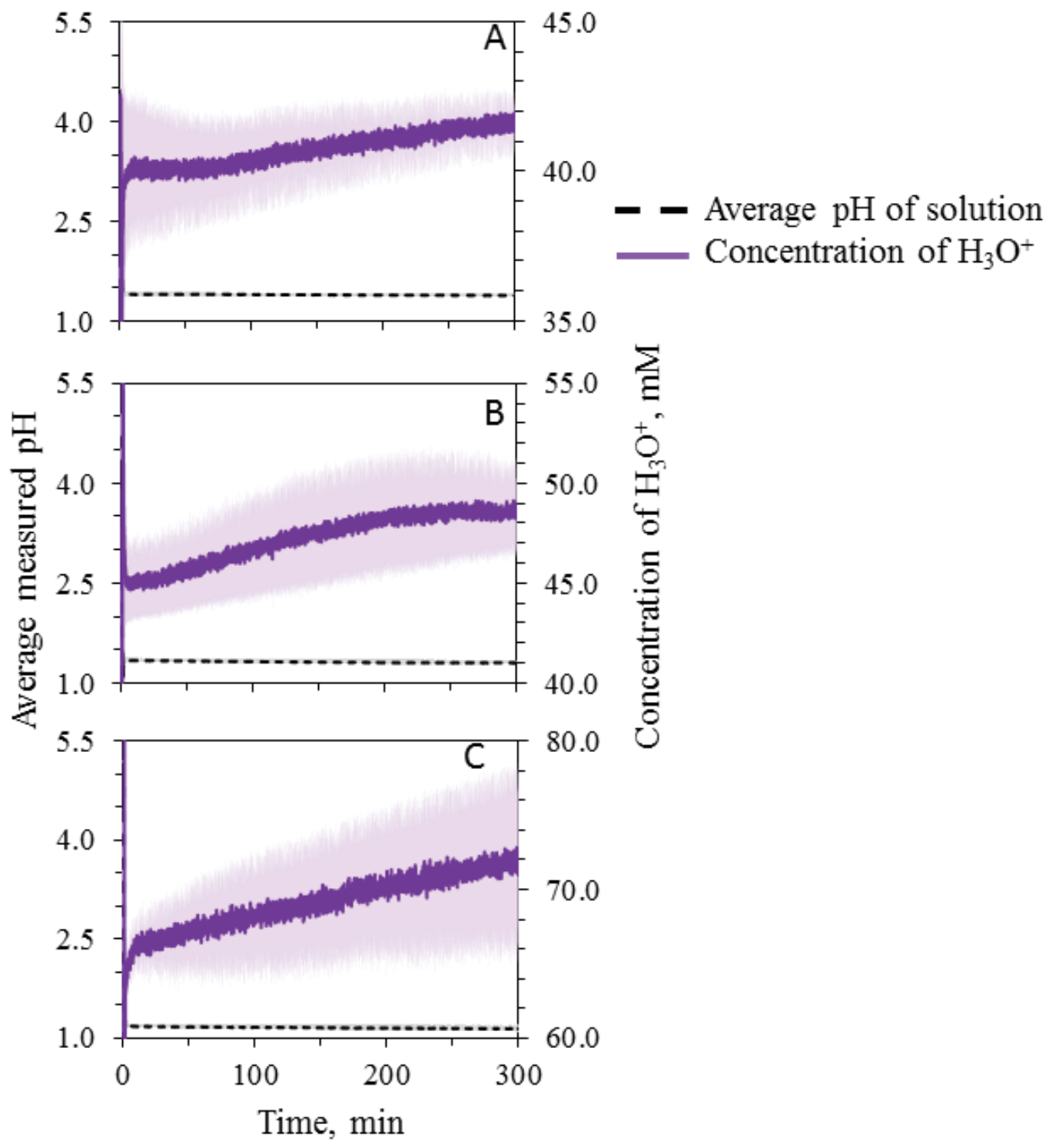

Figure A.1.8: A temporal variation of solution $\mathrm{pH}$ (dashed black line) and hydronium ion concentration (purple line) of the reaction solution between glyoxylic acid (GA) and ammonium nitrate (AN). A) AN-3.0 $\mathrm{M}+\mathrm{GA}-1.0 \mathrm{M}, \mathrm{B}) \mathrm{AN}-4.0 \mathrm{M}+\mathrm{GA}-1.0 \mathrm{M}$ and C) AN-6.0 M + GA-1.0 M. The shaded region represents the standard deviation from the replicated analyses. 


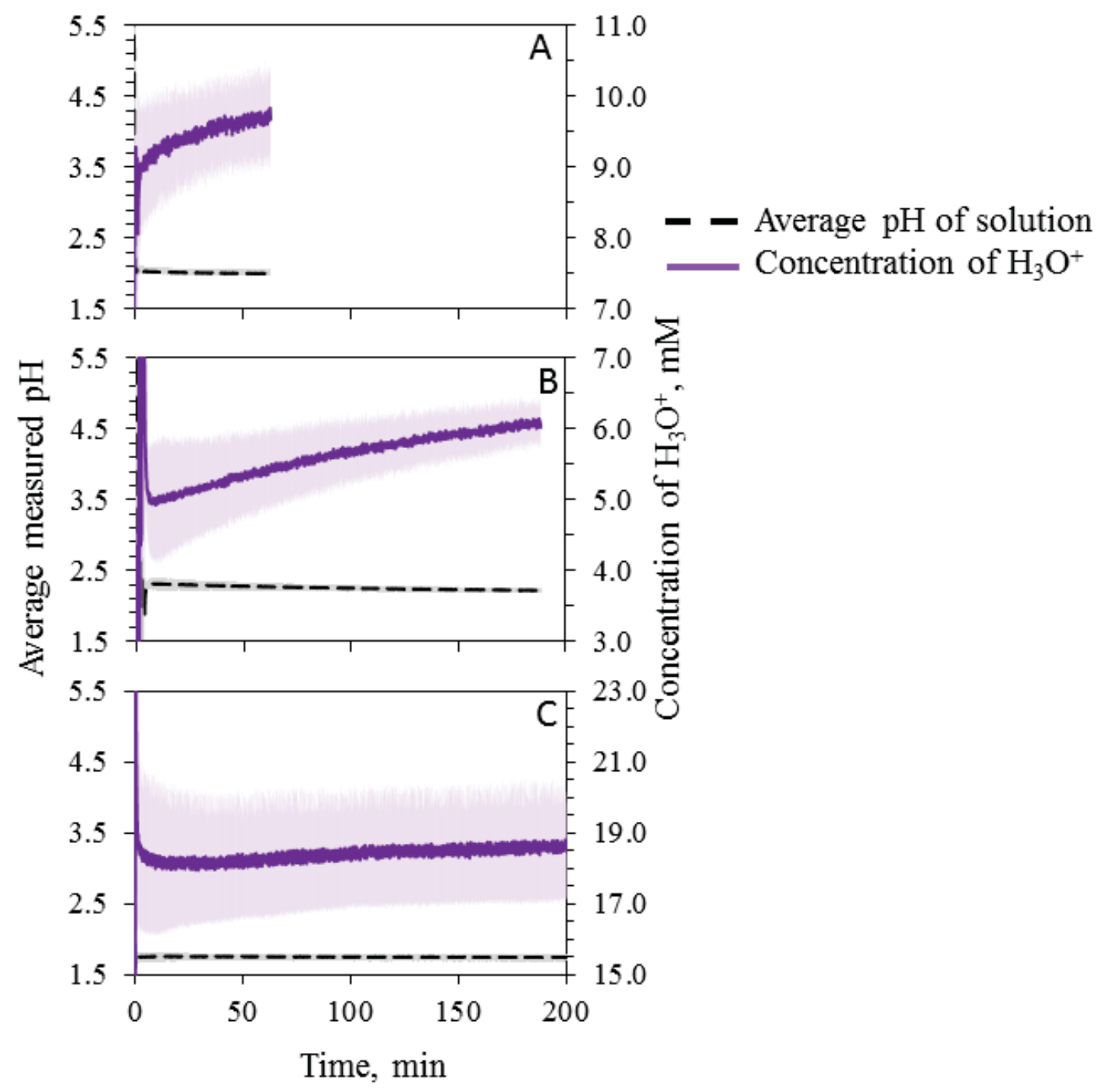

Figure A.1.9: The temporal variation of the $\mathrm{pH}$ (black dashed line) and the concentration of the hydronium ion (purple line) in the reaction solution of ammonium sulfate (AS) and other organic acids. A) Pyruvic acid $(1.0 \mathrm{M})+\mathrm{AS}(2.0 \mathrm{M}), \mathrm{B})$ pyruvic acid $(0.5 \mathrm{M})+\mathrm{AS}(2.0 \mathrm{M})$ and $\mathrm{C})$ oxalic acid $(0.6 \mathrm{M})+\mathrm{AS}(2.0 \mathrm{M})$. 


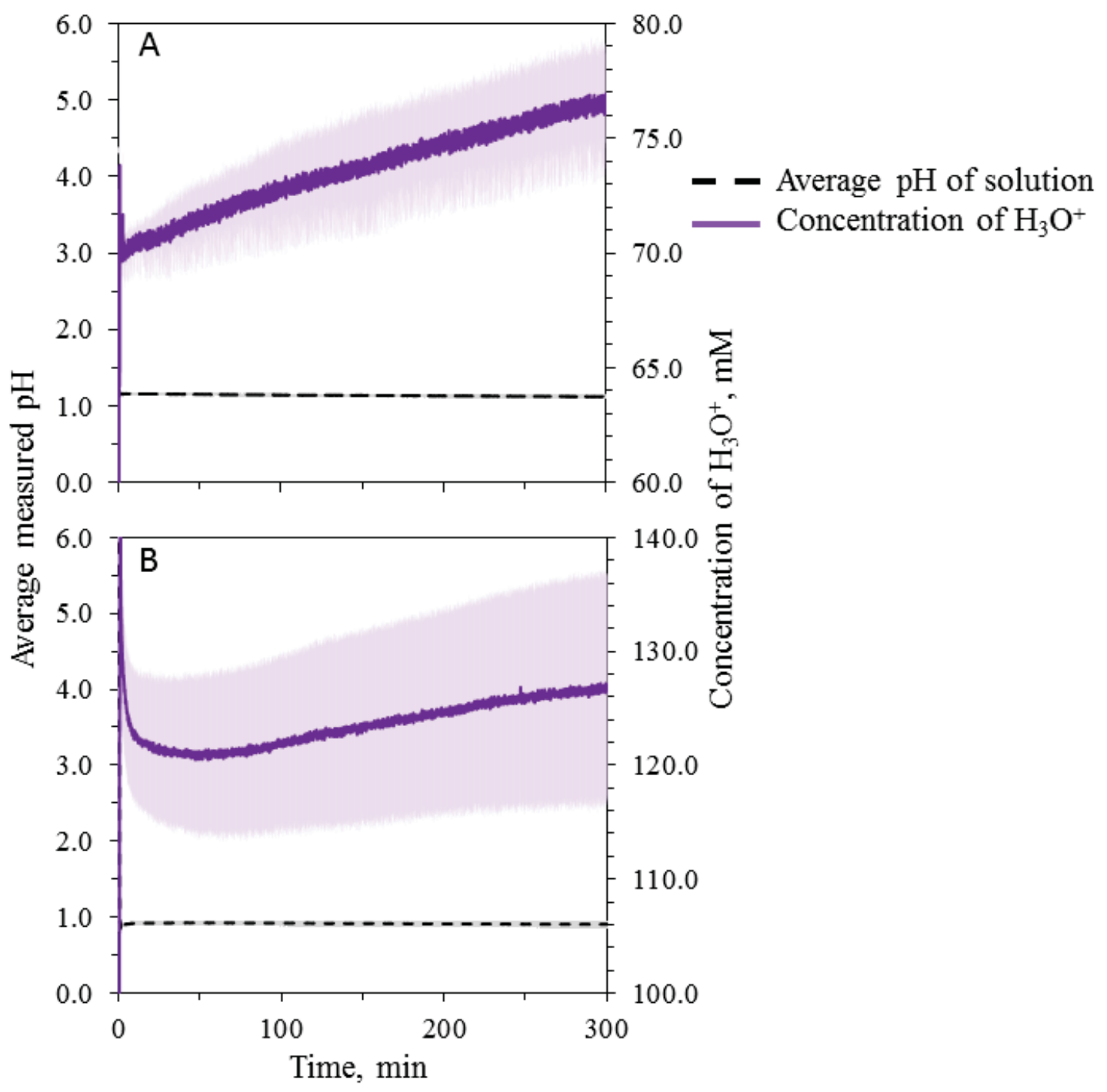

Figure A.1.10: The temporal variation of the $\mathrm{pH}$ (dashed black line) and the hydronium ion concentration (purple line) of the reaction solution of glyoxylic acid $(1.0 \mathrm{M})$ in chloride salts. A) Reactions with ammonium chloride $(4.0 \mathrm{M})$ and B) Reactions with sodium chloride $(4.0 \mathrm{M})$. The shaded region represents the standard deviation from the replicated analyses. 


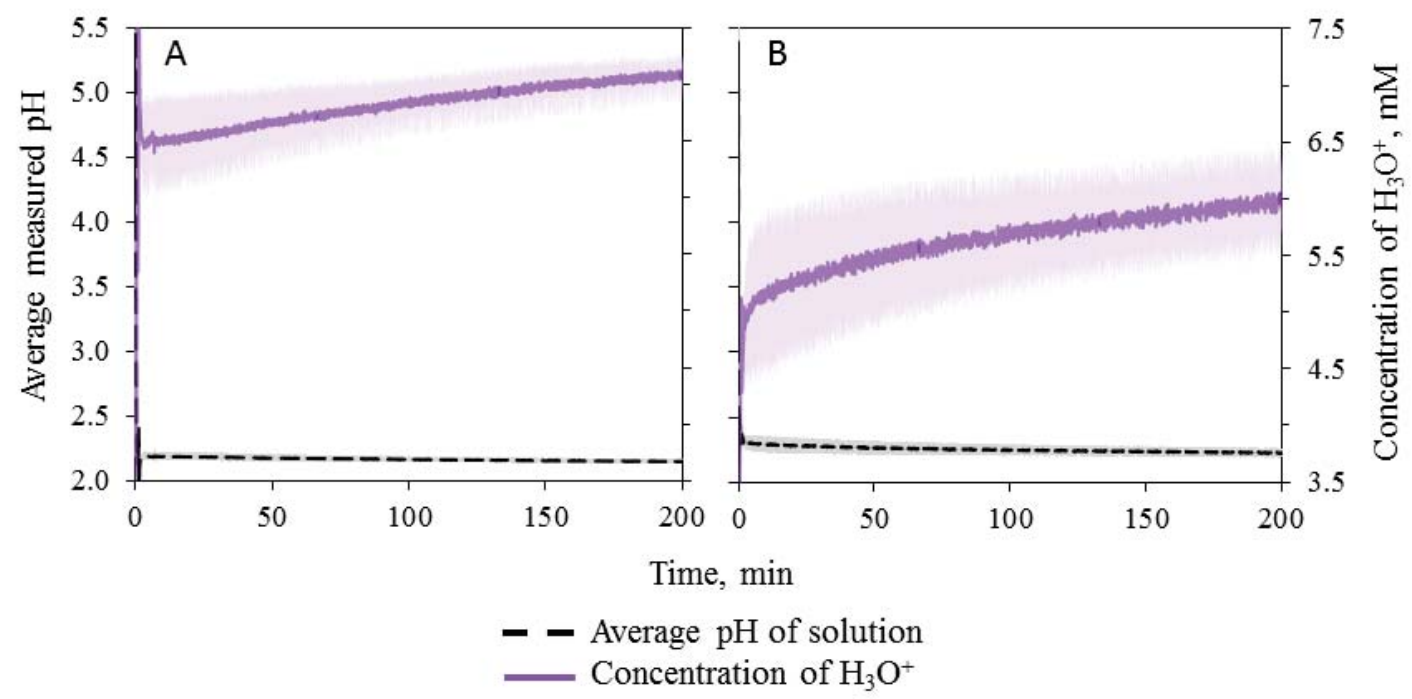

Figure A.1.11: The evolution of the $\mathrm{pH}$ (dashed black line) and the hydronium ion concentration (purple line) of the reaction solution of glyoxylic acid $(1.0 \mathrm{M})$ in ammonium sulfate $(2.0 \mathrm{M})$ at various ionic strengths, $\mu$. A) $\mu=7.0 \mathrm{M}$ and B) $\mu=6.0 \mathrm{M}$. The shaded region represents the standard deviation from the four replicated analyses. 


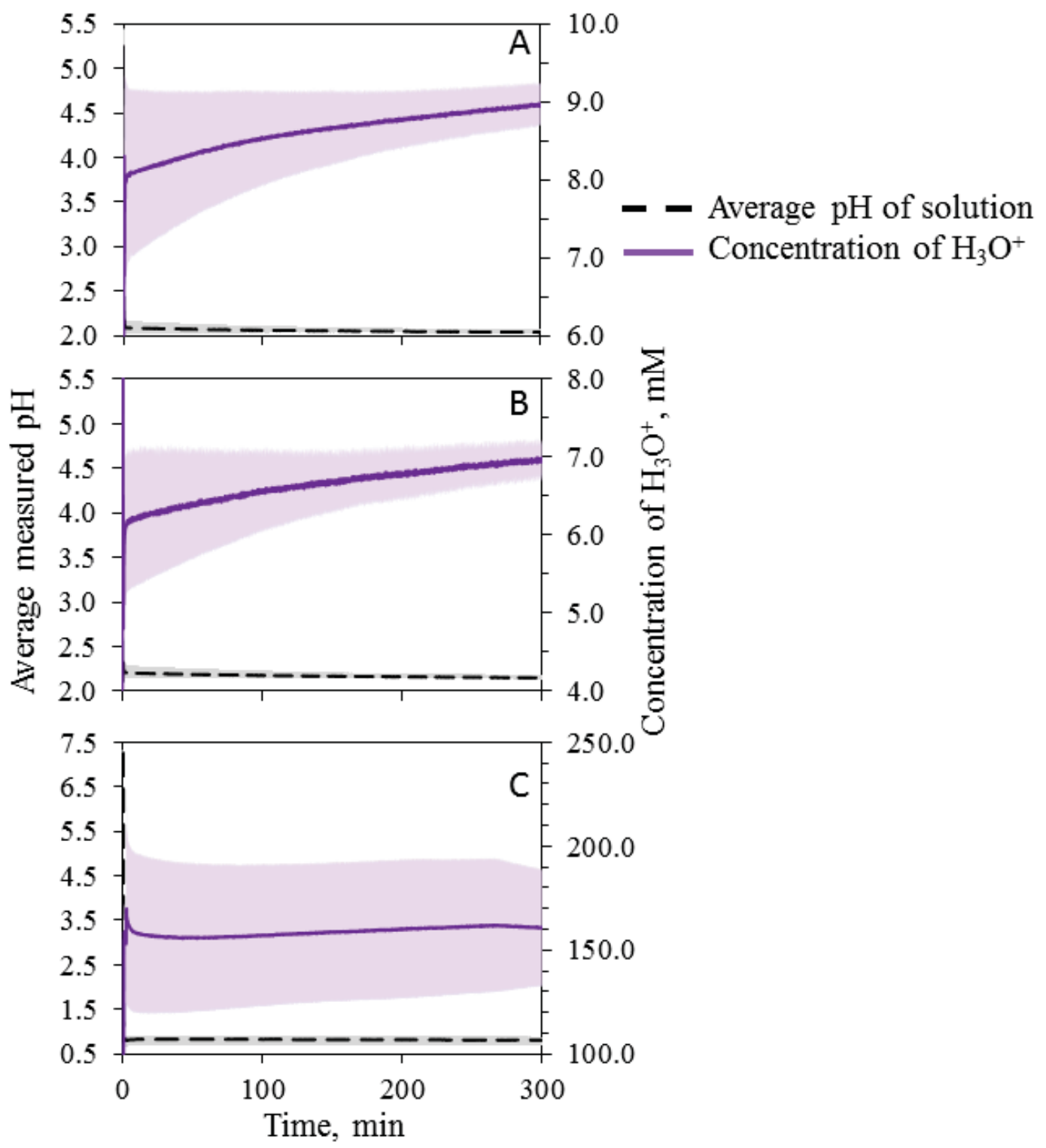

Figure A.1.12: The temporal evolution of the $\mathrm{pH}$ (dashed black line) and the hydronium ion concentration (purple line) of the control experiments with sodium salts. A) $\mathrm{Na}_{2} \mathrm{SO}_{4}(2.0 \mathrm{M})+$ glyoxylic acid $(1.0 \mathrm{M})$, B) $\mathrm{Na}_{2} \mathrm{SO}_{4}(2.0 \mathrm{M})+$ glyoxylic acid $(0.7 \mathrm{M})$ and $\left.\mathrm{C}\right) \mathrm{NaNO}_{3}(6.0 \mathrm{M})+$ glyoxylic acid $(1.0 \mathrm{M})$. . The shaded region represents the standard deviation from four replicated analyses. 


\section{A.2 Supplemental Information: Ultrahigh Resolution FT-ICR Mass Spectrometry Characterization of Aqueous SOA Formed in Dark Reac- tion of Methylglyoxal and Ammonium Sulfate}

\section{A.2.1 Supplemental Schemes}

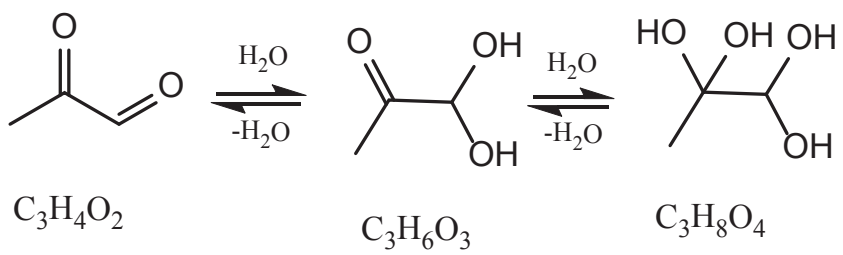

Scheme A.2.1: Hydration of methylglyoxal. In the $40 \%$ methylglyoxal solution monohydrate exists as a higher fraction.
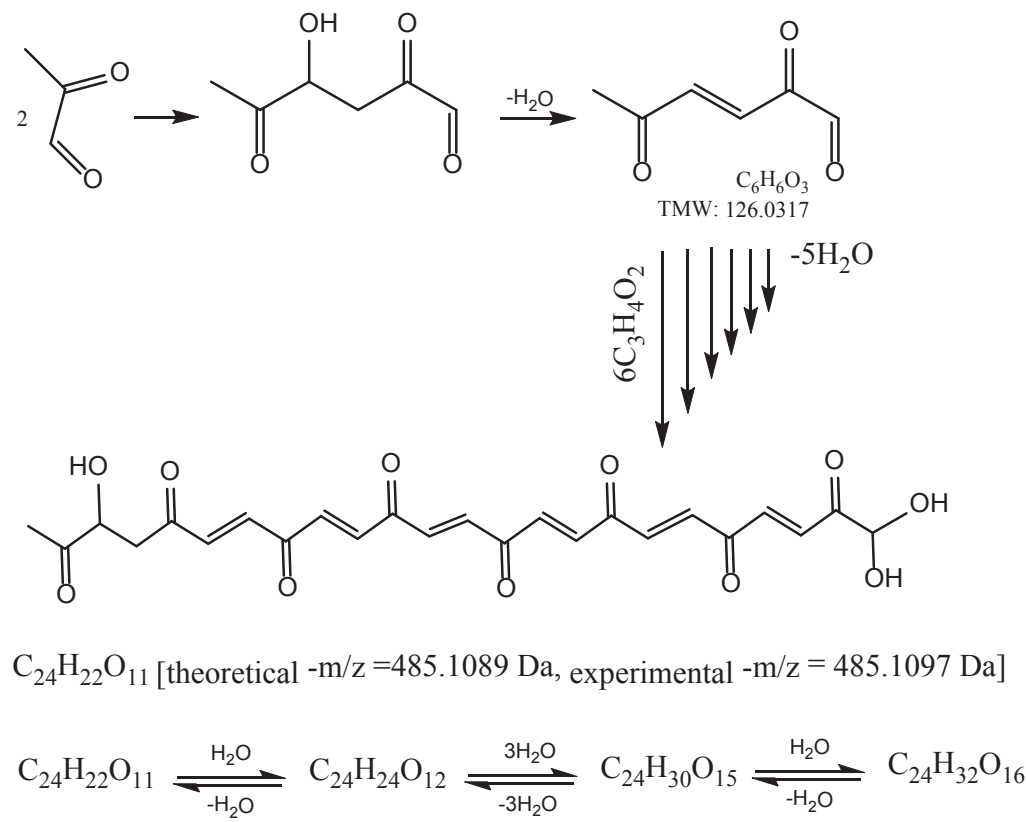

Scheme A.2.2: Possible formation of $\mathrm{C}_{24} \mathrm{H}_{22} \mathrm{O}_{11}$ and relevant hydrated compounds via aldol condensation pathway (only one structure is shown, other structures are possible). The peaks for all these $\mathrm{C}_{24}$ was detected in the ESI FT-ICR MS experiment. 


\section{A.2.2 Supplemental Table}

Table A.2.1: Summery of previous studies of methylglyoxal in aqueous phase

\begin{tabular}{|c|c|c|c|}
\hline Authors & Reaction setup & Observation & Conclusion \\
\hline $\begin{array}{c}\text { Kalberer } \\
\text { et al., } \\
2004\end{array}$ & $\begin{array}{l}\text { LDI-MS of methyl- } \\
\text { glyoxal solution }\end{array}$ & $\begin{array}{l}\text { Oligomers, mono-hydrated } \\
\text { oligomers and di hydrated } \\
\text { oligomers up to } \mathrm{m} / \mathrm{z} 723\end{array}$ & $\begin{array}{l}\text { Methylglyoxal self- } \\
\text { oligomerization could } \\
\text { contributes to SOA } \\
\text { mass }\end{array}$ \\
\hline $\begin{array}{l}\text { Loeffler } \\
\text { et al., }\end{array}$ & $\begin{array}{l}1 \mu \mathrm{L} \text { of solution (10 } \\
\text { to } 1000 \mathrm{mM} \text { ) were } \\
\text { allowed to evaporate } \\
\text { under controlled hu- } \\
\text { midity on a diamond } \\
\text { window of FT-ATR- } \\
\text { IR }\end{array}$ & $\begin{array}{l}\text { Drying increased absorp- } \\
\text { tion in the region where } \\
\mathrm{C}=\mathrm{O} \text { and } \mathrm{C}-\mathrm{O} \text { would ab- } \\
\text { sorb. Upon evaporation of } \\
\text { droplet, absorption at } \mathrm{C}=\mathrm{O} \\
\text { band increased more than } \\
\mathrm{C}-\mathrm{O} \text { in the beginning, } \\
\text { which was reversed later in } \\
\text { time. }\end{array}$ & $\begin{array}{l}\text { Upon evaporation for- } \\
\text { mation of monohy- } \\
\text { drate caused relatively } \\
\text { faster increase of ab- } \\
\text { sorption in } \mathrm{C}=\mathrm{O} \text { band. } \\
\text { Further evaporation } \\
\text { caused oligomer for- } \\
\text { mation via acetal } \\
\text { pathway. }\end{array}$ \\
\hline
\end{tabular}


Table A.2.1: Continued

\begin{tabular}{|c|c|c|c|}
\hline Authors & Reaction setup & Observation & Conclusion \\
\hline $\begin{array}{l}\text { Kroll et } \\
\text { al., } 2005\end{array}$ & $\begin{array}{l}\text { Methylglyoxal uptake to } \\
\left(\mathrm{NH}_{4}\right)_{2} \mathrm{SO}_{4} \text { or acidified } \\
\left(\mathrm{NH}_{4}\right)_{2} \mathrm{SO}_{4} \text { poly-dispersed } \\
\text { particle in a static environ- } \\
\text { mental chamber. Uptake } \\
\text { was monitored using DMA, } \\
\text { CPC and AMS. }\end{array}$ & $\begin{array}{l}\text { No particle or } \\
\text { organic growth } \\
\text { was observed }\end{array}$ & $\begin{array}{l}\text { Methylglyoxal is unlikely } \\
\text { be heterogeneously } \\
\text { uptake on }\left(\mathrm{NH}_{4}\right)_{2} \mathrm{SO}_{4} \\
\text { particle. }\end{array}$ \\
\hline $\begin{array}{c}\text { J Zhao } \\
\text { et al., } \\
2006\end{array}$ & $\begin{array}{l}\text { Uptake of methylglyoxal on } \\
\text { acidic seed particle (55- } \\
85 \% \mathrm{H}_{2} \mathrm{SO}_{4} \text { ) in flow tube. } \\
\text { Uptake was monitored us- } \\
\text { ing ID-CIMS. }\end{array}$ & $\begin{array}{l}\text { Uptake of } \\
\text { methylglyoxal } \\
\text { decrease upon } \\
\text { the increment of } \\
\text { concentration of } \\
\mathrm{H}_{2} \mathrm{SO}_{4} \text {. }\end{array}$ & $\begin{array}{l}\text { Acidity was unlikely cat- } \\
\text { alyzing the uptake. Effec- } \\
\text { tive Henry's law constant } \\
\text { was determined at differ- } \\
\text { ent temperature for vari- } \\
\text { ous acid levels. } \\
\text { Hydration and acetal re- } \\
\text { action leading to di-ox- } \\
\text { olane formation facili- } \\
\text { tated the uptake }\end{array}$ \\
\hline
\end{tabular}


Table A.2.1: Continued

\begin{tabular}{|c|c|c|c|}
\hline Authors & Reaction setup & Observation & \\
\hline Altieri et & $\begin{array}{l}\text { Photochemical oxidation } \\
\text { (UV) of methylglyoxal (2 } \\
\mathrm{mM}) \text { by } \mathrm{H}_{2} \mathrm{O}_{2} \text { at } \mathrm{pH} \text { 4.2- } \\
4.5 \text { then mass } \\
\text { spectrometry were done } \\
\text { using low resolution ESI- } \\
\text { MS and ultra high } \\
\text { resolution ESI-FTICR- } \\
\text { MS }\end{array}$ & $\begin{array}{l}\text { High abundance of Ox- } \\
\text { alic acid. Low } \\
\text { abundance of pyruvic } \\
\text { acid, glyoxylic acid. } \\
\text { Increment of peak } \\
\text { abundance at higher mo- } \\
\text { lecular peak up to } \sim 69 \\
\text { mins and gradual de- } \\
\text { crease afterward. }\end{array}$ & $\begin{array}{l}\text { Production of oxalic } \\
\text { acid by photooxidation } \\
\text { reaction of methylgly- } \\
\text { oxal. Oligomers } \\
\text { formed } \\
\text { esterification of or- } \\
\text { ganic acids having reg- } \\
\text { ular intervals } \mathrm{C}_{3} \mathrm{H}_{4} \mathrm{O}_{2} \text {. }\end{array}$ \\
\hline al., 2010 & $\begin{array}{l}\text { Methylglyoxal (30-3000 } \\
\mu \mathrm{M}) \text { photochemical } \\
\text { oxidation by } \mathrm{H}_{2} \mathrm{O}_{2} \text { and } \\
\text { UV-light in presence or } \\
\text { absence } \mathrm{H}_{2} \mathrm{SO}_{4} \text { then he } \\
\text { samples were introduced } \\
\text { into IC-ESI-MS. Based on } \\
\text { relative ion abundance at } \\
\text { different time a model was } \\
\text { constructed ad tested. }\end{array}$ & $\begin{array}{l}\text { Rapid decrease of } \\
(+) \mathrm{m} / \mathrm{z} \\
\text { be } 131 \text { (claimed to } \\
\text { methylglyoxal!?) and } \\
\text { matched with model } \\
\text { prediction. Formations } \\
\text { of pyruvic acid, } \\
\text { glyoxylic acid, oxalic } \\
\text { acid, mesoxalic acid } \\
\text { were observed. }\end{array}$ & $\begin{array}{l}\text { Model predicted con- } \\
\text { centration in a close } \\
\text { manner at lower con- } \\
\text { centration } \\
\text { experiments. However, } \\
\text { at higher concentration } \\
\text { experiment indicted } \\
\text { the model lacks other } \\
\text { unknown chemical } \\
\text { pathways. }\end{array}$ \\
\hline
\end{tabular}


Table A.2.1: Continued

\begin{tabular}{|c|c|c|c|}
\hline Authors & Reaction setup & Observation & Conclusion \\
\hline Haan et & $\begin{array}{l}\text { 1) Methylglyoxal solu- } \\
\text { tion was nebulized } \\
\text { pneumatically or ultra- } \\
\text { sonically and then dried } \\
\text { at variable rate and then } \\
\text { HR-ToF-AMS was used } \\
\text { to study the organic con- } \\
\text { tent of the aerosol. } 2 \text { ) } \\
\text { Methylglyoxal solution } \\
\text { dried at ambient condi- } \\
\text { tion and then upon redis- } \\
\text { solving in water applied } \\
\text { to ESI source to get a } \\
\text { fragment free mass } \\
\text { methylglyoxal in } \mathrm{D}_{2} \mathrm{O}\end{array}$ & $\begin{array}{l}\text { 1) Several fragment } \\
\text { species was observed } \\
\text { and assigned formula } \\
\text { below } \mathrm{m} / \mathrm{z} 200 \text { from } \\
\text { HR-ToF-AMS data } \\
\text { 2) Species as high as } \\
\text { m/z } 585 \text { was ob- } \\
\text { served along with } \\
\text { regular interval of } \\
\text { peak separation, } \\
\Delta \mathrm{m} / \mathrm{z} 18,56,72 \text { and } \\
\text { 128. } \\
\text { 3)Peaks in NMR } \\
\text { spectra similar to hy- } \\
\text { ruvic acid }\end{array}$ & $\begin{array}{l}\text { Upon evaporation al- } \\
\text { dol condensation path- } \\
\text { way was concluded to } \\
\text { be the dominant path- } \\
\text { ways catalyzed by py- } \\
\text { ruvic acid. Where py- } \\
\text { ruvic acid formed via } \\
\text { disproportion reaction } \\
\text { of methylglyoxal. For- } \\
\text { mation of higher mo- } \\
\text { lecular weight species } \\
\text { involved reaction of } \\
\text { having carbon atoms } \\
\text { and hydroxyacetone } \\
\text { hothylglyoxal }\end{array}$ \\
\hline
\end{tabular}


Table A.2.1: Continued

\begin{tabular}{|c|c|c|c|}
\hline Authors & Reaction setup & Observation & Conclusion \\
\hline $\begin{array}{l}\text { et al., } \\
2010\end{array}$ & $\begin{array}{l}\text { Methylglyoxal }(0-2.0 \mathrm{M}) \\
\text { were allowed to react in- } \\
\text { dividually with } \\
\left(\mathrm{NH}_{4}\right)_{2} \mathrm{SO}_{4} \text {, } \mathrm{NaCl} \text {, } \\
\mathrm{Na}_{2} \mathrm{SO}_{4} \text { and } \mathrm{NH}_{4} \mathrm{NO}_{3} \text { in } \\
\text { acidic condition (pH=0- } \\
5 \text { ). UV-Vis spectra were } \\
\text { collected at different } \\
\text { time. Mass spectra of } \\
\text { products were collected } \\
\text { using Aerosol-CIMS. } \\
\text { Surface tensions of the so- } \\
\text { lutions were measured. } \\
\text { of absorption of light by } \\
\text { products were performed. }\end{array}$ & $\begin{array}{l}\text { UV-Vis absorption } \\
\text { by products increased } \\
\text { with time most in- } \\
\text { tensely with } \\
\left(\mathrm{NH}_{4}\right)_{2} \mathrm{SO}_{4} \text {. For- } \\
\text { mations of high mo- } \\
\text { lecular weight spe- } \\
\text { cies were observed. } \\
\text { Organonitrogen and } \\
\text { organosulfate species } \\
\text { thought to be formed } \\
\text { as well. Surface ten- } \\
\text { sion of the solution } \\
\text { was decreased upon } \\
\text { glyoxal. }\end{array}$ & $\begin{array}{l}\text { Methylglyoxal can } \\
\text { contribute to the } \\
\text { modified absorptive } \\
\text { organic mass in the } \\
\text { aqueous phase via al- } \\
\text { dol addition and aldol } \\
\text { condensation reac- } \\
\text { tion. }\end{array}$ \\
\hline
\end{tabular}


Table A.2.1: Continued

\begin{tabular}{|c|c|c|c|}
\hline Authors & Reaction setup & Observation & Conclusion \\
\hline $\begin{array}{l}\text { Yasmeen } \\
\text { et al., } \\
2010\end{array}$ & $\begin{array}{l}\text { Methylglyoxal (1 mM) } \\
\text { and }\left(\mathrm{NH}_{4}\right)_{2} \mathrm{SO}_{4}\left(10^{-4} \text { to }\right. \\
\left.10^{-5} \mathrm{M}\right) \text { was allowed to } \\
\text { react at the dark-acidic } \\
\text { condition ( } \mathrm{pH}=3-5) \text { at } \\
15{ }^{0} \mathrm{C} \text { at variable ionic } \\
\text { strength. At different } \\
\text { time interval aliquot } \\
\text { sample were taken and } \\
\text { diluted with methanol } \\
\text { up to twice of taken vol- } \\
\text { ume. Then mass spectra } \\
\text { and tandem mass spec- } \\
\text { tra was taken using an q- } \\
\text { ion trap ESI MS. }\end{array}$ & $\begin{array}{l}\text { Species were ob- } \\
\text { served to be between } \\
\mathrm{m} / \mathrm{z} 200 \text { and } \mathrm{m} / \mathrm{z} 800 \\
\text { having multiple pat- } \\
\text { tern of mass interval } \\
(\Delta \mathrm{m} / \mathrm{z}=12,14,16 \text {, } \\
72) \text { Tandem MS ex- } \\
\text { periment showed } \\
\text { losses of one or more } \\
\mathrm{H}_{2} \mathrm{O} \text {, one or more } \\
\text { methanol and } 72 \text { Da } \\
\text { mass losses. }\end{array}$ & $\begin{array}{l}\text { Higher } \mathrm{pH} \text { (4-5) fa- } \\
\text { vored aldol reactions } \\
\text { over hydration/acetal } \\
\text { pathways. Whereas } \mathrm{pH} \\
\text { below } 3.5 \text { the scenario } \\
\text { was reversed. }\end{array}$ \\
\hline
\end{tabular}




\section{A.2.3 Supplemental Figures}

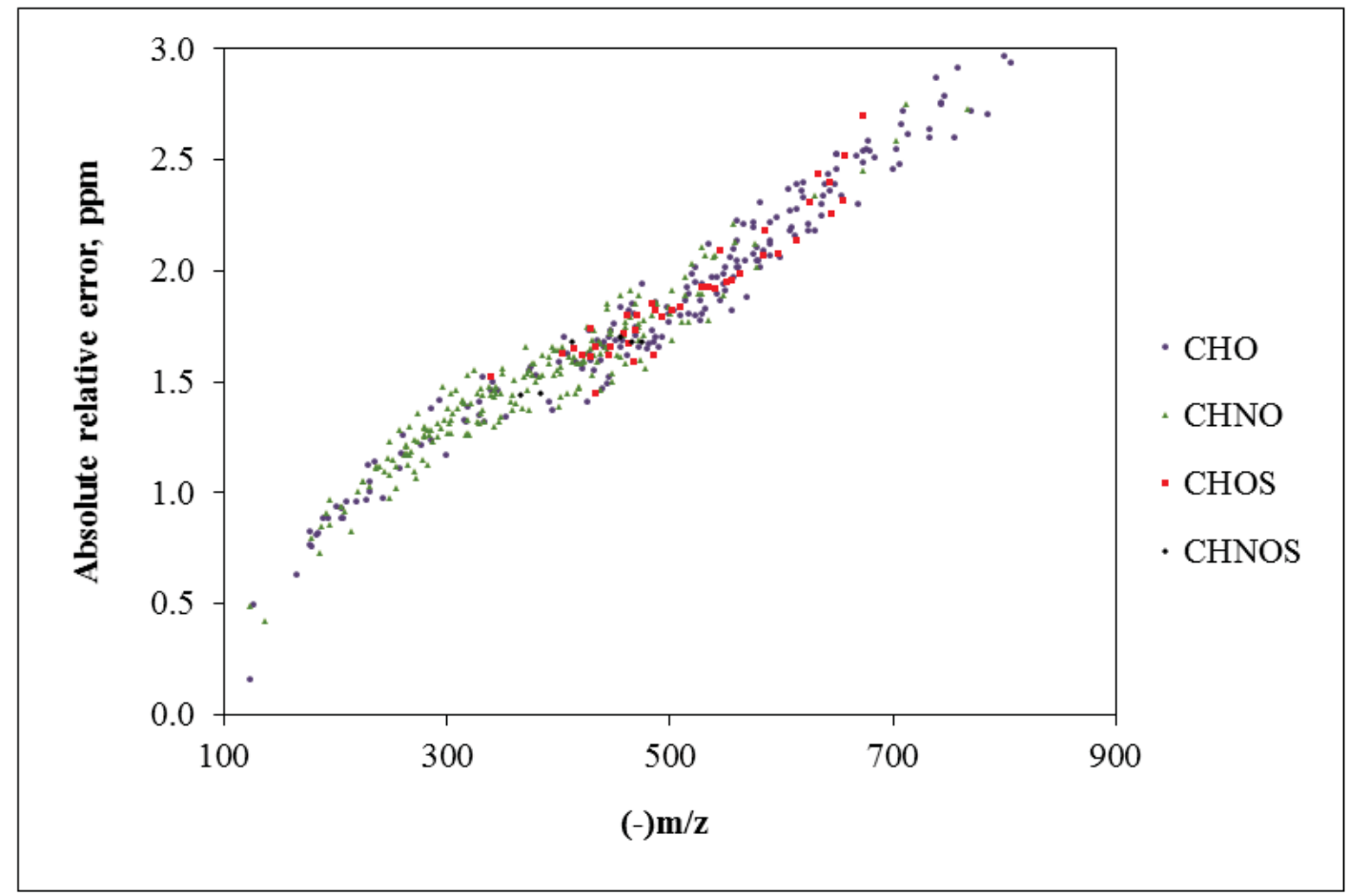

Figure A.2.1: Variation of the absolute relative error with $\mathrm{m} / \mathrm{z}$. Absolute relative error increases with the increment of $\mathrm{m} / \mathrm{z}$ but was less than $3 \mathrm{ppm}$. Classes of compounds are color-coded. 


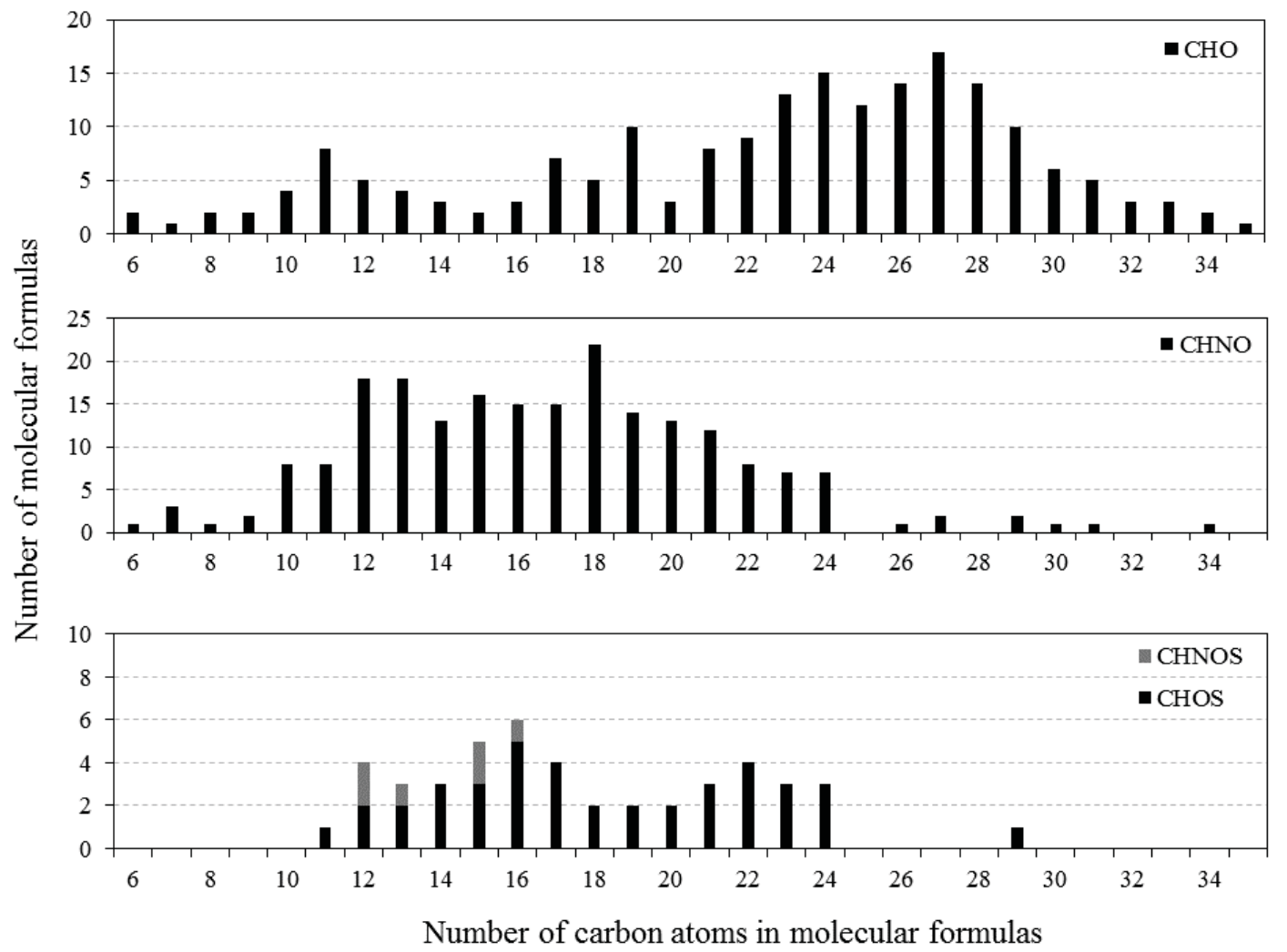

Figure A.2.2: Frequency of molecular formulas containing various numbers of carbon atoms. (Top) CHO species have higher frequencies at higher numbers of carbon atoms. (Middle) CHNO species have higher frequencies at lower numbers of carbon atoms. (Bottom) Sulfur containing species occur at the lower numbers of carbon atoms. Note that the scale on the vertical axis varies with species. 

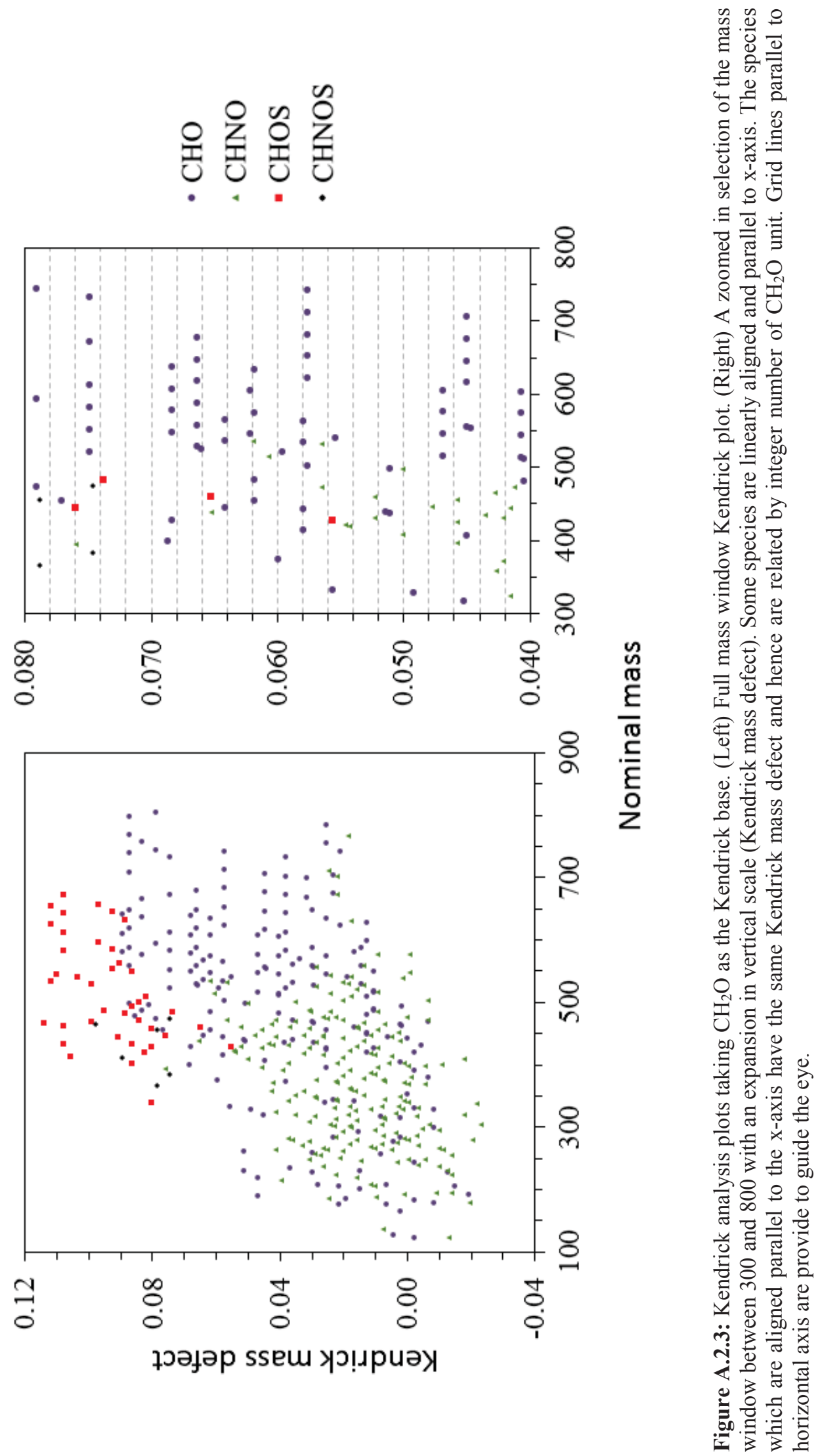


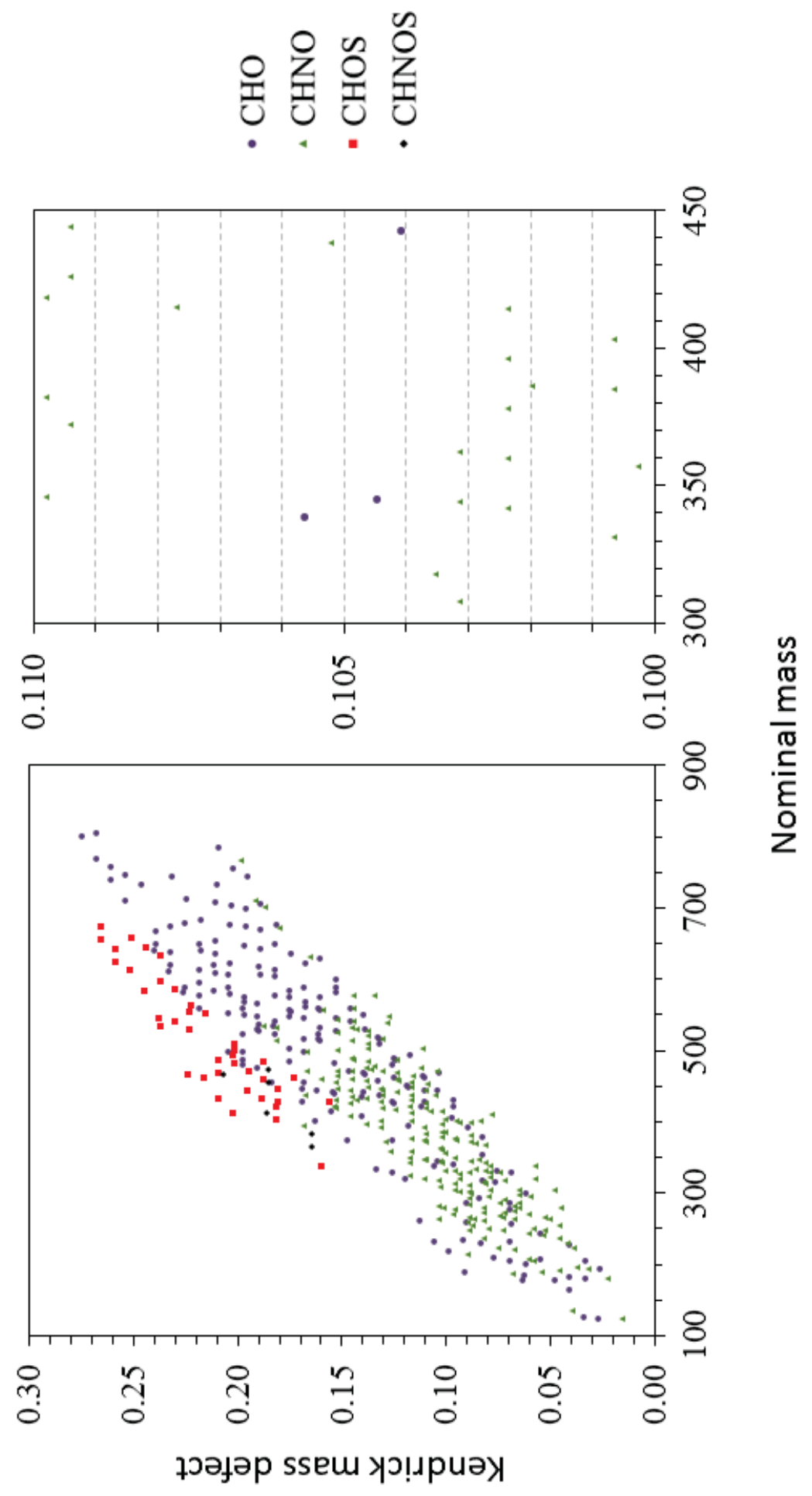



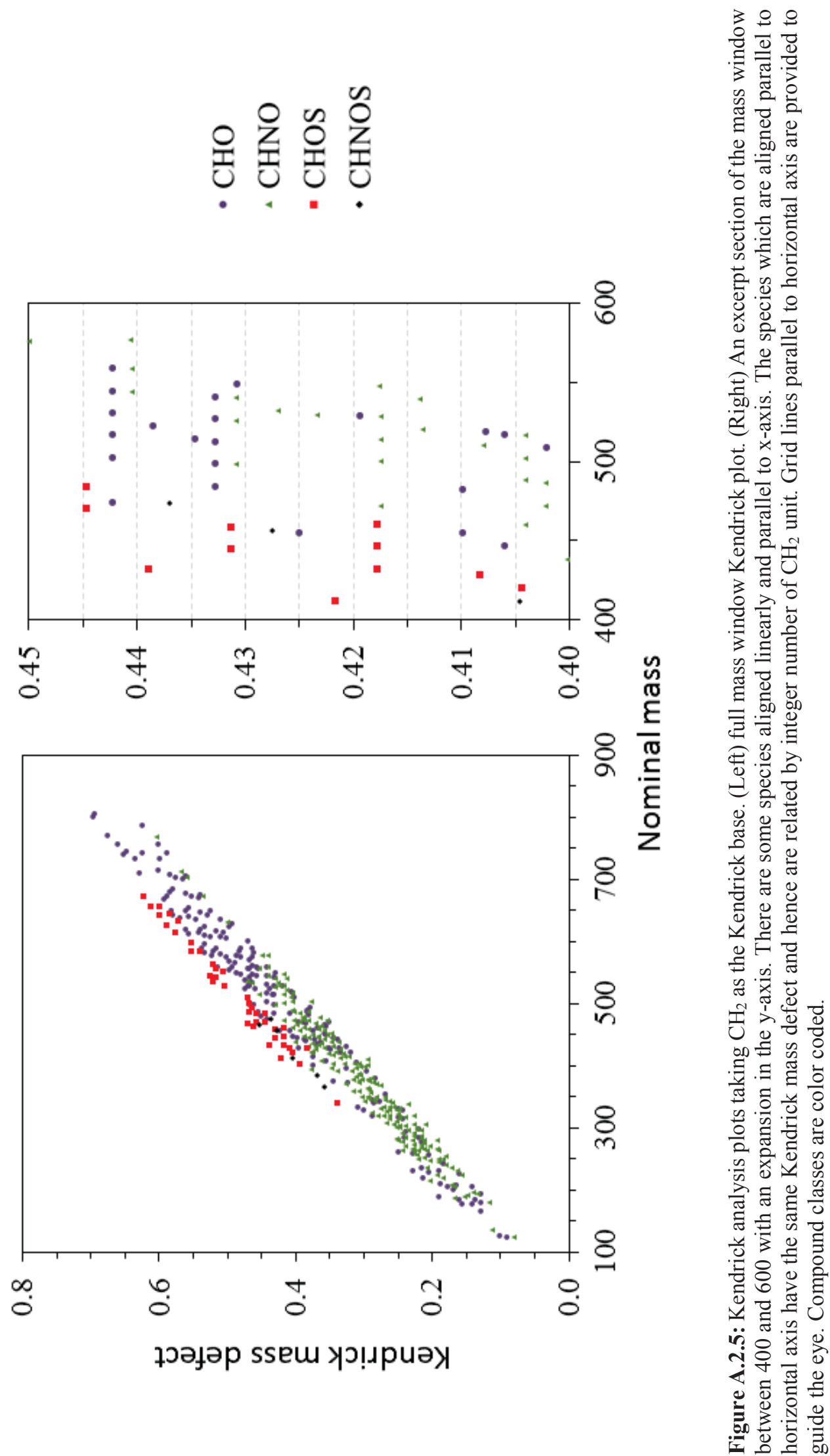


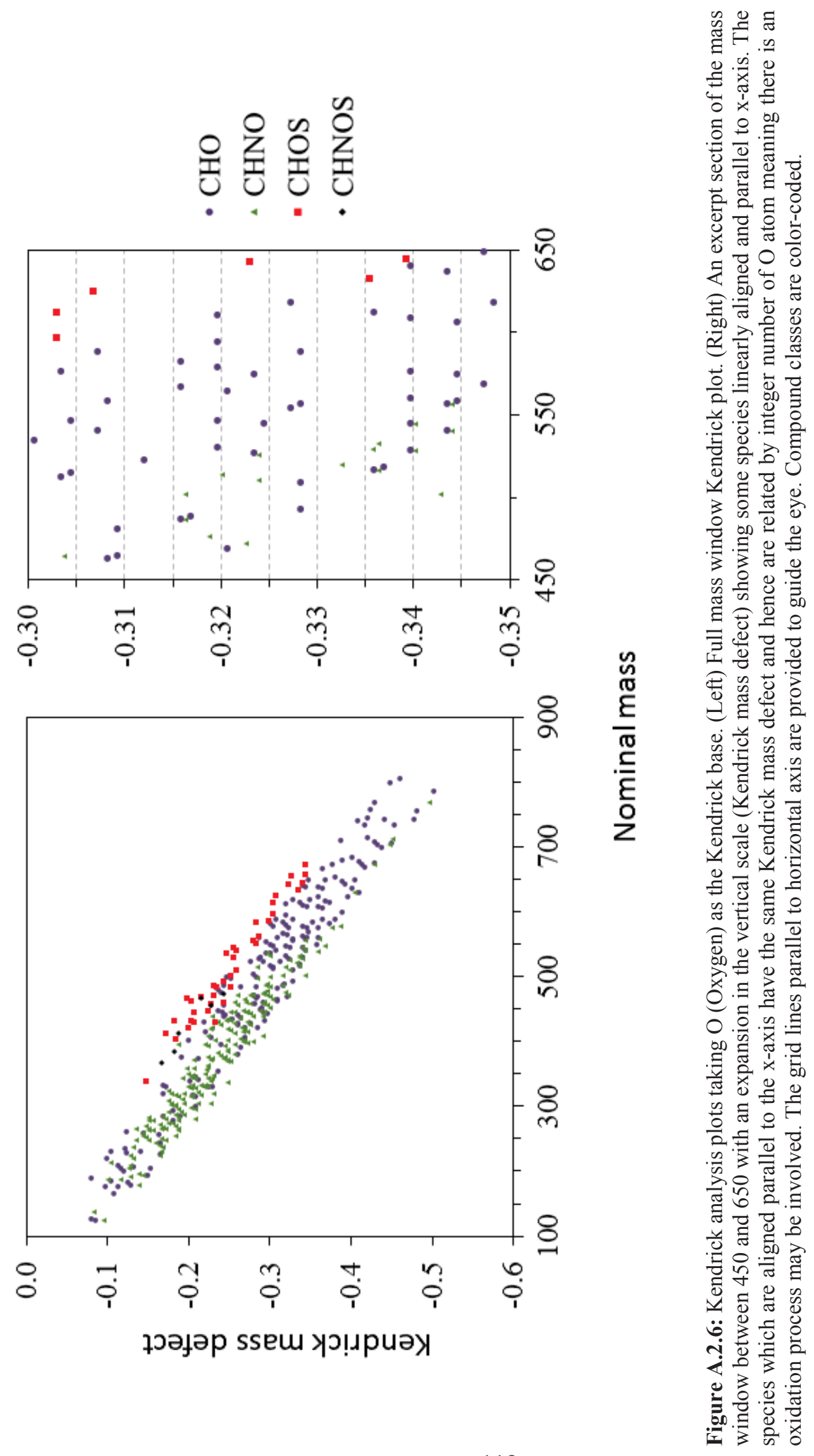



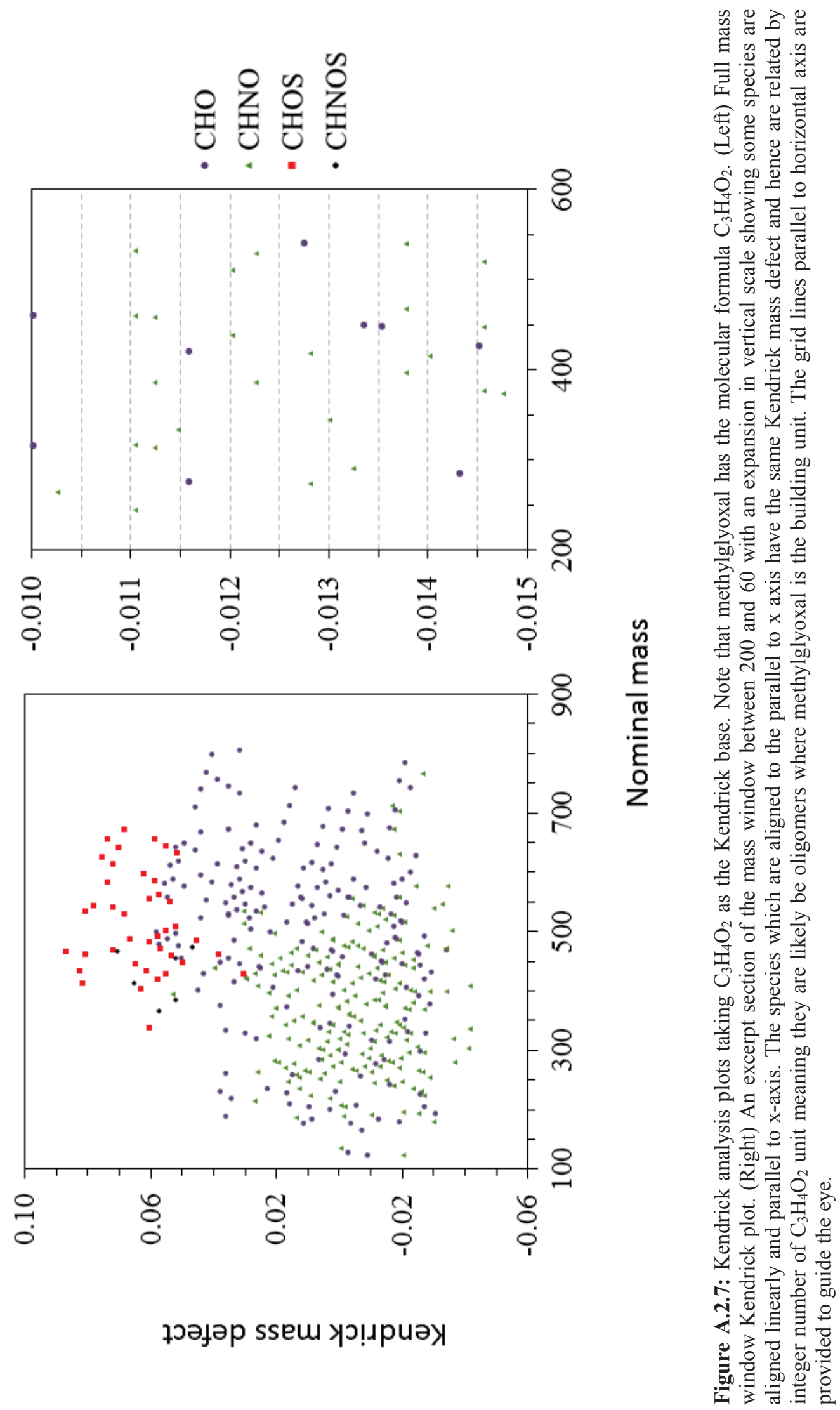


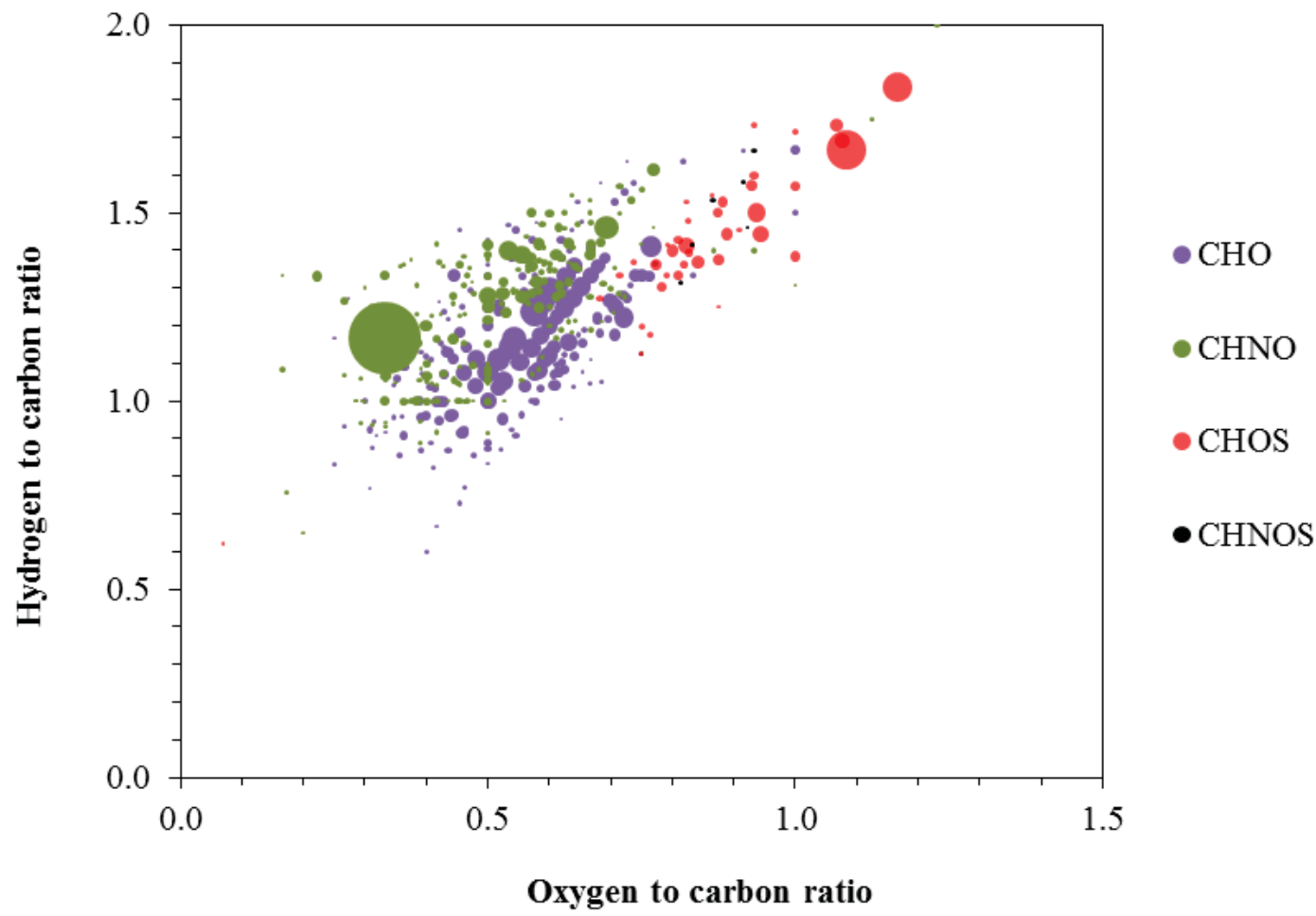

Figure A.2.8: van Krevelen plot of the CHO, CHNO, CHOS and CHNOS species formed from the dark reaction of methylglyoxal in the presence of ammonium sulfate. The compound classes are separated in the 2-D space of van Krevelen Plot. The size of the bubble represents the analyte relative abundance. 


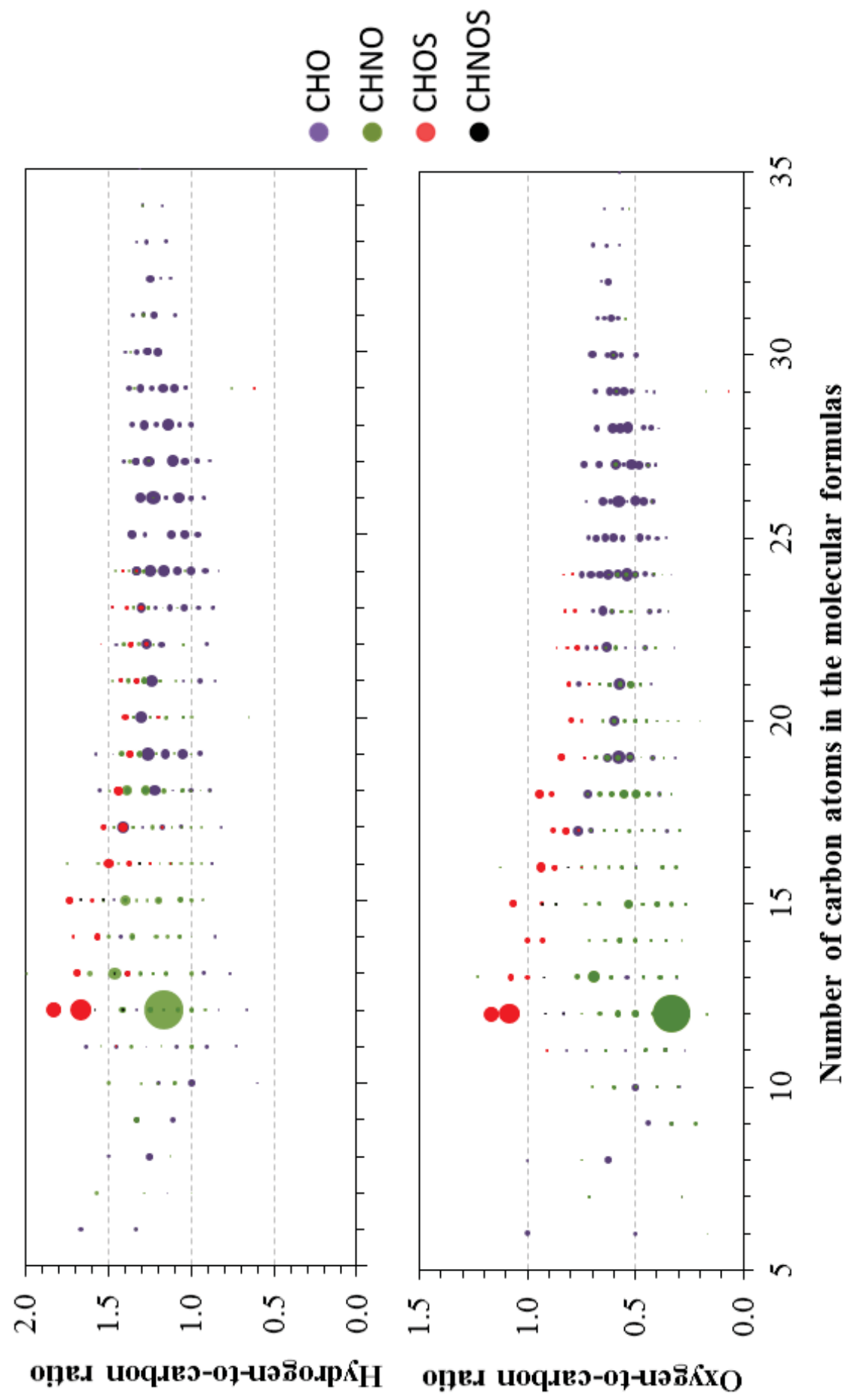

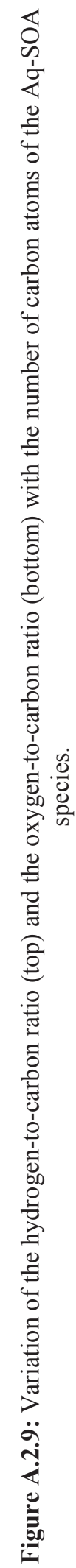

